\title{
MANEJO DA RESISTÊNCIA DO ÁCARO DA LEPROSE Brevipalpus phoenicis (Geijskes, 1939) (ACARI: TENUIPALPIDAE) AO ACARICIDA DICOFOL
}

\author{
EVERALDO BATISTA ALVES
}

Engenheiro Agrônomo

Orientador: Prof. Dr. CELSO OMOTO

\begin{abstract}
Dissertação apresentada à Escola Superior de Agricultura "Luiz de Queiroz", Universidade de São Paulo, para obtenção do título de Mestre em Ciências, Área de Concentração: Entomologia.
\end{abstract}

\author{
PIRACICABA \\ Estado de São Paulo - Brasil
}

Agosto - 1999 
Dados Internacionais de Catalogação na Publicação (CIP) DIVISÃo DE BIBLIOTECA E DOCUMENTAÇÃO - Campus "Luiz de Queiroz"/USP

\section{Alves, Everaldo Batista}

Manejo da resistència do ácaro da leprose Brevipalpus phoenicis (Geijskes, 1939)(Acari: Tenuipalpidae) ao acaricida dicofol / Everaldo Batista Alves. - - Piracicaba, 1999.

$91 \mathrm{p}$.

Dissertaçāo (mestrado) - - Escola Superior de Agricultura Luiz de Queiroz, 1999.

Bibliografia.

1. Ácaro-vetor-de-doença 2. Controle quimico 3. Leprose cítrica 4. Resistència ao acaricida I. Titulo

CDD 632.0542

Sermitida a copta total ou parcial deste docamento, desde que citada a fonte $O \mathrm{Autor}$ 


\section{AGRADECIMENTOS}

Ao Prof. Dr. Celso Omoto, pela orientação, confiança, amizade e respeito demonstrados durante nosso convívio, e pelas oportunidades que me foram dadas.

Ao Prof. Dr. Sinval Silveira Neto pelas constantes e valiosas sugestões dadas para a melhora deste trabalho.

Aos professores do Setor de Entomologia da ESALQ/USP pelos valiosos conhecimentos transmitidos no decorrer do curso de pós-graduação.

À FAPESP pelo financiamento do projeto e à CAPES pela concessão da bolsa de estudos para a execução deste trabalho.

Aos bolsistas Claudio Roberto Franco e Ruben de Brito Silva, pelo companheirismo e serviços prestados na elaboração do trabalho.

Ao engenheiro agrônomo Roberto H. Konno pelo companheirismo e amizade.

À Rohm and Haas Química Ltda. e à AgrEvo pelo fornecimento de acaricidas e auxílio na coleta de populações de ácaro da leprose.

Aos bibliotecários da Prefeitura do Campus de Piracicaba da ESALQ/USP, pela dedicação e em particular à Eliana Maria Garcia Sabino e Kátia Maria de Andrade Ferraz. 


\section{SUMÁRIO}

Página

LISTA DE FIGURAS............................................................................... vii

LISTA DE TABELAS...................................................................... ix

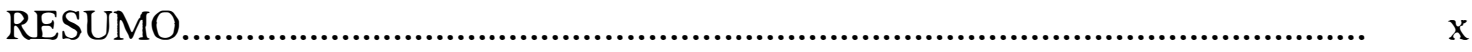



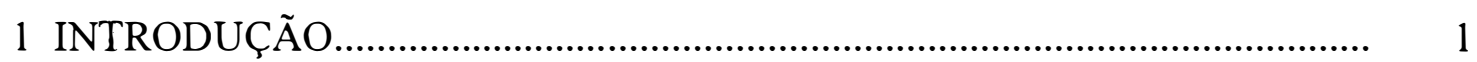

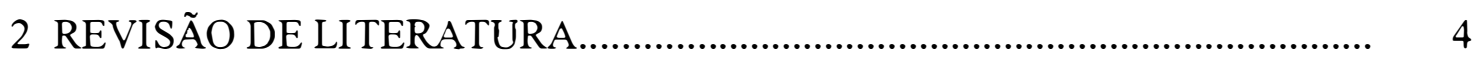

2.1 Aspectos taxonômicos de Brevipalpus phoenicis........................................ 4

2.2 Aspectos bioecológicos de Brevipalpus phoenicis...................................... 4

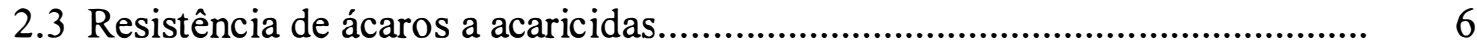

2.3.1 A magnitude do problema da resistência................................................. 6

2.3.2 Resistência de ácaros ao acaricida dicofol............................................... 7

2.3.3 Fatores que afetam o desenvolvimento da resistência de ácaros a

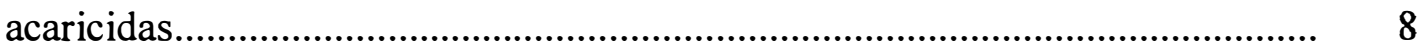

2.3.4 Manejo da resistência de ácaros a acaricidas......................................... 10

3 CARACTERIZAÇÃO DA RESISTÊNCIA DE Brevipalpus phoenicis (ACARI: TENUIPALPIDAE) AO ACARICIDA DICOFOL ......................... 13

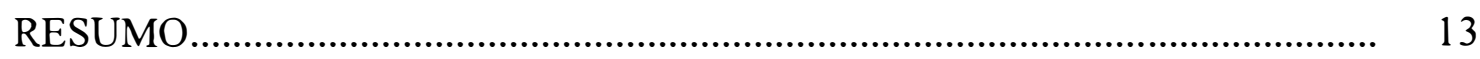

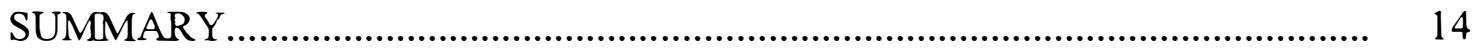

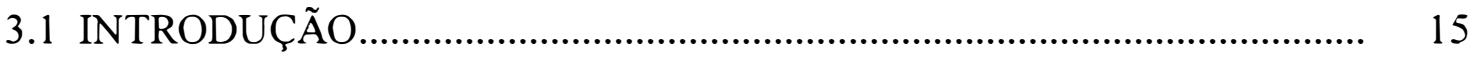

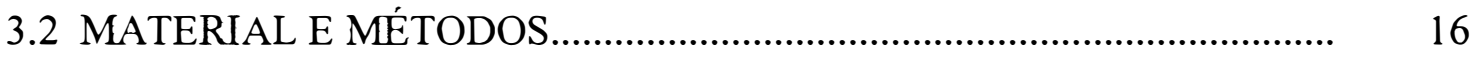

3.3 RESULTADOS E DISCUSS ÃO................................................................ 19

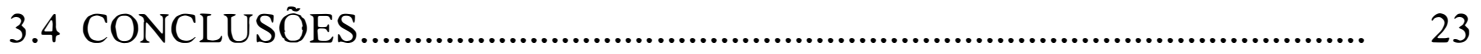

4 CUSTO ADAPTATIVO ASSOCIADO À RESISTÊNCIA DE Brevipalpus phoenicis (ACARI: TENUIPALPIDADE) AO ACARICIDA DICOFOL...... 24

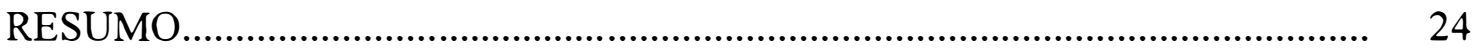

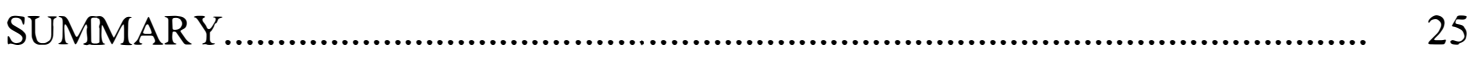

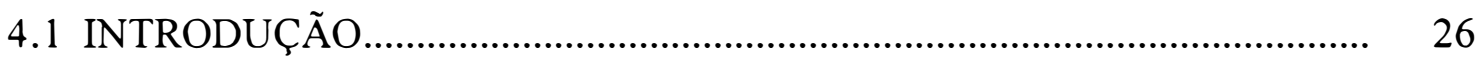


4.2 MATERIAL E MÉTODOS............................................................... 28

4.2.1 Dinâmica da resistência de Brevipalpus phoenicis ao dicofol em condições laboratoriais.................................................................................... 28

4.2.2 Biologia das linhagens de Brevipalpus phoenicis susceptível e resistente

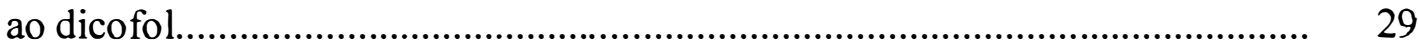

4.3 RESULTADOS E DISCUSSÃO................................................................ 30

4.3.1 Dinâmica da resistência de Brevipalpus phoenicis ao dicofol em condições laboratoriais................................................................................ $\quad 30$

4.3.2 Biologia das linhagens de Brevipalpus phoenicis susceptível e resistente

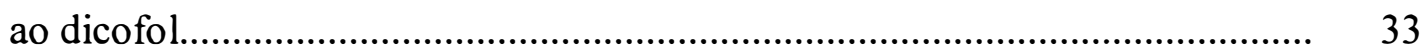

4.3.3 Implicações para o manejo da resistência de Brevipalpus phoenicis ao

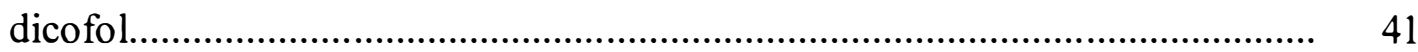

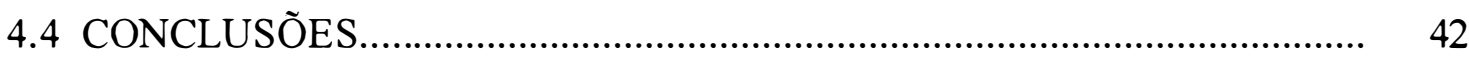

5 RESISTÊNCIA CRUZADA ENTRE O DICOFOL E OUTROS ACARICIDAS EM Brevipalpus phoenicis (ACARI: TENUIPALPIDAE)..... 43 RESUMO.

SUMMARY

5.1 INTRODUÇÃO................................................................................ 45

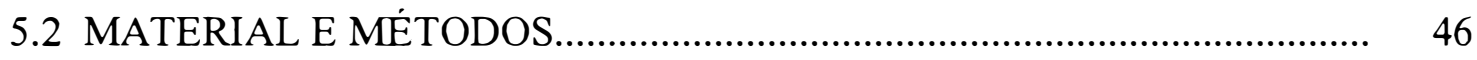

5.3 RESULTADOS E DISCUSSÃO................................................................. 48

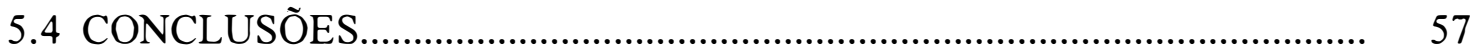

6 MSTURA DE DICOFOL COM FENPYROXIMATE NO MANEJO DA RESISTÊNCIA DE Brevipalpus phoenicis (ACARI: TENUIPALPIDAE) AO DICOFOL .................................................................................. 58

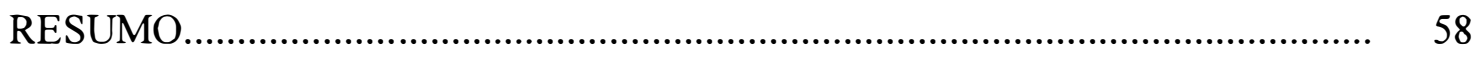

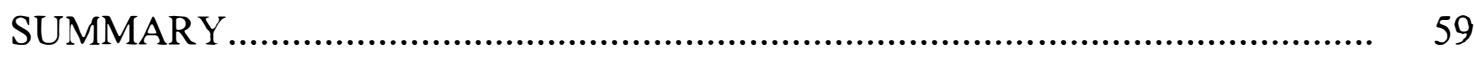

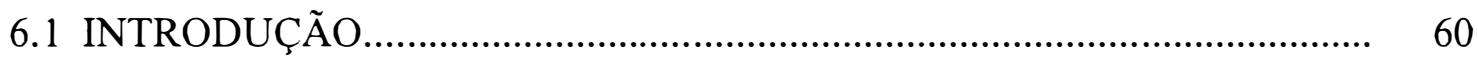

6.2 MATERIAL E MÉTODOS..................................................................... 61

6.2.1 Interação de dicofol e fenpyroximate........................................................... 61 
6.2.2 Persistência de resíduos da mistura de dicofol e fenpyroximate e dos produtos isolados............................................................................................. 63

6.3 RESULTADOS E DISCUSSÃO............................................................... 64

6.3.1 Interação de dicofol e fenpyroximate.......................................................... 64

6.3.2 Persistência de resíduos da mistura de dicofol e fenpyroximate e dos produtos isolados....................................................................................... 67

6.3.3 Implicações para o manejo da resistência de Brevipalpus phoenicis ao

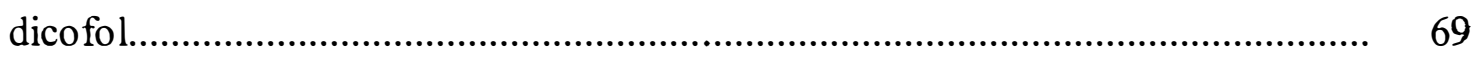

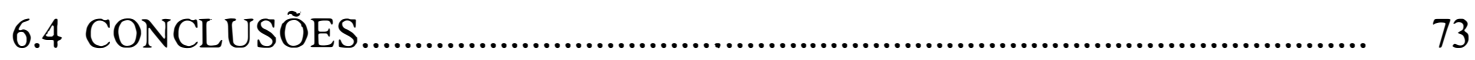

7 CONCLUSÕES GERAIS....................................................................... 74

REFERÊNCIAS BIBLIOGRÁFICAS............................................................... 75

APÊNDICES........................................................................................... 88 


\section{LISTA DE FIGURAS}

Página

1 Curvas de concentração-resposta das linhagens de Brevipalpus phoenicis susceptível (S) e resistente (R) ao acaricida dicofol. A área hachureada representa o intervalo de concentrações discriminatórias de dicofol para um programa de monitoramento da resistência de $B$. phonicis ao dicofol..............

2 Mudanças nas freqüências de resistência de Brevipalpus phoenicis ao dicofol em populações com freqüências iniciais de 20\%, 50\% e $80 \%$ de ácaros resistentes em condições de laboratório, à temperatura de $25 \pm 2{ }^{\circ} \mathrm{C}$,

UR superior a $60 \%$ e fotofase de 14 horas.

3 Sobrevivência de fêmeas (lx) das linhagens de Brevipalpus phoenicis suscpetível (S) e resistente $(\mathrm{R})$ ao dicofol, à temperatura de $25 \pm 1^{\circ} \mathrm{C}$, UR de $70 \pm 10 \%$ e fotofase de 14 horas.

4 Fecundidade acumulada das linhagens de Brevipalpus phoenicis susceptível (S) e resistente $(\mathrm{R})$ ao dicofol, à temperatura de $25 \pm 1{ }^{\circ} \mathrm{C}$, UR de $70 \pm 10 \%$ e fotofase de 14 horas.

5 Mudanças nas freqüências esperadas de resistência obtidas através de simulação de aumento populacional das linhagens de Brevipalpus phoenicis susceptível e resistente ao dicofol com razões finitas de aumento $(\lambda)$ de 1,095 e 1,081 fềmeas/fềmea/dia, respectivamente. A simulação foi realizada em populações com freqüências iniciais de resistência de 20,50 e $80 \%$

6 Respostas de concentração-mortalidade das linhagens de Brevipalpus phoenicis susceptível $(\mathrm{S})$ e resistente $(\mathrm{R})$ ao dicofol testadas com óxido de fenbutatina.

7 Respostas de concentração-mortalidade das linhagens de Brevipalpus phoenicis suscpetível (S) e resistente (R) ao dicofol testadas com propargite 
8 Respostas de concentração-mortalidade das linhagens de Brevipalpus phoenicis susceptível (S) e resistente (R) ao dicofol testadas com fenpyroximate.

9 Respostas de concentração-mortalidade das linhagens de Brevipalpus phoenicis susceptível (S) e resistente (R) ao dicofol testadas com bromopropilato.

10 Mortalidade ( \pm erro padrão da média) de ácaros da linhagem de Brevipalpus phoenicis susceptível ao dicofol ocasionada pelas concentrações de $5 \mu \mathrm{g}$ de dicofol / $\mathrm{mL}$ de água destilada [ppm (I.A.)] e $24 \mathrm{ppm}$ de fenpyroximate

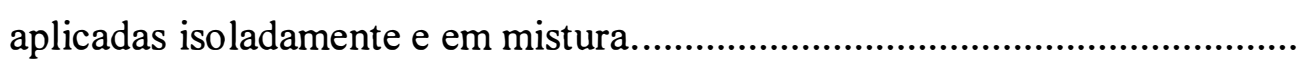

11 Mortalidade ( \pm erro padrão da média) de ácaros da linhagem de Brevipalpus phoenicis resistente ao dicofol ocasionada pelas concentrações de $260 \mu \mathrm{g}$ de dicofol / $\mathrm{mL}$ de água destilada [ppm (I.A.)] e $8 \mathrm{ppm}$ de fenpyroximate aplicadas isoladamente e em mistura.

12 Avaliação em laboratório das respostas (porcentagem de mortalidade \pm erro padrão da média) das linhagens de Brevipalpus phoenicis susceptível (S) e resistente $(\mathrm{R})$ ao dicofol, expostas a diferentes idades de resíduos de dicofol durante 48 horas.

13 Avaliação em laboratório das respostas (porcentagem de mortalidade \pm erro padrão da média) das linhagens de Brevipalpus phoenicis susceptível (S) e resistente (R) ao dicofol, expostas a diferentes idades de resíduos de fenpyroximate durante 48 horas.

14 Avaliação em laboratório das respostas (porcentagem de mortalidade \pm erro padrão da média) das linhagens de Brevipalpus phoenicis susceptível (S) e resistente $(\mathrm{R})$ ao dicofol, expostas a diferentes idades de resíduos da mistura de dicofol e fenpyroximate durante 48 horas 


\section{LISTA DE TABELAS}

Página

1 Duração média \pm erro padrão da média (em dias) dos estágios embrionário e pós-embrionário das linhagens de Brevipalpus phoenicis susceptível e resistente ao dicofol, à temperatura de $25 \pm 1{ }^{\circ} \mathrm{C}$, UR de $70 \pm 10 \%$ e fotofase de 14 horas.

2 Duração média \pm erro padrão da média (em dias) dos períodos de préoviposição, oviposição e pós-oviposição e número de ovos por fềmea das linhagens de Brevipalpus phoenicis susceptível e resistente ao dicofol, à temperatura de $25 \pm 1^{\circ} \mathrm{C}$, UR de $70 \pm 10 \%$ e fotofase de 14 horas.

3 Duração média \pm erro padrão da média (em dias) da longevidade e do ciclo completo das linhagens de Brevipalpus phoenicis susceptível e resistente ao dicofol, à temperatura de $25 \pm 1^{\circ} \mathrm{C}$, UR de $70 \pm 10 \%$ e fotofase de 14 horas.

4 Parâmetros biológicos obtidos através da tabela de vida e fertilidade para as linhagens de Brevipalpus phoenicis susceptivel e resistente ao dicofol: taxa líquida de reprodução $\left(R_{o}\right)$, duração média de uma geração $(T)$, capacidade inata de aumentar em número $\left(r_{m}\right)$ e razão finita de aumento $(\lambda)$

5 Respostas de concentração-mortalidade das linhagens de Brevipalpus phoenicis susceptível (S) e resistente ( $\mathrm{R}$ ) ao dicofol quando testadas com óxido de fenbutatina. propargite, fenpyroximate e bromopropilato

6 Percentagem de ácaros da linhagem de Brevipalpus phoenicis resistente ao dicofol, vivos, mortos e presos na solução ágar-água. 24 horas após a exposição em resíduos de diferentes concentraçòes do acaricida bromopropilato 


\section{MANEJO DA RESISTÊNCIA DO ÁCARO DA LEPROSE Brevipalpus phoenicis (Geijskes, 1939) (ACARI: TENUIPALPIDAE) AO ACARICIDA DICOFOL}

Autor: Everaldo Batista Alves

Orientador: Prof. Dr. Celso Omoto

\section{RESUMO}

Informações básicas para a implementação de um programa de manejo da resistência de Brevipalpus phoenicis (Geijskes) ao acaricida dicofol foram coletadas neste trabalho. A caracterização da resistência de B. phoenicis susceptível (S) e resistente $(\mathrm{R})$ ao dicofol foi realizada através de um método de bioensaio residual. As $\mathrm{CL}_{50}$ s estimadas para as linhagens $\mathrm{S}$ e $\mathrm{R}$ foram $7,44 \mu \mathrm{g}$ de dicofol $/ \mathrm{mL}$ de água destilada [ppm (I.A.)] (IC 95\% 6,74 - 8,23) e 422,45 ppm (I.A.) (IC 95\% 369,41 - 482,80), respectivamente. A razão de resistência derivada das $\mathrm{CL}_{50}$ s foi de aproximadamente 57 vezes. Concentrações discriminatórias entre 32 e 100 ppm (I.A.) foram definidas para um programa de monitoramento da resistência de $B$. phoenicis ao dicofol. Posteriormente, o custo adaptativo associado à resistência de $B$. phoenicis ao dicofol foi avaliado em laboratório. Estudos de dinâmica da resistência comprovaram que a resistência ao dicofol é instável; ou seja, a freqüência de resistência diminui significativamente na ausência de pressão seletiva. Comparações de parâmetros biológicos entre as linhagens $\mathrm{S}$ e $\mathrm{R}$ mostraram que a baixa longevidade e fecundidade da linhagem $\mathrm{R}$ foram os principais parâmetros biológicos que afetaram a estabilidade da resistência. Relações de resistência cruzada entre dicofol e os acaricidas óxido de fenbutatina, propargite, fenpyroximate e bromopropilato foram avaliadas. Os resultados 
indicaram que dentre os acaricidas testados, somente o bromopropilato deve ser evitado em programas de manejo da resistência de $B$. phoenicis ao dicofol. Foi verificada uma resistência cruzada negativa entre o dicofol e fenpyroximate. E por último, a mistura de dicofol e fenpyroximate foi avaliada para o manejo da resistência de $B$. phoenicis ao dicofol. Uma interação sinérgica entre dicofol e fenpyroximate foi detectada em laboratório. No entanto, estudos de campo não demonstraram nenhum benefício da mistura no controle da linhagem $\mathrm{R}$ de $B$. phoenicis na dosagem recomendada de $240 \mathrm{~g}$ de dicofol / $1.000 \mathrm{~L}$ de água e $25 \mathrm{~g}$ de fenpyroximate / $1.000 \mathrm{~L}$ de água. 


\title{
MANAGEMENT OF CITRUS LEPROSIS MITE Brevipalpus phoenicis (Geijskes, 1939) (ACARI: TENUIPALPIDAE) RESISTANCE TO DICOFOL
}

\author{
Author: Everaldo Batista Alves \\ Adviser: Prof. Dr. Celso Omoto
}

\section{SUMMARY}

The objective of this research was to collect basic information for the implementation of a resistance management program of Brevipalpus phoenicis (Geijskes) to the acaricide dicofol. A residual bioassay technique was used to characterize the responses of susceptible ( $\mathrm{S}$ ) and resistant $(\mathrm{R})$ strains of $B$. phoenicis to dicofol. The estimated $\mathrm{LC}_{50} \mathrm{~S}$ for the $\mathrm{S}$ and $\mathrm{R}$ strains were $7.44 \mu \mathrm{g}$ of dicofol $/ \mathrm{mL}$ of distilled water [ppm (A.I.)] (95\% CI 6.74 - 8.23) and 422.45 ppm (A.I.) (95\% CI 369.41 - 482.80), respectively. The resistance ratio derived from $\mathrm{LC}_{50} \mathrm{~S}$ was about 57-fold. Based on this difference, discriminating concentrations between 32 and 100 ppm (A.I.) were defined for monitoring dicofol-resistant mites. Then, fitness cost associated with dicofol resistance in B. phoenicis was evaluated under laboratory conditions. Studies of dynamics of resistance revealed that the resistance is unstable; that is, the frequency of dicofol-resistant mites declines significantly in the absence of selection pressure. Lifehistory comparisons between $\mathrm{S}$ and $\mathrm{R}$ strains showed that the lower longevity and fecundity of $\mathrm{R}$ strain mites were the major biological constraints that affected the stability of resistance. Studies of cross-resistance relationships between dicofol and other acaricides such as fenbutatin oxide, propargite, fenpyroximate and bromopropilate showed that only bromopropilate should be avoided in resistance management programs 
of B. phoenicis to dicofol. Negative cross-resistance was detected between dicofol and fenpyroximate. And finally, the mixture of dicofol and fenpyroximate was evaluated for managing dicofol resistance in B. phoenicis. Synergistic interaction between dicofol and fenpyroximate was detected under laboratory conditions. However, field data did not show any benefit of the mixture for controlling dicofol-resistant B. phoenicis at recommended rate of $240 \mathrm{~g}$ of dicofol and $25 \mathrm{~g}$ of fenpyroximate / 1,000 L of water. 


\section{INTRODUÇÃO}

O ácaro da leprose Brevipalpus phoenicis (Geijskes, 1939) é uma das principais pragas da citricultura brasileira, devido aos sérios prejuizos que acarreta na produção, em especial para o Estado de São Paulo que é responsável por aproximadamente $80 \%$ da produção nacional de laranja (FNP Consultoria \& Comércio, 1999). Este ácaro é responsável pela transmissão da leprose, doença causada por um rabdovírus de ação localizada que afeta ramos, folhas e frutos (Knorr \& Denmark, 1970; Kitajima et al., 1972; Kitajima et al., 1995).

Os sintomas decorrentes da alimentação do ácaro da leprose em condições de campo não são facilmente perceptíveis, em razão do baixo nível populacional em que geralmente ocorrem, embora seja suficiente para a eficaz disseminação da doença. Os sintomas da leprose são manifestados desde manchas cloróticas nas regiões atacadas pelo ácaro até a queda dos órgãos. A qualidade e quantidade de frutos são afetados pela doença, que dependendo da intensidade do ataque do ácaro da leprose pode tornar a planta improdutiva ou pré-disposta aos ataques subsequentes de outras pragas e moléstias (Guirado \& Silverio, 1992; Oliveira, 1994; Salva \& Massari, 1995).

Atualmente para o controle do ácaro da leprose, pesquisadores tem intensificado as pesquisas dando ênfase aos aspectos bioecológicos do ácaro (Chiavegato, 1986b; Oliveira, 1986), métodos de amostragem da densidade populacional (Gravena, et al., 1988; Salva, 1994; Negri, 1994), preservação de inimigos naturais (Komatsu \& Nakano, 1988; Yamamoto et al., 1992; Moraes \& Sá, 1995; Reis, 1996), tratos culturais (Nakano et al., 1987; Gravena, 1994a) e desenvolvimento de novos acaricidas. O controle químico ainda tem sido a principal tática para manter a densidade populacional de B. phoenicis a níveis abaixo do dano econômico. 
Pesquisadores e técnicos brasileiros, tem registrado a ineficiência de acaricidas utilizados com freqüência para o controle de B. phoenicis (Suplicy Filho et al., 1977; Myazaki et al., 1982; Chiavegato, 1987; Gravena, 1994b). Nestes casos, diversos fatores poderiam estar afetando a eficiência dos acaricidas, como inspeções deficientes, falhas no controle da verrugose, falhas na aplicação, má regulagem dos equipamentos de pulverização, dosagem incorreta e a seleção de linhagens resistentes ao acaricida. Embora alguns trabalhos atribuam a falta de controle ao desenvolvimento da resistência do ácaro da leprose a acaricidas (Gravena, 1994b; Omoto, 1995), não existem trabalhos para a implementação de estratégias de manejo da resistência.

No Brasil, a rotação de acaricidas tem ganhado destaque como uma das estratégias de manejo da resistência de B. phoenicis a acaricidas (Gravena, 1994a, b; Nakano, 1995). No entanto, vários fatores devem ser considerados, como por exemplo estudos de dinâmica da resistência e relações de resistência cruzada e resistência múltipla entre acaricidas, para a implementação de qualquer estratégia para o manejo da resistência (Omoto et al., 1995b; Omoto, 1995).

Devido à ineficiência de certos acaricidas, os citricultures e extensionistas passaram a utilizar misturas de produtos em alguns casos. A utilização de misturas em tanque foi regulamentada no Brasil a partir da portaria $n^{0} 67$, de 30 de maio de 1995, proferida pela Legislação Federal de Agrotóxicos e Afins para aumentar a eficiência de controle de pragas que não estão sendo controladas satisfatoriamente. Várias misturas já foram registradas para o controle do ácaro da leprose, como por exemplo dicofol e fenpyroximate, fenpyroximate e hexythiazox, fenpyroximate e acrinatrin, e hexythiazox e acrinatrin. Porém dados científicos com relação ao benefício das misturas para o manejo da resistência são carentes nas nossas condições.

O acaricida dicofol a mais de 25 anos vem sendo utilizado para o controle de ácaros fitófagos, em especial os ácaros-chaves dos citros no Brasil. Após os acaricidas do grupo dos organoestânicos, o dicofol tem sido o princípio ativo mais utilizado no controle de $B$. phoenicis em citros devido à sua especificidade de ação e ao seu custo relativamente baixo (Nakano, 1995). Além dos produtos tradicionais utilizados no controle de $B$. phoenicis, novas moléculas têm sido periodicamente lançadas no 
mercado. O desenvolvimento de um produto novo está se tornando cada vez mais difícil e oneroso. Sendo assim, dentro do contexto de manejo da resistência, há a necessidade da realização de estudos para a implementação de estratégias preventivas de manejo da resistência para os novos produtos que estão sendo lançados no mercado, assim como as estratégias curativas para alguns produtos tradicionais, principalmente aqueles que se enquadram dentro de um programa de manejo integrado de pragas (MIP) como é o caso do dicofol.

O objetivo geral do presente trabalho foi o de coletar informações básicas para a implementação de um programa de manejo da resistência de $B$. phoenicis ao acaricida dicofol. Para tanto foram realizados estudos de caracterização da resistência de $B$. phoenicis ao dicofol para a estimativa da intensidade da resistência e definição de concentrações discriminatórias de dicofol para um programa de monitoramento da resistência (Capitulo 3). Posteriormente foram conduzidos experimentos para avaliar o custo de adaptação de $B$. phoenicis resistente ao dicofol através de um acompanhamento da freqüência de resistência na ausência de pressão seletiva em condições laboratoriais e através da comparação de parâmetros biológicos entre as linhagens susceptível e resistente de B. phoenicis ao dicofol (Capítulo 4). Relações de resistência cruzada entre o dicofol e outros acaricidas recomendados para o controle de B. phoenicis também foram avaliadas com o intuito de identificar produtos que poderiam ser utilizados em um programa de rotação ou mistura de acaricidas (Capitulo 5). E por último, as vantagens da recomendação da mistura de dicofol e fenpyroximate no manejo da resistência de $B$. phoenicis ao dicofol foram avaliadas em condições de laboratório e campo (Capítulo 6). 


\section{REVISÃO DE LITERATURA}

\subsection{Aspectos taxonômicos de Brevipalpus phoenicis}

O ácaro da leprose Brevipalpus phoenicis (Geijskes) pertence à família Tenuipalpidae, superfamília Tetranychoidea, ordem Prostigmata, classe Arachnida e subclasse Acari. O gênero Brevipalpus Donnadieu, 1875 é separado em dois grandes grupos de acordo com o número de setas marginais no histerossoma. O maior grupo tem seis pares de setas e contém 46 espécies incluindo B. californicus (Banks). O outro grupo apresenta apenas cinco pares de setas marginais no histerossoma e contém nove espécies, incluindo B. phoenicis e B. obovatus Donnadieu. A divisão destes grupos é baseado também no número de setas sensoriais (solenídias) na parte distal do tarso II. Até 1975 apenas $B$. phoenicis possuía a combinação de 5 pares de setas histerossomais marginais e 2 solenídias (Gonzáles, 1975; Oomen, 1982). Gonzáles neste mesmo ano descreveu mais 4 novas espécies apresentando estes mesmos caracteres. A partir de então, além dos outros caracteres, a reticulação da área propodossomal dorso mediana e o comprimento da seta propodossomal passaram a distinguir B. phoenicis das novas espécies descritas.

\subsection{Aspectos bioecológicos de Brevipalpus phoenicis}

Brevipalpus phoenicis é largamente distribuído pelo mundo, ocorrendo em diferentes regiões do mediterràneo, África, antiga União Soviética, Ásia. América e região do Pacífico (Gonzáles, 1975). Associado a sua ampla distribuição está o grande número de plantas hospedeiras deste ácaro. O ácaro da leprose é uma importante praga 
de citros e chá, podendo causar danos em café, algodão, frutíferas decíduas e tropicais. Esta espécie tem também atacado mais de 50 gêneros de plantas ornamentais. No sudeste da África, B. phoenicis comumente ocorre em plantas indígenas junto com $B$. californicus e B. obovatus (Meyer, 1981). Segundo Chiavegato \& Mischan (1987), mais de 83 gêneros de plantas têm sido relatados como hospedeiros desse ácaro, destacando o citros como o principal hospedeiro. Por sua vez, Trindade \& Chiavegato (1994) encontraram 34 hospedeiros desta praga entre plantas cultivadas, omamentais e invasoras de pomares cítricos no Estado de São Paulo.

Devido à grande gama de hospedeiros de B. phoenicis, existem inúmeras alternativas de substrato para a criação deste ácaro em condições de laboratório. A criação deste ácaro já foi reportada em folhas de Oroxylum indicum Vent. e Clerodendrom siphonanthus $\mathrm{R}$. Br. (Lal, 1978), folhas de azaléia (Trindade e Chiavegato, 1994), frutos de laranjas Valência e Pera Rio (Chiavegato, 1986b) e Ligustrum lucidum Ait. (Rodrigues, 1995). Comparando os trabalhos destes autores, observa-se que os melhores resultados de criação são aqueles onde B. phoenicis foi criado em frutos de Laranja Valência ou Pera Rio. As diferentes variedades de um hospedeiro podem influenciar o desenvolvimento do ácaro como é mostrado por Chiavegato \& Mischan (1987), onde constataram que o ácaro apresentava um melhor desenvolvimento em frutos das variedades de laranja Valência e Tangor Murcote do que em relação ao Limão Taiti, Limão Siciliano e Lima da Pérsia.

Outro fator bastante marcante nas preferências de substrato por B. phoenicis é a verrugose dos citros, uma doença causada pelo fungo Elsinoe fawcetti Bitancourt \& Jenkins que forma uma placa rugosa na superficie do fruto. Foi constatado que quando o ácaro foi criado em frutos com verrugose, a população inicial apresentou um maior número de sobreviventes. maior oviposição e menor número de ácaros mortos naturalmente e na barreira de cola utilizada para confinar os mesmos, que quando criado em frutos sadios (Chiavegato, 1986a; Nakano, et al., 1987).

Este ácaro reproduz-se por partenogênese telítoca do tipo automítica (Helle et al., 1980), colocando durante a sua vida de 9 a 40 ovos de acordo com a temperatura e o substrato alimentar a que estão expostos. Chiavegato (1986b) estudando a biologia 
sobre frutos e folhas de laranja Valência e Pera Rio, a temperaturas de 20,25 e $30 \pm 1{ }^{\circ} \mathrm{C}$, umidade relativa de $60 \pm 10 \%$ e fotofase de 14 horas, constatou um desenvolvimento mais rápido em frutos, assim como uma maior produção de descendentes nos frutos. Com o aumento da temperatura ocorreu o desenvolvimento mais rápido e o número de ovos aumentou significativamente. Porém, a temperatura de $25^{\circ} \mathrm{C}$ proporcionou maior viabilidade da fase larval caracterizada como crítica, associada a um período de desenvolvimento de ovo a adulto de 19,20 dias que foi significativamente inferior ao obtido à temperatura de $20^{\circ} \mathrm{C}$ cujo valor médio foi de 43,47 dias e próximo ao obtido à temperatura de $30^{\circ} \mathrm{C}$ que foi de 14,37 dias.

Estudando o número de gerações por ano sob diferentes condições laboratoriais de temperatura e usando folhas de $O$. indicum e $C$. siphonanthus como substrato, Lal (1978) descreveu que B. phoenicis pode dar nove gerações por ano. Segundo Oliveira (1986), o ácaro da leprose ocorre no Estado de São Paulo durante todo o ano, aumentando sua população nos pomares cítricos a partir dos meses de março e abril, que correspondem ao período em que as precipitações geralmente diminuem. A densidade populacional atinge níveis altos a partir de julho, com o máximo nos meses de setembro e outubro, para depois decrescer com o início das chuvas por volta dos meses de novembro e dezembro.

\subsection{Resistência de ácaros a acaricidas}

\subsubsection{A magnitude do problema da resistência}

Resistência tem sido definida como "o desenvolvimento de uma habilidade em uma linhagem de um organismo de tolerar doses de tóxicos que seriam letais para a maioria dos indivíduos da população normal (susceptível) da espécie" (World Health Organization $^{1}$ citado por Croft \& Van de Baan, 1988). Esta habilidade desenvolvida é o

\footnotetext{
' WORLD HEALTH ORGANIZATION. World health Expert committee on insecticides: 7 th report. 1957. 88p. (Technical Report Series, 125).
} 
resultado da seleção de indivíduos com uma capacidade herdável para resistir a um tóxico.

O desenvolvimento de resistência em artrópodos tem uma história de aproximadamente 86 anos, mas seu grande aumento e mais forte impacto ocorreu durante os últimos 50 anos, seguindo a descoberta e o uso extensivo dos inseticidas e acaricidas organossintéticos. Os casos de resistência de organismos a pesticidas tem expandido e intensificado consideravelmente nos últimos anos. Há registro de pelo menos 504 espécies resistentes de insetos e ácaros a uma ou mais classes de pesticidas (Georghiou \& Tejeda, 1991). Das 504 espécies entre ácaros e insetos que desenvolveram linhagens resistentes no final da década de $80,56,1 \%$ eram pragas de importância agrícola, 39,3\% pragas de importância médico-veterinária e 4,6\% de artrópodos benéficos. A resistência tem sido mais freqüentemente documentada em Diptera $(35,1 \%)$, refletindo a alta pressão de seleção com pesticidas que tem sido aplicada contra os representantes desta ordem. Números substanciais de espécies resistentes são também evidentes em outros grupos de importância agrícola como Lepidoptera e Coleoptera (14,7 e 14,3 \%, respectivamente), Acarina (14,1\%), Hemiptera-Auchenorrhyncha, Sternorrhyncha (10,1\%) e Hemiptera-Heteroptera $(20,4 \%)$ (Georghiou \& Tejada, 1991).

Como conseqüências da evolução da resistência de pragas a pesticidas podemos citar o aumento da dosagem aplicada, aumento na freqüência das aplicações, substituição do produto ineficiente por uma nova molécula. Estas conseqüências levam a um aumento do custo de controle da praga e uma maior contaminação do meio ambiente, além da perda do produto para o qual a espécie desenvolveu resistência (Georghiou, 1986).

\subsubsection{Resistência de ácaros ao acaricida dicofol}

O primeiro caso de resistência ao acaricida dicofol foi registrado em 1958, através de testes de laboratório que relacionaram a resistência de Tetranychus mcdanieli McGregor ao dicofol com a ineficiência de controle deste ácaro em pomares de maçã da 
região centro-norte do Estado de Washington nos Estados Unidos (Hoyt \& Harries, 1961). No decorrer das décadas, diversos casos de resistência a este acaricida foram registrados envolvendo principalmente ácaros da família Tetranychidae como Tetranychus urticae (Koch) e Panonychus ulmi (Koch) (Dennehy \& Granett, 1984b; Dennehy et al., 1990). Populações de T. urticae e P. ulmi selecionadas em laboratório para resistência podem atingir intensidades de resistência acima de 1.000 vezes (Dennehy et al., 1988) Em geral a intensidade da resistência de ácaros tetraníquideos ao dicofol em condições de campo varia de 100 a 1.000 vezes conforme a espécie. local e metodologias de bioensaio empregadas (Dennehy \& Granett, 1984a). No ácaro da ferrugem Phyllocoptruta oleivora (Ashmead) a intensidade de resistência ao dicofol detectada foi de apenas 8,8 vezes (Omoto et al., 1994).

Apesar dos inúmeros casos de resistência detectados ao dicofol, este acaricida continua sendo um importante componente do manejo integrado de pragas em alguns sistemas agrícolas como algodão na Califórnia (Dennehy \& Granett, 1984a, b), pomares de maçã em Nova York (Dennehy et al., 1988) e de citros na Flórida e no Brasil (Omoto et al., 1994; Nakano, 1995) devido à sua especificidade de ação e custo relativamente baixo. Um outro importante fator para a continuidade de uso do dicofol está associado à alta instabilidade da resistência, ou seja, a constatação da redução significativa na freqüência de ácaros resistentes na ausência da pressão seletiva (Dennehy et al., 1988; Omoto et al., 1995b).

\subsubsection{Fatores que afetam o desenvolvimento da resistência de ácaros a acaricidas}

Diversos fatores podem influenciar a evolução da resistência. Estes fatores são agrupados em genéticos. bioecológicos e operacionais (Georghiou \& Taylor, 1977a, b).

Os fatores genéticos referem-se ao número de genes envolvidos na resistência, intensidade da resistência, dominância dos alelos resistentes e valor adaptativo dos indivíduos resistentes. Um fator responsável pelo desenvolvimento da resistência em tetraniquídeos é o reduzido número de cromossomos em sua constituição genética (Helle \& Pijnacker, 1985), o que favorece o desenvolvimento da resistência cruzada e/ou 
múltipla, ou seja, a resistência para dois ou mais compostos químicos. $\mathrm{O}$ ácaro da leprose, por exemplo, apresenta um número de cromossomos igual a dois, o que aumenta as chances de dois mecanismos distintos de resistência se localizarem num mesmo cromossomo. Desta forma a aplicação de um determinado acaricida pode levar à seleção de ácaros resistentes a um outro grupo de acaricidas, se os genes que conferem resistência a estes dois grupos de acaricidas estiverem no mesmo cromossomo (Omoto, 1995).

Diferenças no valor adaptativo entre os indivíduos de uma população podem interferir significativamente na evolução da resistência. Por exemplo, Mable \& Pree (1992) estudando a dinâmica da resistência de $P$. ulmi ao dicofol em laboratório concluíram que ela era altamente estável, pois os autores não encontraram desvantagem adaptativa dos ácaros resistentes em relação a atributos biológicos como por exemplo fecundidade, percentagem de eclosão, sobrevivência, razão sexual e tempo de desenvolvimento. Estudando a dinâmica da resistência de $P$. oleivora para o acaricida dicofol, Omoto et al. (1995b) observaram que a freqüência de indivíduos resistentes diminuía na ausência de pressão de seleção, refletindo alguma desvantagem adaptativa associada à resistência.

Dentre os fatores bioecológicos que afetam o desenvolvimento da resistência de ácaros destacam-se o modo de reprodução, hábito alimentar da espécie, mobilidade da espécie, presença de refúgio para a população susceptível, número de gerações por ano e taxa de reprodução. Entre os tetraniquídeos, a evolução da resistência se dá principalmente devido à alta taxa reprodutiva e ao modo de reprodução (predominantemente partenogenético). Segundo Helle et al. (1980), as fềmeas de $B$. phoenicis são haplóides e se reproduzem por partenogênese telítoca do tipo automítica. Com base nestes conhecimentos, todos os descendentes de um indivíduo são geneticamente idênticos. Este fato associado a uma taxa de reprodução moderadamente elevada. fazem com que a evolução da resistência seja teoricamente bastante rápida com o uso contínuo de um determinado acaricida.

A influência do habito alimentar também desempenha papel fundamental no desenvolvimento da resistência. Dennehy et al. (1990), estudando a dinâmica da 
resistência de $P$. ulmi e $T$. urticae ao dicofol na cultura de maçã no Estado de Nova York, demonstraram que a resistência de $P$. ulmi era bastante estável enquanto que a de T. urticae era altamente instável. Esses resultados se devem ao hábito alimentar monófago de P. ulmi. Por outro lado, T. urticae apresenta grande número de hospedeiros, e sendo assim, há possibilidade de migração de ácaros susceptíveis provenientes de áreas não tratadas para as tratadas, diluindo a freqüência de resistência. É claro que relações de custo adaptativo também poderiam estar envolvidas nesta instabilidade da resistência. O hábito alimentar polífago de $B$. phoenicis e a presença de vários refúgios para os indivíduos susceptíveis podem impedir ou retardar que a freqüência de indivíduos resistentes a um determinado acaricida se torne crítica (Omoto, 1995).

Embora os fatores bioecológicos sejam extremamente importantes e o conhecimento dos mesmos auxiliem na elaboração de estratégias de manejo, como a utilização de refúgios, tanto estes como os fatores genéticos são inerentes da espécie. Desta forma, os fatores operacionais são aqueles passíveis de manipulação pelo homem. Estes são divididos em dois grupos: aqueles referentes às características do composto químico (grupo químico, persistência, seletividade, formulação) e aqueles referentes às características de aplicação (nível de controle; estágio de desenvolvimento da praga; método de aplicação; estratégias para o uso de produtos químicos) (Georghiou \& Taylor, 1977b). Manipular as características dos produtos químicos como uma estratégia isolada pode não resultar em um controle eficiente. É necessário, associar as características dos produtos químicos com aquelas referentes ao modo de exposição do produto à praga, em especial aos métodos de aplicação e as estratégias para o uso de produtos químicos.

\subsubsection{Manejo da resistência de ácaros a acaricidas}

O manejo da resistência de pragas a pesticidas constitui-se num importante componente do manejo integrado de pragas (MIP) e vice-versa. O manejo da resistência usa uma variedade de táticas desde o uso de pesticidas em associações até a adoção de 
medidas não químicas de controle, como por exemplo o controle biológico e a adoção de refúgio para conter ou suprimir a resistência de uma praga. Segundo Georghiou (1983), as medidas para o manejo da resistência podem ser divididas em três categorias principais: manejo por moderação, manejo por saturação e manejo por ataque múltiplo.

O manejo por moderação tem como principal objetivo reduzir a pressão de seleção através de estratégias como a utilização de baixas dosagens, aplicações menos freqüentes do produto, utilização de químicos de baixa persistência, aplicações localizadas, controle em reboleiras (quando viável) e manutenção de refúgio para os indivíduos susceptíveis.

O manejo da resistência por saturação tem como premissa reduzir o valor adaptativo dos indivíduos resistentes através da utilização de estratégias como o uso de altas dosagens e utilização de sinergistas quando o mecanismo de resistência é por aumento na destoxificação do pesticida.

E por último, a estratégia de manejo por ataque múltiplo consiste na utilização de dois ou mais produtos químicos para controle de uma praga. A utilização dos produtos podem ser em rotação ou mistura. As duas táticas exigem que os produtos a serem utilizados apresentem modos de ação distintos e que não ocorra resistência cruzada entre os produtos utilizados.

Associado à resistência a um acaricida está o problema da resistência cruzada a outros acaricidas o que pode levar ao fracasso de uma estratégia de manejo por ataque múltiplo (Georghiou, 1983). Cranham \& Helle (1985) citaram que repetidas seleções com dicofol resultaram em marcante aumento da tolerância de $T$. urticae e $P$. ulmi para certos acaricidas organofosforados. Fergusson-Kolmes et al. (1991), estudando as relações de resistência cruzada do acaricida dicofol com 21 produtos para o controle de T. urticae, encontraram que este acaricida apresentava resistência cruzada forte e positiva com amitraz, bromopropilato e clorobenzilato sugerindo que estes acaricidas não deveriam ser usados em um programa de manejo da resistência designado para explorar a instabilidade da resistência ao dicofol.

Além das relações de resistência cruzada e múltipla entre os acaricidas, outros fatores devem ser observados para o sucesso das estratégias de ataque múltiplo. Uma 
das premissas da rotação de pesticidas baseia-se na existência de uma desvantagem adaptativa dos indivíduos resistentes em relação aos susceptíveis. Já para o sucesso da mistura de pesticidas, várias outras condições devem ser observadas como por exemplo, que a freqüência de resistência para os dois compostos seja baixa na população, resistência para cada pesticida seja preferencialmente monogênica e funcionalmente recessiva, os indivíduos duplamente resistentes sejam raros, a utilização de misturas seja iniciada antes que a resistência a um dos compostos tenha sido selecionada, ocorra a presença de refúgio na área tratada, e que os pesticidas tenham a mesma persistência (Mani, 1985; Roush, 1989; Tabashnik, 1989; Denholm \& Rowland, 1992). 


\title{
3 CARACTERIZAÇÃO DA RESISTÊNCIA DE Brevipalpus phoenicis (ACARI: TENUIPALPIDAE) AO ACARICIDA DICOFOL
}

\author{
Autor: Everaldo Batista Alves \\ Orientador: Prof. Dr. Celso Omoto
}

\section{RESUMO}

Um método de bioensaio residual foi utilizado para caracterizar as linhagens susceptível (S) e resistente (R) de Brevipalpus phoenicis (Geijskes) ao acaricida dicofol. Arenas confeccionadas com folhas de laranjeira foram pulverizadas com diferentes concentrações de dicofol com o auxílio da torre de Potter. Posteriormente, as arenas foram acondicionadas em placas de acrílico contendo uma solução a 2,3 \% de ágar-água. Após a transferência de ácaros adultos na arena pulverizada, as placas foram mantidas à temperatura de $25 \pm 1{ }^{\circ} \mathrm{C}$, umidade relativa de $70 \pm 10 \%$ e fotofase de $14 \mathrm{~h}$. A avaliação da mortalidade foi realizada 24 horas após a infestação dos ácaros. As $\mathrm{CL}_{50} \mathrm{~s}$ estimadas para as linhagens $\mathrm{S}$ e $\mathrm{R}$ foram 7,44 $\mu \mathrm{g}$ de dicofol / $\mathrm{mL}$ de água destilada [ppm (I.A.)] (IC $95 \% 6,74$ - 8,23) e 422,45 ppm (I.A.) (IC 95\% 369,41 - 482,80), respectivamente; resultando numa razão de resistência de aproximadamente 57 vezes. Concentrações discriminatórias entre 32 e 100 ppm (I.A.) foram definidas para um programa de monitoramento da resistência de B. phoenicis ao dicofol. 


\title{
CHARACTERIZATION OF Brevipalpus phoenicis (ACARI: TENUIPALPIDAE) RESISTANCE TO THE ACARICIDE DICOFOL
}

\author{
Author: Everaldo Batista Alves \\ Adviser: Prof. Dr. Celso Omoto
}

\section{SUMMARY}

A residual bioassay technique was developed to characterize the responses of susceptible (S) and resistant (R) strains of Brevipalpus phoenicis (Geijskes) to the acaricide dicofol. Different concentrations of dicofol were sprayed on citrus leaf disks with a Potter spray tower. After treatment, each leaf disk was placed on an agar-water solution at concentration of $2.3 \%$ in a petri dish. Then, adult mites were tranferred onto the arena and bioassay dishes were kept at temperature of $25 \pm 1{ }^{\circ} \mathrm{C}$, relative humidity of $70 \pm 10 \%$ and photoperiod of 14:10 (L:D). The mortality was assessed $24 \mathrm{~h}$ after mite infestation. The estimated $\mathrm{LC}_{50} \mathrm{~S}$ for $\mathrm{S}$ and $\mathrm{R}$ strains were $7.44 \mu \mathrm{g}$ of dicofol $/ \mathrm{mL}$ of distilled water [ppm (A.I.)] (95\% CI 6.74 - 8.23) and 422.45 ppm (A.I.) (95\% CI 369.41 - 482.80), respectively. A resistance ratio derived from $\mathrm{LC}_{50} \mathrm{~S}$ was about 57-fold. Based on this difference, discriminating concentrations between 32 and 100 ppm (A.I.) were defined for monitoring dicofol-resistant B. phoenicis. 


\subsection{INTRODUÇÃO}

O ácaro da leprose Brevipalpus phoenicis (Geijskes) é uma das principais pragas que afetam a produção de laranja no Brasil. Este ácaro é o transmissor da leprose, doença provocada por um rabdovírus de ação não sistêmica (Kitajima et al., 1972). Os sintomas da doença se manifestam em folhas, galhos e frutos, onde causa desde cloroses até a queda dos órgãos atacados, resultando em perdas tanto na quantidade como na qualidade dos frutos e até mesmo na morte da planta (Chagas \& Rossetti, 1980; Chiavegato \& Salibe, 1981; Chiavegato, 1987).

O controle de $B$. phoenicis tem sido realizado principalmente através da aplicação de acaricidas para manter a densidade populacional desta praga abaixo do nível de dano econômico. Estima-se que mais de 100 milhões de reais são gastos com acaricidas em citros no Brasil. Esta grande quantidade de acaricidas se deve também à ocorrência do ácaro da falsa ferrugem, Phyllocoptruta oleivora (Ashmead), uma outra importante praga da cultura. Tanto B. phoenicis como P. oleivora ocorrem durante o ano todo, porém as maiores densidades populacionais são observadas durante o período seco para B. phoenicis e durante o período chuvoso para $P$. oleivora, resultando em uma média de duas a quatro aplicações anuais de acaricidas na cultura de citros (Oliveira, 1986; Salvo Filho, 1997).

Por mais de 25 anos o acaricida dicofol vem sendo utilizado para o controle de B. phoenicis e P. oleivora. Falhas no controle com este e outros acaricidas vem sendo reportadas com freqüência por produtores e técnicos da área citrícola paulista. A alta intensidade de uso destes acaricidas pode ser um dos fatores responsáveis pela ineficiência dos mesmos. Acredita-se que muitas destas falhas sejam devido à evolução da resistência de B. phoenicis a estes acaricidas comumente utilizados; embora fatores como condições climáticas favoráveis ao desenvolvimento da praga, má regulagem dos equipamentos de pulverização e outros fatores operacionais também devam ser considerados para avaliar os fracassos no controle (Omoto, 1995).

Estudos preliminares demostraram que há uma grande variabilidade na susceptibilidade ao acaricida dicofol em populações de B. phoenicis oriundas de 
diferentes pomares da região citrícola paulista e que a freqüência de resistência está intimamente associada ao regime de uso deste acaricida (Alves et al., 1998). Devido às características do dicofol, como por exemplo a sua especificidade de ação e custo relativamente baixo, este acaricida tem sido um importante componente em programas de manejo integrado de pragas em diversas culturas, o que justifica os esforços para prolongar a sua vida útil (Dennehy \& Granett 1984b; Omoto et al., 1995b).

Uma das etapas fundamentais para a implementação de um programa de manejo da resistência está no isolamento e caracterização da resistência para estimar a intensidade da resistência e definir uma concentração discriminatória (i.e., uma concentração que discrimine indivíduos susceptíveis dos resistentes) para o monitoramento da resistência. Sendo assim, o objetivo deste trabalho foi a caracterização da resistência de $B$. phoenicis ao acaricida dicofol através da definição de uma técnica de bioensaio para avaliar a susceptibilidade de populações de $B$. phoenicis ao dicofol, seleção de uma população resistente, e comparação das estimativas das linhas de concentração-resposta das populações susceptível e resistente ao dicofol.

\subsection{MATERIAL E MÉTODOS}

O trabalho foi conduzido no Laboratório de Resistência de Artrópodos a Pesticidas do Departamento de Entomologia, Fitopatologia e Zoologia Agrícola da Escola Superior de Agricultura "Luiz de Queiroz", Universidade de São Paulo, Piracicaba, SP em 1998. Uma população de Brevipalpus phoenicis foi obtida a partir de uma criação deste ácaro mantida em Ligustrum lucidum Ait. no Centro de Energia Nuclear na Agricultura (CENA) em Piracicaba, SP em 1995. Esta população foi tomada como a linhagem susceptível de referência $(S)$, pelo fato desta estar na ausência de pressão seletiva com acaricidas por um período superior a 5 anos. A linhagem resistente de $B$. phoenicis ao dicofol (R) foi obtida através da seleção com dicofol em condições laboratoriais, a partir de uma população de B. phoenicis coletada em um pomar comercial de citros da região de Itápolis, SP em 1997. A intensidade de uso do dicofol 
neste pomar era bastante alta e falhas no controle de B. phoenicis com este acaricida já tinham sido reportadas com freqüência.

Criação de B. phoenicis. A criação de B. phoenicis foi realizada sobre frutos de laranja da variedade Pera Rio ou Valência coletados em pomares sem a aplicação de acaricidas. Os frutos coletados eram lavados com água e após a secagem, eram parafinados deixando-se uma arena de aproximadamente 8 a $16 \mathrm{~cm}^{2}$ circundada com cola adesiva (Tanglefoot ${ }^{\circledR}$, Grand Rapids, MI, Estados Unidos) para confinar os ácaros. Em cada fruto foram transferidos de 40 a 50 ácaros adultos com auxílio de um pincel com apenas um pêlo e dois microscópios estereoscópicos. Os frutos infestados com os ácaros foram colocados em caixas plásticas (dimensões de $41 \times 34 \times 14 \mathrm{~cm}$ ) contendo em seu fundo uma prancha de isopor com 12 orificios onde os frutos eram acondicionados. A criação foi mantida em sala climatizada à temperatura de $25 \pm 2^{\circ} \mathrm{C}$, umidade relativa ao redor de $70 \%$ e fotofase de 14 horas. Para a manutenção de cada população de B. phoenicis foram estabelecidos aproximadamente 72 frutos. Os frutos eram renovados a cada 30 ou 40 dias onde a arena do fruto novo era mantida em contato com a arena do fruto infestado com os ácaros até que grande parte dos ácaros transferissem para o fruto novo.

Procedimentos de Bioensaio. O método de bioensaio adotado foi o de contato residual. O acaricida utilizado foi o Kelthane ${ }^{\circledR} 480 \mathrm{CE}$ (480 g de dicofol por litro de produto comercial, formulação concentrado emulsionável, Rohm and Haas Química Ltda.). As diferentes concentrações do produto escolhidas para os bioensaios foram preparadas através da diluição do produto comercial em água destilada. Os bioensaios foram realizados em arenas de 2,6 cm de diâmetro confeccionadas com folhas de laranjeira da variedade Pera Rio coletadas em um pomar sem a aplicação de acaricidas. As arenas de folha foram mantidas sobre algodão embebido em água até a pulverização do produto. A aplicação foi feita sobre a superfície adaxial dos discos de folha através do uso da torre de pulverização de Potter (Burkard Manufacturing, Rickmansworth, Herts, Reino Unido) calibrada a uma pressão de $10 \mathrm{psi}(68,95 \mathrm{kPa})$. Foi utilizado um volume de $2 \mathrm{~mL}$ de solução em cada pulverização, obtendo-se uma deposição média de resíduo úmido de $1,56 \mathrm{mg} / \mathrm{cm}^{2}$ sobre as arenas. Após a aplicação, as arenas foram 
retornadas sobre o algodão umedecido até a secagem do produto. Em seguida. as arenas foram acondicionadas individualmente em placas acrílicas de $3,5 \mathrm{~cm}$ de diâmetro (Falcon 1008, Becton Dickinson Labware, Lincoln Park, NJ, Estados Unidos) contendo $2 \mathrm{~mL}$ de uma mistura ainda não geleificada de ágar-água na concentração de $2,3 \%$. Após a geleificação do substrato no fundo da placa. uma barreira para evitar a fuga dos ácaros foi construída ao redor dos discos de folha com a mesma mistura de ágar-água (adaptado de Vestergaard et al., 1995).

Foram transferidos 10 ácaros adultos por arena. Cada concentração foi repetida 5 a 6 vezes ao longo do tempo e cada repetição foi constituída por aproximadamente 40 ácaros. Após a infestação dos ácaros nas arenas, as placas foram tampadas e mantidas em câmara climatizada regulada à temperatura de $25 \pm 1^{\circ} \mathrm{C}$, umidade relativa de $70 \pm 10 \%$ e fotofase de 14 horas. A mortalidade foi avaliada 24 horas após a infestação com o auxílio de um pincel com um único pêlo e microscópio estereoscópico. Os ácaros foram virados de costas e aqueles que retornaram à posição normal e andaram foram considerados vivos. As repetições que apresentaram uma mortalidade superior a $15 \%$ na testemunha foram descartadas, assim como aquelas cuja perda de ácaros no ágar ultrapassou $15 \%$.

Seleção da Linhagem Resistente. A seleção de B. phoenicis resistente ao dicofol a partir da população proveniente de um pomar comercial da região de Itápolis, SP, foi realizada de acordo com os procedimentos de bioensaio descritos anteriormente. Foram feitas duas etapas de seleção utilizando-se a concentração de $320 \mu \mathrm{g}$ de dicofol / $\mathrm{mL}$ de água destilada [ppm (I.A.)]. Esta concentração foi escolhida baseada em trabalhos preliminares que evidenciaram uma mortalidade de $100 \%$ da linhagem susceptível. Os ácaros sobreviventes da primeira etapa de seleção foram transferidos em frutos parafinados para a sua multiplicação por uma a duas gerações. Após a obtenção de um número suficiente de descendentes dos ácaros selecionados na primeira etapa, a segunda etapa de seleção foi realizada. Pelo fato do ácaro da leprose se reproduzir por partenogènese telítoca do tipo automítica, originando descendentes fêmeas geneticamente idênticas à geração maternal, apenas uma etapa de seleção seria o suficiente para eliminar todos os susceptíveis, porém na tentativa de diminuir qualquer 
falha no processo que ocasionasse a sobrevivência de ácaros susceptíveis, foram realizadas duas etapas de seleção. A população obtida após as duas etapas de seleção foi considerada como uma população de B. phoenicis resistente ao dicofol (R).

Caracterização da Resistência de B. phoenicis ao Acaricida Dicofol. Cinco concentrações de dicofol espaçadas logaritmicamente foram testadas entre 1,8 a $18 \mu \mathrm{g}$ de dicofol / $\mathrm{mL}$ de água destilada [ppm (I.A.)] para a linhagem S, e seis concentrações entre 100 a 1.800 ppm (I.A.) para a linhagem R.

Os dados de mortalidade para as linhagens $\mathrm{S}$ e $\mathrm{R}$ foram submetidos à análise de próbite através do programa POLO-PC (LeOra Software, 1987). Um teste de paralelismo das linhas de concentração-resposta para as duas linhagens foi conduzido para determinar se o coeficiente angular de cada linha era significativamente diferente. O nível de significância do teste foi de $\alpha=0,05$. A razão de resistência foi estimada através da divisão da $\mathrm{CL}_{50}$ da linhagem $\mathrm{R}$ pela $\mathrm{CL}_{50}$ da linhagem $\mathrm{S}$, e o seu intervalo de confiança (IC) a $95 \%$ foi estimado de acordo com os procedimentos descritos por Robertson \& Preisler (1992).

\subsection{RESULTADOS E DISCUSSÃO}

As linhas de concentração-resposta das linhagens $\mathrm{S}$ e $\mathrm{R}$ de Brevipalpus phoenicis ao acaricida dicofol estão representadas na Figura 1. Foram testados $1.169 \mathrm{e}$ 1.183 indivíduos para as linhagens $\mathrm{S}$ e $\mathrm{R}$, respectivamente. $\mathrm{A} \mathrm{CL}_{50}$ para a linhagem $\mathrm{S}$ foi de 7,44 ppm de dicofol (IC 95\% 6,74-8,23), coeficiente angular ( \pm desvio padrão) de $3,85( \pm 0,19), \chi^{2}$ de 3,37 (graus de liberdade $=3, P>0,05$ ). Para a linhagem $\mathrm{R}, \mathrm{CL}_{50}$ foi de 422,45 ppm (I.A.) (IC 95\% 369,41-482,80), coeficiente angular ( \pm desvio padrão) de $3,21( \pm 0,15), \chi^{2}$ de 7,56 (graus de liberdade $=4, P>0,05$ ). Os fatores de heterogeneidade para as linhagens $\mathrm{S}$ e $\mathrm{R}$ foram de 1,12 e 1,89, respectivamente. A razão de resistência derivada da $\mathrm{CL}_{50}$ das duas linhagens foi de 56,82 (IC 95\% 53,54-60,29).

$\mathrm{O}$ coeficiente angular da linhagem $\mathrm{R}$ foi significativamente menor que o da linhagem $S\left(\chi^{2}=7,44\right.$, grau de liberdade $\left.=1, P<0,05\right)$. Segundo Hoskins e Gordon (1956), uma interpretação biológica do coeficiente angular está relacionado à 
homogeneidade de uma determinada população; isto é, quanto maior o coeficiente angular, maior a homogeneidade de uma população. A inclinação da reta pode também estar relacionada ao método de bioensaio (ffrench-Constant \& Roush, 1990). Como o método de bioensaio para a caracterização da linha de concentração-resposta das linhagens $\mathrm{S}$ e $\mathrm{R}$ foi o mesmo neste trabalho, os resultados obtidos indicam uma maior homogeneidade da linhagem S. Provavelmente este resultado se deve ao fato desta linhagem estar em condições laboratoriais por um maior período do que a linhagem $\mathrm{R}$, aumentando assim as chances de seleção de indivíduos mais adaptados no laboratório. Uma outra explicação poderia estar ligado à possibilidade de um estrangulamento da variabilidade genética durante o processo de colonização desta linhagem no laboratório (Bartlett, 1984). Qualquer alteração na composição genética de populações de $B$. phoenicis poderia ser mantida devido ao seu modo de reprodução, predominantemente por partenogênese telítoca, e a ausência de migração em condições laboratoriais. Por outro lado, a linhagem $\mathrm{R}$ foi obtida através de uma população proveniente do campo e submetida a apenas duas pressões de seleção com o acaricida dicofol em condições laboratoriais; e sendo assim, a preservação da variabilidade genética original do campo seria maior nesta linhagem.

Como a sobreposição das linhas de concentração-resposta das populações S e $\mathrm{R}$ ao dicofol não foi observada (Figura 1), concentrações entre 32 e 100 ppm de dicofol poderiam ser utilizadas como discriminatórias para a estimativa da freqüência de resistência de $B$. phoenicis ao dicofol em um determinado pomar. Vantagens da utilização de concentrações discriminatórias em relação à comparação da $\mathrm{CL}_{50}$ em um programa de monitoramento da resistência foram discutidas por Roush \& Miller (1986). O nível de ação preconizado para B. phoenicis em citros é baixo (ao redor de $10 \%$ de frutos infestados), e sendo assim a quantidade de ácaros que poderia ser amostrada para os bioensaios para estimar a freqüência de resistência a um determinado acaricida também seria limitada. Nestas condições, se todos os ácaros amostrados fossem submetidos a uma única concentração discriminatória, ao invés de se estimar a $\mathrm{CL}_{50}$, a precisão na detecção da resistência seria maior. 
Os resultados obtidos na presente pesquisa confirmaram a presença de $B$. phoenicis resistente ao dicofol. Com o isolamento e caracterização da resistência de $B$. phoenicis ao dicofol, outros estudos poderão ser realizados para a implementação de um programa de manejo da resistência; como por exemplo os estudos da dinâmica da resistência para verificar se existe custo de adaptação dos indivíduos resistentes na ausência da pressão seletiva (Capítulo 4) e de relações de resistência cruzada entre o dicofol e outros acaricidas recomendados para o controle de B. phoenicis (Capítulo 5). Se a resistência de $B$. phoenicis ao dicofol for instável, a instabilidade da resistência pode ser explorada em um programa de manejo da resistência através da rotação de acaricidas. Os estudos de resistência cruzada possibilitarão identificar os produtos que poderiam ser utilizados em rotação ou em mistura com o dicofol. Uma vez implementada uma estratégia de manejo da resistência de $B$. phoenicis ao dicofol, esta poderá ser avaliada facilmente através da estimativa da freqüência de resistência utilizando-se de bioensaios de concentrações discriminatórias definidas no presente trabalho. 


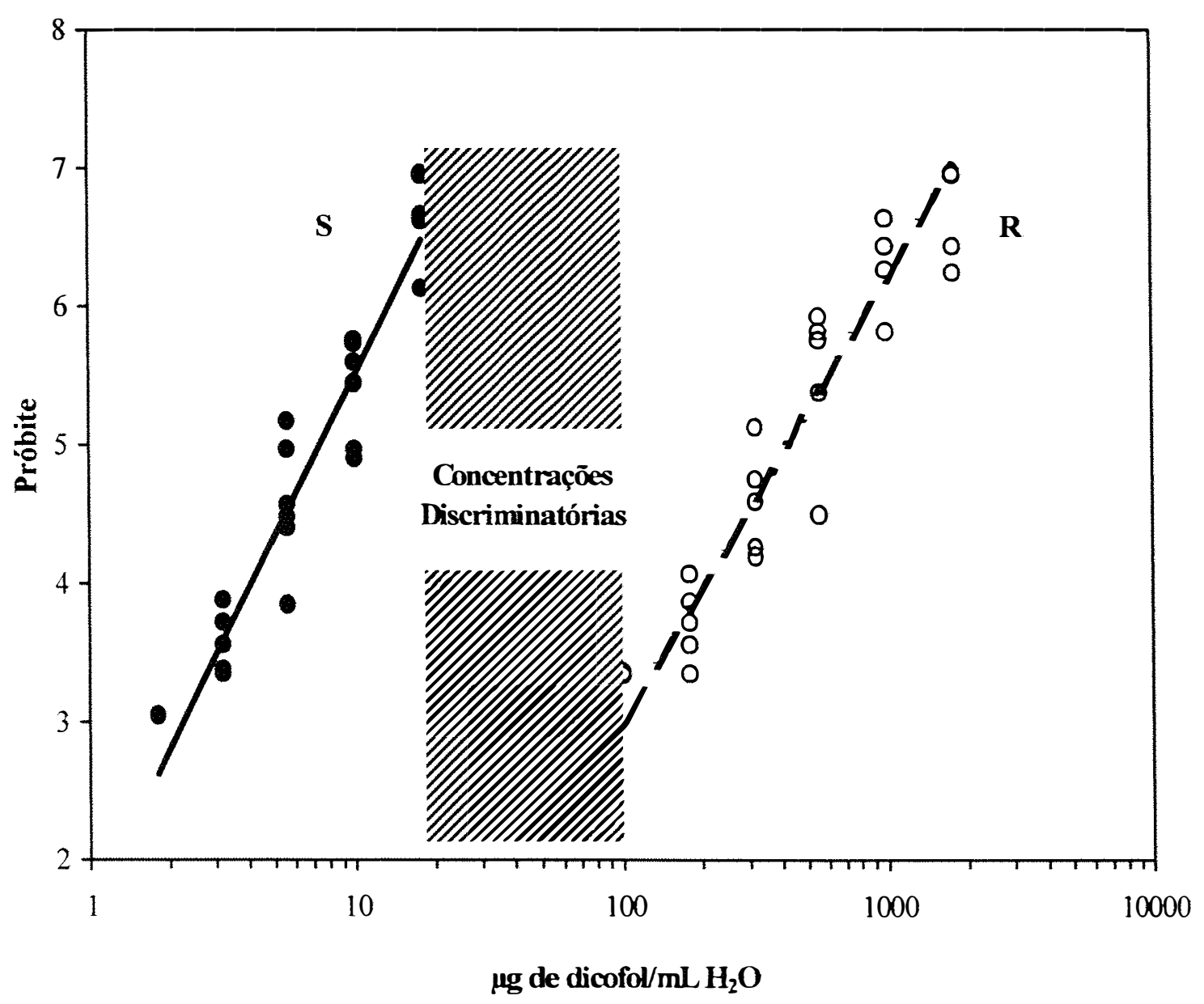

Figura 1. Curvas de concentração-resposta das linhagens de Brevipalpus phoenicis susceptível (S) e resistente (R) ao acaricida dicofol. A área hachureada representa o intervalo de concentrações discriminatórias de dicofol para um programa de monitoramento da resistência de B. phoenicis ao dicofol. 


\subsection{CONCLUSÕES}

- A intensidade da resistência de Brevipalpus phoenicis ao dicofol é de 56,82 (IC 95\% $53,54-60,29)$.

- Concentrações discriminatórias entre 32 e 100 ppm de dicofol podem ser utilizadas para um programa de monitoramento da resistência de B. phoenicis ao dicofol. 


\title{
4 CUSTO ADAPTATIVO ASSOCIADO À RESISTÊNCIA DE Brevipalpus phoenicis (ACARI: TENUIPALPIDAE) AO ACARICIDA DICOFOL
}

\author{
Autor: Everaldo Batista Alves \\ Orientador: Prof. Dr. Celso Omoto
}

\section{RESUMO}

O custo adaptativo associado à resistência de Brevipalpus phoenicis (Geijskes) ao acaricida dicofol foi avaliado em condições de laboratório. Para tanto, a dinâmica da resistência de B. phoenicis ao dicofol foi avaliada através do monitoramento da resistência em populações com freqüências iniciais de 20,50 e $80 \%$ de ácaros resistentes. As freqüências de resistência foram estimadas mensalmente, por um período de seis meses, através de um bioensaio de concentração discriminatória de $32 \mu \mathrm{g}$ de dicofol / $\mathrm{mL}$ de água destilada. A resistência de B. phoenicis ao dicofol mostrou ser bastante instável, ou seja, a freqüência de resistência diminuiu significativamente na ausência da pressão seletiva. Comparações de parâmetros biológicos entre as linhagens susceptível (S) e resistente (R) não demonstraram diferenças no tempo de desenvolvimento de ovo a adulto para as duas linhagens. Porém, foram observadas diferenças significativas na longevidade e fecundidade. A longevidade média das linhagens S e R foram de 31.4 e 21,7 dias, respectivamente. A fecundidade da linhagem $\mathrm{R}$ foi de $51,5 \%$ da linhagem $\mathrm{S}$. As razões finitas de aumento $(\lambda)$ estimadas através das tabelas de vida e fertilidade foram de 1.095 e 1.081 fềmeas/fềmea/dia para as linhagens $S$ e R, respectivamente. 


\title{
FITNESS COST ASSOCIATED WITH DICOFOL RESISTANCE IN Brevipalpus phoenicis (ACARI: TENUIPALPIDAE)
}

\author{
Author: Everaldo Batista Alves \\ Adviser: Prof. Dr. Celso Omoto
}

\section{SUMMARY}

Fitness cost associated with resistance of Brevipalpus phoenicis (Geijskes) to the acaricide dicofol was evaluated under laboratory conditions. Initially, we conducted cage studies to evaluate the dynamics of resistance in populations of $B$. phoenicis with 20,50 and $80 \%$ of dicofol-resistant mites. The frequency of resistance was estimated monthly in a 6-month period with a discriminating concentration bioassay of $32 \mu \mathrm{g}$ of dicofol / $\mathrm{mL}$ of distilled water. The resistance revealed to be very unstable; that is, the frequency of dicofol-resistant mites declines significantly in the absence of selection pressure. Then, life-history studies of susceptible (S) and dicofol-resistant (R) strains were evaluated. No difference in the egg-adult developmental time was detected between strains. However, significant differences were found in the longevity and fecundity of mites. The mean longevity of S and R strains were 31.4 and 21.7 days, respectively. The fecundity of $\mathrm{R}$ strain was about $51.5 \%$ of the $\mathrm{S}$ strain. The finite rate of increase $(\lambda)$ estimated from life and fertility tables were 1.095 and 1.081 females/female/day for S and R strains, respectively. 


\subsection{INTRODUÇÃO}

A desvantagem adaptativa de indivíduos resistentes em relação aos susceptíveis a um determinado pesticida tem sido uma característica bastante explorada em estratégias de manejo da resistência de pragas a pesticidas. Uma das condições básicas para o sucesso da rotação de produtos, por exemplo, está na presença de custo adaptativo dos indivíduos resistentes quando um determinado produto não é utilizado (Georghiou, 1972, 1983; Tabashnik, 1989). Este custo geralmente está associado a fatores que são relevantes à sobrevivência e reprodução da espécie (Roush \& McKenzie, 1987; Roush \& Daly, 1990). Sendo assim, quando um pesticida não é utilizado por um determinado período de tempo, pode-se observar o restabelecimento da susceptibilidade. Este restabelecimento pode também ser auxiliado pela migração de indivíduos susceptíveis de áreas não tratadas para as tratadas.

Inúmeros casos de resistência de ácaros ao acaricida dicofol já foram relatados a nível mundial (Hoyt \& Harries, 1961; Inoue, 1980; Dennehy \& Granett, 1984b; Pree, 1987; Dennehy et al., 1990; Omoto et al., 1994). No entanto, este acaricida continua desempenhando um importante papel no controle de ácaros em diversas culturas (Dennehy et al., 1990; Omoto et al., 1995b). Uma das razões para o sucesso do uso de dicofol está relacionado à instabilidade da resistência.

Alguns estudos têm apontado diferenças no valor adaptativo entre os ácaros resistentes e susceptíveis ao dicofol, como por exemplo em Panonychus citri (McGregor) no Japão (Inoue, 1980). Por outro lado estudos realizados por Mable \& Pree (1992) demonstraram que não existem diferenças em atributos biológicos entre as populações susceptível e resistente de Panonychus ulmi (Koch) ao dicofol no Canadá.

Estudos de dinâmica da resistência realizados por Dennehy et al. (1990) demonstraram que a resistência de Tetranychus urticae (Koch) ao dicofol na cultura de maçã no Estado de Nova York. Estados Unidos é bastante instável, enquanto que a resistência de $P$. ulmi se mostrou bastante estável a este mesmo acaricida. Os autores explicaram esses resultados através da possibilidade de migração de ácaros susceptíveis de T. urticae de outras plantas hospedeiras, enquanto que esta migração não poderia ser 
esperada para $P$. ulmi que ataca quase que exclusivamente a cultura de maçã. Por outro lado, em condições de casa de vegetação na Holanda, a resistência de $T$. urticae ao dicofol se mostrou bastante estável (Overmeer et al., 1975). Sendo assim, a dinâmica da resistência não pode ser generalizada para uma determinada espécie e produto, pois esta depende também do ecossistema e do mecanismo de resistência (Roush \& McKenzie, 1987; Roush \& Daly, 1990).

A caracterização da resistência de Brevipalpus phoenicis (Geijskes) foi reportada no Capítulo 3. B. phoenicis é uma espécie de ácaro bastante polífaga. A sua ocorrência foi reportada em mais de 30 espécies de plantas hospedeiras nos pomares de citros do Estado de São Paulo (Trindade \& Chiavegato, 1994). Sendo assim, acredita-se que os hospedeiros alternativos de B. phoenicis poderiam servir de refúgio para os ácaros susceptíveis, e estes poderiam migrar para as áreas tratadas e diminuir a freqüência de resistência (Omoto, 1998). Porém não se tem estudos relacionados à capacidade efetiva de migração desta espécie. Mesmo assumindo-se que a migração ocorra, não se tem conhecimento se a reprodução sexuada ocorre nesta espécie para possibilitar a segregação da resistência, pois sabe-se que este ácaro se reproduz principalmente por partenogênese telítoca (Helle et al., 1980).

Para um melhor entendimento da dinâmica da resistência de $B$. phoenicis ao acaricida dicofol, procurou-se avaliar no presente estudo se há custo adaptativo associado à resistência que poderia contribuir no restabelecimento da susceptibilidade na ausência de pressão de seleção. Para tanto, a freqüência de resistência foi estimada mensalmente em populações de $B$. phoenicis com diferentes freqüências de resistência ao dicofol por um período de seis meses em condições laboratoriais. Estudos de biologia das linhagens susceptível e resistente de $B$. phoenicis ao dicofol foram conduzidos para avaliar se existem diferenças nos parâmetros biológicos entre as duas linhagens. 


\subsection{MATERIAL E MÉTODOS}

No presente trabalho duas linhagens de Brevipalpus phoenicis foram utilizadas, sendo uma linhagem susceptível de referência (S) que foi obtida a partir de uma criação de B. phoenicis mantida em Ligustrum lucidum Ait. no Centro de Energia Nuclear na Agricultura (CENA) em Piracicaba, SP em 1995, e a outra resistente ao dicofol (R) que foi obtida através da seleção de uma população de B. phoenicis oriunda de um pomar comercial de citros da região de Itápolis, SP em 1997. O processo de seleção da linhagem resistente e a metodologia de criação de $B$. phoenicis estão descritos no Capítulo 3.

\subsubsection{Dinâmica da resistência de Brevipalpus phoenicis ao dicofol em condições laboratoriais}

A freqüência de resistência de B. phoenicis ao dicofol foi acompanhada mensalmente por um período de seis meses em três populações de $B$. phoenicis com diferentes frequiências de resistência. A partir das linhagens $\mathrm{S}$ e $\mathrm{R}$ foram estabelecidas populações com 20 , 50 e $80 \%$ de ácaros resistentes. As populações com $100 \%$ de S e $100 \%$ de R foram tomadas como populações controle. Para cada população foram estabelecidos 12 frutos com 100 ácaros adultos por fruto. As populações foram mantidas em laboratório à temperatura de $25 \pm 2^{\circ} \mathrm{C}$, umidade relativa superior a $60 \% \mathrm{e}$ fotofase de 14 horas.

As freqüências de resistência foram estimadas através do bioensaio de concentração discriminatória de $32 \mu \mathrm{g}$ de dicofol / $\mathrm{mL}$ de água destilada. Os procedimentos de bioensaio estão descritos no Capítulo 3. Os bioensaios foram repetidos quatro vezes (cinco arenas por repetição, contendo 10 ácaros por arena) para cada população. Em cada bioensaio foram utilizadas duas arenas tratadas apenas com água destilada como testemunhas. Os bioensaios com mortalidade superior a $15 \%$ na testemunha foram descartados, assim como aqueles cuja perda de ácaros no ágar ultrapassou $15 \%$. 
Os dados de porcentagem de sobrevivência $(X)$ de cada população, coletados durante os seis meses, foram transformados para arc sen (RAIZ (X/100)) e submetidos à análise de variância de dois fatores (população e tempo) com interação. O nível de significância dos testes foi de $\alpha=0,05$.

\subsubsection{Biologia das linhagens de Brevipalpus phoenicis susceptível e resistente ao dicofol}

A biologia das linhagens $\mathrm{S}$ e $\mathrm{R}$ de $B$. phoenicis ao dicofol foi estudada em condições de câmara climática controlada à temperatura de $25 \pm 1^{\circ} \mathrm{C}$, umidade relativa de $70 \pm 10 \%$ e fotofase de 14 horas. Para tanto, frutos de laranja da variedade Valência foram parafinados deixando-se uma arena de aproximadamente $1,5 \mathrm{~cm}$ de diâmetro. Sobre a arena foi colocado um tubo de acrílico transparente $\mathrm{com} 2,5 \mathrm{~cm}$ de diâmetro por $2 \mathrm{~cm}$ de altura com duas aberturas opostas nas laterais de aproximadamente $1 \mathrm{~cm}$ de diâmetro fechadas com tela para permitir trocas gasosas. A extremidade inferior do tubo foi fixada à parafina do fruto com cera de abelha purificada e a extremidade superior foi fechada com um filme de PVC fixado com elástico. Para evitar distúrbios no fruto e excessiva transpiração na arena, foram feitas três aberturas de aproximadamente 1,5 a 2 $\mathrm{cm}^{2}$ na área parafinada do fruto.

Dentro da arena foi confeccionado um local de oviposição para o ácaro, pincelando-se uma mistura de gesso, areia e água. Posteriormente, foram transferidos cinco ácaros fêmeas adultos da linhagem a ser estudada. Os ácaros permaneceram na arena até a obtenção de um ou mais ovos. O acompanhamento da biologia foi iniciado com ovos de 0 a 8 horas de idade. As avaliações das fases de ovo a adulto foram feitas duas vezes ao dia nos horários das 8:00 e 17:00 horas, registrando-se a duração e a mortalidade de cada estágio. A partir do estágio adulto as avaliações passaram a ser realizadas uma vez ao dia. Na fase adulta foram registrados a duração dos períodos de pré-oviposição, oviposição, pós-oviposição e o número de ovos colocados por fềmea. 
Os dados dos parâmetros biológicos obtidos para as duas linhagens foram analisados para cada parâmetro biológico estudado através do teste $t$. O nível de significância foi de $\alpha=0,05$.

Os dados obtidos também foram analisados através da confecção de tabelas de vida e fertilidade segundo o método de Andrewartha \& Birch $^{2}$ citado por Sinval Silveira Neto et al. (1976). Parâmetros da tabela de vida e fertilidade (taxa líquida de reprodução $\left(R_{o}\right)$, duração média de uma geração $(T)$, capacidade inata de aumentar em número $\left(r_{m}\right)$ e razão finita de aumento $(\lambda)$ ) foram estimados para as linhagens S e R (Apêndices 1 e 2). Para a elaboração das tabelas de vida e fertilidade foram observadas 30 e 31 fềmeas das linhagens $\mathrm{S}$ e R, respectivamente. Fêmeas que não colocaram ovos (uma fềmea de cada linhagem) também foram incluídas nos cálculos.

Após a estimativa da razão finita de aumento $(\lambda)$ para cada linhagem, uma simulação das mudanças nas freqüências de resistência esperadas no decorrer do tempo foi realizada para populações de $B$. phoenicis com freqüências iniciais de 20,50 e $80 \%$ de resistentes.

\subsection{RESULTADOS E DISCUSSÃO}

\subsubsection{Dinâmica da resistência de Brevipalpus phoenicis ao dicofol em condições laboratoriais}

As freqüências de resistência ao dicofol das três populações de Brevipalpus phoenicis estudadas declinaram significativamente na ausência de pressão de seleção em condições de laboratório (Figura 2). A interação entre os fatores população e tempo foi significativo $(F=4,53$; graus de liberdade $=10,54: P<0,05)$, ou seja as populações se comportaram de forma diferente uma das outras no decorrer dos seis meses de avaliação.

\footnotetext{
2 ANREWARTHA H. G.; BIRCH. L. G. The distribution and abundance of animals. Chicago: University of Chicago Press, 1954. 782p.
} 
Um maior decréscimo na freqüência de resistência foi observado em populações com freqüências iniciais altas do alelo $\mathrm{R}$. Quedas significativas nas freqüências de resistência das populações com freqüências iniciais de 50 e $80 \%$ de resistentes foram observadas a partir do terceiro e quarto mês de avaliação, respectivamente. Quedas significativas na freqüência de resistência da população com freqüência inicial de $20 \%$ de resistentes foram observadas a partir do quinto mês. Em teoria este fato pode ser melhor explicado devido a curva de freqüência de resistência ao longo do tempo assumir um forma assintótica em direção à susceptibilidade. Este fato também foi observado por Inoue (1980) em trabalhos de simulação, onde freqüências baixas do alelo que conferia resistência ao acaricida dicofol em Panonychus citri sofriam menores variações e podiam ser mantidas por mais tempo na população e por Omoto et al. (1995b) que estudaram a dinâmica da resistência de Phyllocoptruta oleivora (Ashmead) ao dicofol em condições laboratoriais. Nestas condições, um aumento mais rápido da freqüência de resistência após a retomada de aplicações com o dicofol seria esperado, comparado a uma população que não recebeu pressão de seleção anteriormente.

O declínio da resistência observado no presente trabalho não pode ser explicado pela migração de ácaros susceptíveis, pelo fato deste estudo ter sido conduzido em condições fechadas de laboratório. Também, estes resultados não foram causados por deriva genética, porque a população inicial foi bastante alta para as três populações. Segundo Georghiou (1972) variações nutricionais e ambientais poderiam causar pequenas mudanças na susceptibilidade dos organismos no bioensaio. Porém através das populações controle não foram constatadas variações na susceptibilidade dos organismos durante os bioensaios. decorrente de variações nutricionais e ambientais. 


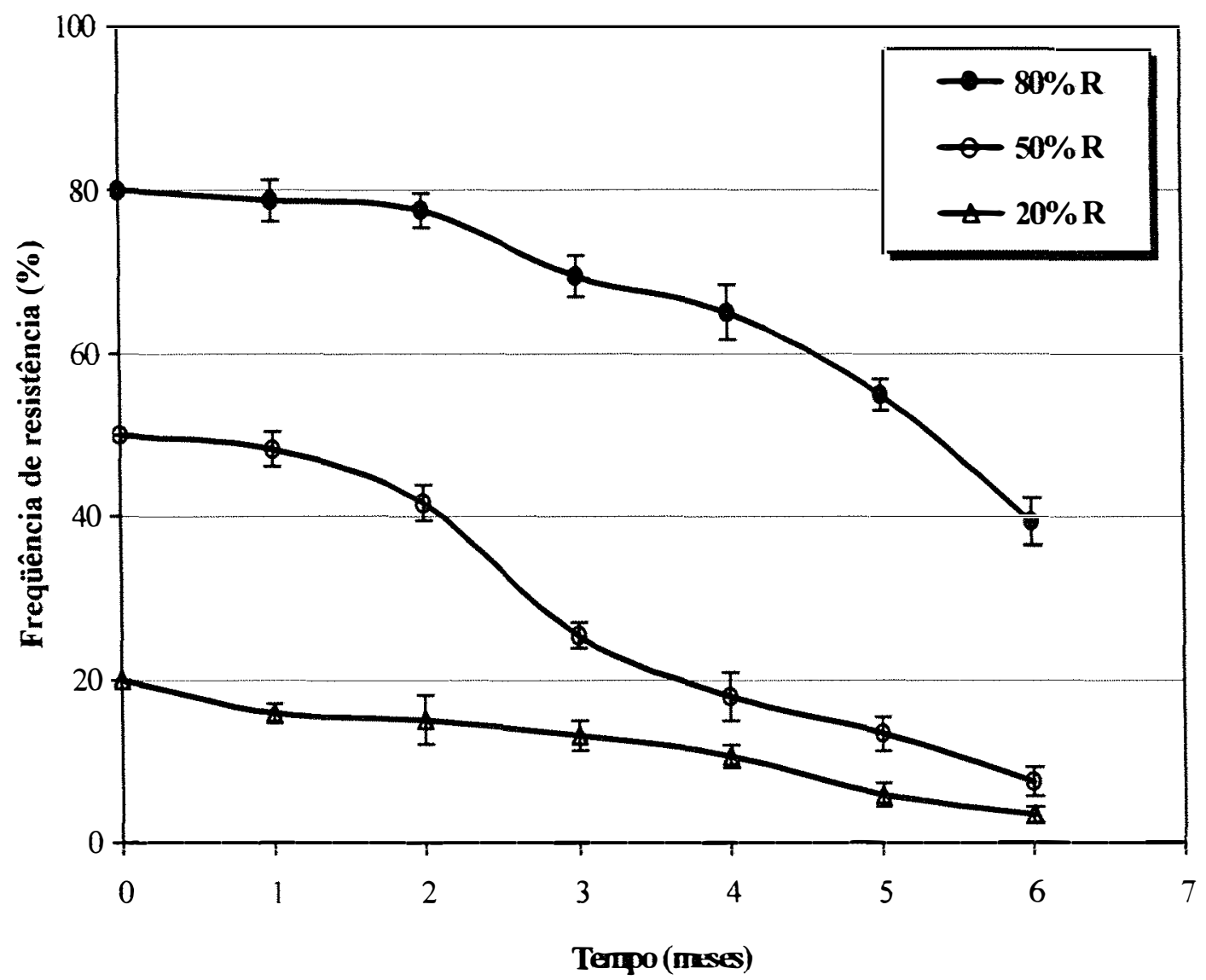

Figura 2. Mudanças nas freqüências de resistência de Brevipalpus phoenicis ao dicofol em populações com freqüências iniciais de $20 \%, 50 \%$ e $80 \%$ de ácaros resistentes em condições de laboratório, à temperatura de $25 \pm 2^{\circ} \mathrm{C}$, UR superior a $60 \%$ e fotofase de 14 horas. 


\subsubsection{Biologia das linhagens de Brevipalpus phoenicis susceptível e resistente ao dicofol}

Não foram verificadas diferenças significativas com relação ao tempo de desenvolvimento de ovo a adulto das linhagens $\mathrm{S}$ e R que foram de 20,81 e 20,74 dias, respectivamente. No entanto, um aumento significativo no período de desenvolvimento da fase de protoninfa foi observado para a linhagem $R$ (Tabela 1 ).

Pequenas diferenças na duração das fases imaturas não demostram serem as responsáveis pelo rápida reversão da resistência de B. phoenicis observada no estudo de dinâmica da resistência realizado neste trabalho. Porém, Flexner et al. (1989) estudando o custo adaptativo de Tetranychus urticae resistente a cyhexatin, observaram que mesmo diferenças inferiores a 24 horas no tempo de desenvolvimento eram capazes de afetar significativamente a estabilidade da resistência em condições de campo. Desta forma, para $B$. phoenicis, um maior tempo de desenvolvimento da fase de protoninfa pode significar uma maior exposição deste estágio a ácaros predadores devido ao seu menor tamanho e maior fragilidade comparado com os estágios subsequentes. Trabalhos estudando a predação de B. phoenicis por Euseius concordis (Chant) (Komatsu \& Nakano, 1988) e Euseius citrifolius Denmark \& Muma (Gravena et al., 1994) mostram que a capacidade de predação diminui de acordo com o desenvolvimento dos estágios imaturos de B. phoenicis. Por exemplo, proporcionamente os adultos de E. concordis são capazes de predar $87,74 \%$ de ovos, $61,41 \%$ de formas jovens (larvas e ninfas) e apenas $4,83 \%$ de adultos de $B$. phoenicis.

Não foram observadas diferenças na fertilidade dos ovos, sendo a viabilidade superior a $97 \%$ para ambas as linhagens. A viabilidade da fase larval das linhagens S e $\mathrm{R}$ foram de $95,08 \%$ e $84,75 \%$, respectivamente e a viabilidade da fase ninfal de 96,23 e $98 \%$, para as linhagens S e R, respectivamente. Segundo Chiavegato (1986b), a fase mais crítica para o desenvolvimento de $B$. phoenicis é a de larva. Sendo assim, provavelmente o custo adaptativo associado à resistência de B. phoenicis ao dicofol possa ser atribuído a uma menor viabilidade da fase larval. 
A instabilidade da resistência de B. phoenicis ao dicofol pode ser explicada também pelas diferenças encontradas em parâmetros biológicos da fase adulta das duas linhagens. Diferenças significativas no período de pré-oviposição e oviposição foram detectadas. Estes períodos foram maiores para as fềmeas susceptíveis. O período de oviposição da linhagem $\mathrm{S}$ foi 1,7 vezes maior que o da linhagem $\mathrm{R}$ (Tabela 2), e consequentemente a longevidade e o ciclo completo da linhagem $\mathrm{S}$ foram maiores que $\mathrm{o}$ da linhagem R (Tabela 3, Figura 3). Associado a uma maior capacidade de sobrevivência na fase adulta, as fềmeas susceptíveis foram capazes de colocar mais ovos que as fềmeas resistentes (Tabela 2, Figura 4). A fecundidade da linhagem $\mathrm{R}$ foi de apenas $51,5 \%$ da linhagem susceptível. Os resultados obtidos pela confecção das tabelas de vida e fertilidade para as linhagens $\mathrm{S}$ e $\mathrm{R}$ (Apêndices 1 e 2) são apresentados na Tabela 4. A cada geração da linhagem $\mathrm{S}$ a taxa líquida de reprodução $\left(R_{o}\right)$ dobra em relação ao da linhagem $R$.

As razões finitas de aumento $(\lambda)$ das duas linhagens foram de 1,095 e 1,081 fềmeas/fềmea/dia para as linhagens $\mathrm{S}$ e $\mathrm{R}$, respectivamente. Resultados de simulação demonstraram que estes valores refletiram em diferenças significativas na freqüência de resistência a cada mês (Figura 5), confirmando os resultados obtidos experimentalmente (Figura 2). Como exemplo, tomando as razões finitas de aumento $(\lambda)$ de 1,095 fềmeas/fêmea/dia para a linhagem $\mathrm{S}$ e 1,081 fềmeas/fềmea/dia para a linhagem $\mathrm{R}$ teríamos que ao final de 60 dias uma fêmea da linhagem S seria capaz de produzir 231 indivíduos enquanto uma fềmea da linhagem $\mathrm{R}$ produziria apenas 107 indivíduos.

A baixa taxa líquida de reprodução $\left(R_{o}\right)$ e a baixa longevidade da linhagem $\mathrm{R}$ indicam que ácaros desta linhagem tem uma desvantagem adaptativa comparado a ácaros da linhagem $\mathrm{S}$ na ausência de pressão seletiva. Desvantagens reprodutivas também foram encontradas e designadas serem as responsáveis pela instabilidade da resistência ao acaricida dicofol em Panonychus citri (Inoue, 1980). Porém em P. ulmi não foram encontradas diferenças no potencial biótico entre as linhagens susceptível e resistente quando elas foram expostas às mesmas condições ambientais (Pree, 1987; Mable \& Pree, 1992). Em parte a estabilidade da resistência de $P$. ulmi pode ser explicada pela falta de diferenças no potencial biótico. 
O potencial reprodutivo juntamente com fatores que afetam a sobrevivência constitui um dos principais fatores afetando o desenvolvimento da resistência (Roush \& McKenzie, 1987; Roush \& Daly,1990). Diante dos resultados obtidos conclui-se que os principais fatores que estão ligados à instabilidade da resistência de $B$. phoenicis ao dicofol incluem menor fecundidade e longevidade da linhagem resistente em relação à linhagem susceptível.

Tabela 1. Duração média \pm erro padrão da média (em dias) dos estágios embrionário e pós-embrionário das linhagens de Brevipalpus phoenicis susceptível e resistente ao dicofol, à temperatura de $25 \pm 1^{\circ} \mathrm{C}$, UR de $70 \pm 10 \%$ e fotofase de 14 horas.

\begin{tabular}{|c|c|c|c|c|c|c|}
\hline \multirow{2}{*}{$\begin{array}{c}\text { Estágio de } \\
\text { desenvolvimento }\end{array}$} & \multicolumn{6}{|c|}{ Linhagem } \\
\hline & $n$ & Susceptível & & $n$ & Resistente & \\
\hline Ovo & 85 & $8,14 \pm 0,074$ & $\mathrm{a}$ & 81 & $8,09 \pm 0,07$ & $\mathrm{a}$ \\
\hline Larva & 58 & $2,05 \pm 0,04$ & $\mathrm{a}$ & 50 & $2,22 \pm 0,10$ & $\mathrm{a}$ \\
\hline Protocrisálida & 60 & $1,99 \pm 0,06$ & $\mathrm{a}$ & 49 & $1,86 \pm 0,08$ & $\mathrm{a}$ \\
\hline Protoninfa & 59 & $1,74 \pm 0,06$ & $\mathrm{a}$ & 43 & $1,96 \pm 0,06$ & $\mathrm{~b}$ \\
\hline Deutocrisálida & 51 & $2,08 \pm 0,05$ & $\mathrm{a}$ & 46 & $2,00 \pm 0,05$ & a \\
\hline Deutoninfa & 47 & $2,29 \pm 0,08$ & $\mathrm{a}$ & 39 & $2,25 \pm 0,09$ & a \\
\hline Teliocrisálida & 47 & $2,63 \pm 0,06$ & $\mathrm{a}$ & 44 & $2,69 \pm 0,05$ & $\mathrm{a}$ \\
\hline Ovo-adulto & 44 & $20,81 \pm 0,23$ & $\mathrm{a}$ & 33 & $20,74 \pm 0,26$ & $\mathrm{a}$ \\
\hline
\end{tabular}

$n=$ Número de observações

Médias da mesma linha seguidas por mesma letra não diferem estatisticamente pelo teste $t$ $(\alpha=0,05)$ 
Tabela 2. Duração média \pm erro padrão da média (em dias) dos períodos de préoviposição, oviposição e pós-oviposição e número de ovos por fềmea das linhagens de Brevipalpus phoenicis susceptível e resistente ao dicofol, à temperatura de $25 \pm 1{ }^{\circ} \mathrm{C}$, UR de $70 \pm 10 \%$ e fotofase de 14 horas.

\begin{tabular}{lcccccc}
\hline Características & $\boldsymbol{n}$ & Susceptível & & $\boldsymbol{n}$ & Resistente & \\
Pré-oviposição & 44 & $3,11 \pm 0,10$ & $\mathrm{a}$ & 32 & $2,72 \pm 0,14$ & $\mathrm{~b}$ \\
Oviposição & 30 & $25,57 \pm 1,75$ & $\mathrm{a}$ & 26 & $15,02 \pm 1,81$ & $\mathrm{~b}$ \\
Pós-oviposição & 29 & $2,66 \pm 0,43$ & $\mathrm{a}$ & 25 & $3,28 \pm 0,43$ & $\mathrm{a}$ \\
№ ovos/fêmea & 30 & $30,70 \pm 2,21$ & $\mathrm{a}$ & 31 & $15,81 \pm 1,67$ & $\mathrm{~b}$ \\
\hline
\end{tabular}

$n=$ Número de observações

Médias da mesma linha seguidas por mesma letra não diferem estatisticamente pelo teste $t$ $(\alpha=0,05)$

Tabela 3. Duração média \pm erro padrão da média (em dias) da longevidade e do ciclo completo das linhagens de Brevipalpus phoenicis susceptível e resistente ao dicofol, à temperatura de $25 \pm 1^{\circ} \mathrm{C}$, UR de $70 \pm 10 \%$ e foto fase de 14 horas.

\begin{tabular}{lccccc}
\hline \multirow{2}{*}{ Características } & \multicolumn{3}{c}{ Linhagens } \\
\cline { 2 - 2 } \cline { 5 - 6 } & Susceptível & & Resistente & \\
\hline $\boldsymbol{n}$ & 30 & & $21,73 \pm 1,67$ & $\mathrm{~b}$ \\
Longevidade & $31,41 \pm 1,78$ & $\mathrm{a}$ & & $42,53 \pm 1,61$ & $\mathrm{~b}$ \\
Ciclo completo & $52,61 \pm 1,92$ & $\mathrm{a}$ & & \\
\hline
\end{tabular}

$n=$ Número de observações

Médias da mesma linha seguidas por mesma letra não diferem estatisticamente pelo teste $t$ $(\alpha=0,05)$ 
Tabela 4. Parâmetros biológicos obtidos através da tabela de vida e fertilidade para as linhagens de Brevipalpus phoenicis susceptível e resistente ao dicofol: taxa líquida de reprodução $\left(R_{o}\right)$, duração média de uma geração $(T)$, capacidade inata de aumentar em número $\left(r_{m}\right)$ e razão finita de aumento $(\lambda)$. (Apêndices 1 e 2)

\begin{tabular}{ccc}
\hline Parâmetros Biológicos & Susceptível & Linhagens \\
$\boldsymbol{T}$ & 36,336 & Resistente \\
$\boldsymbol{R}_{\boldsymbol{o}}$ & 26,835 & 32,720 \\
$\boldsymbol{r}_{\boldsymbol{m}}$ & 0,091 & 12,805 \\
$\boldsymbol{\lambda}$ & 1,095 & 0,078 \\
\hline
\end{tabular}




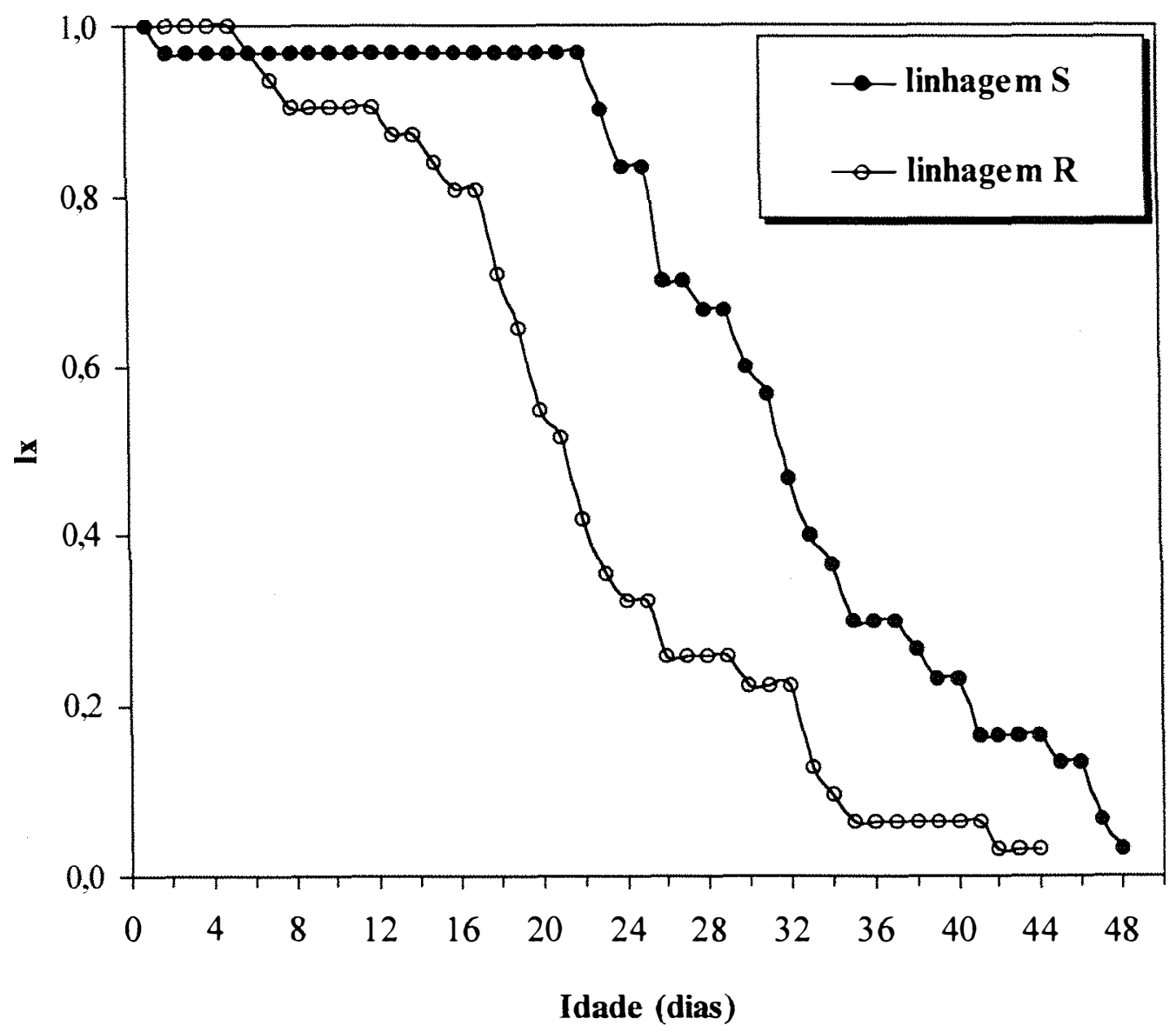

Figura 3. Sobrevivência de fềmeas (lx) das linhagens de Brevipalpus phoenicis susceptível (S) e resistente (R) ao dicofol, à temperatura de $25 \pm 1^{\circ} \mathrm{C}$, UR de $70 \pm 10 \%$ e fotofase de 14 horas. 


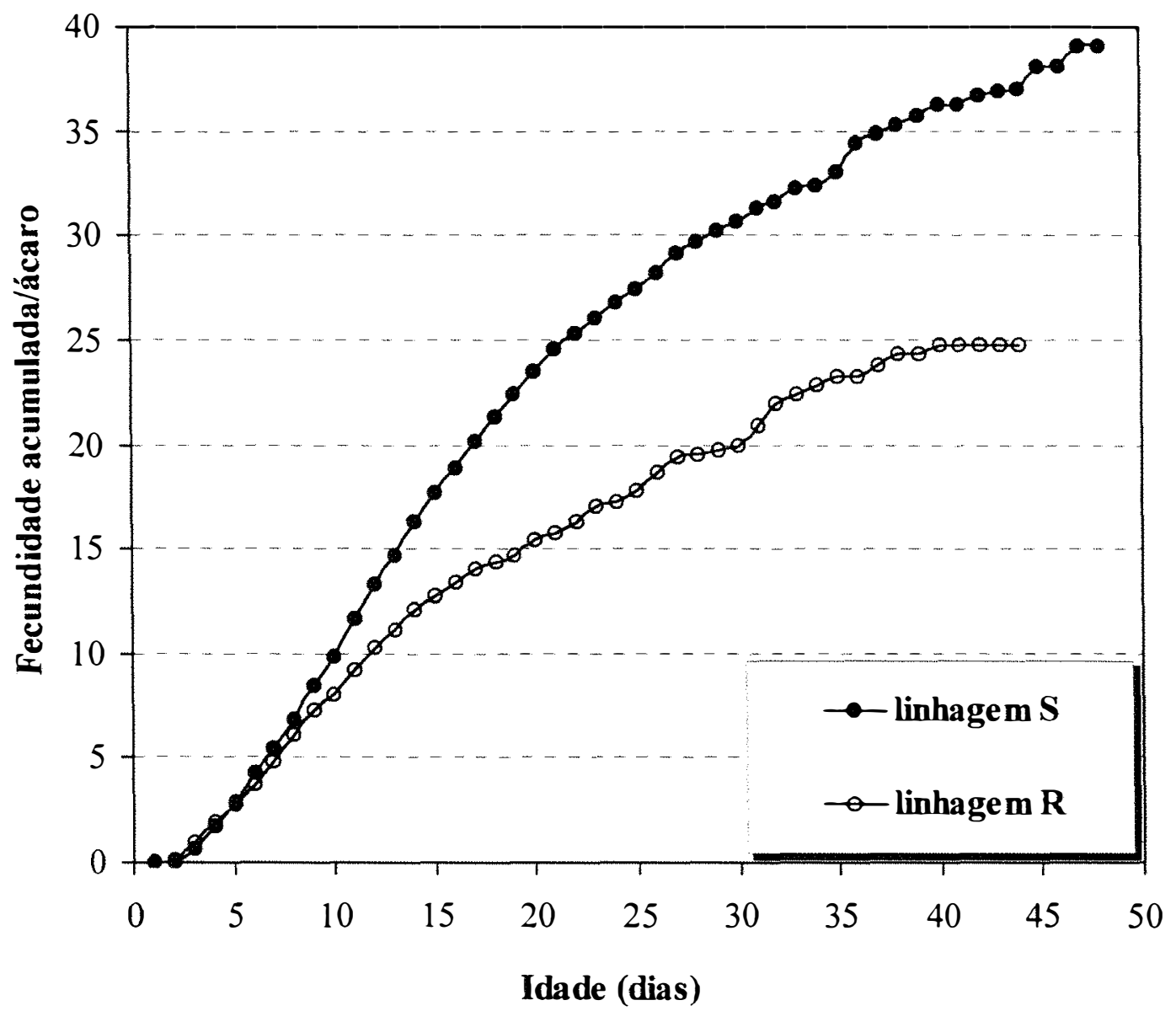

Figura 4. Fecundidade acumulada das linhagens de Brevipalpus phoenicis susceptível (S) e resistente $(\mathrm{R})$ ao dicofol, à temperatura de $25 \pm 1{ }^{\circ} \mathrm{C}$, UR de $70 \pm 10 \%$ e fotofase de 14 horas. 


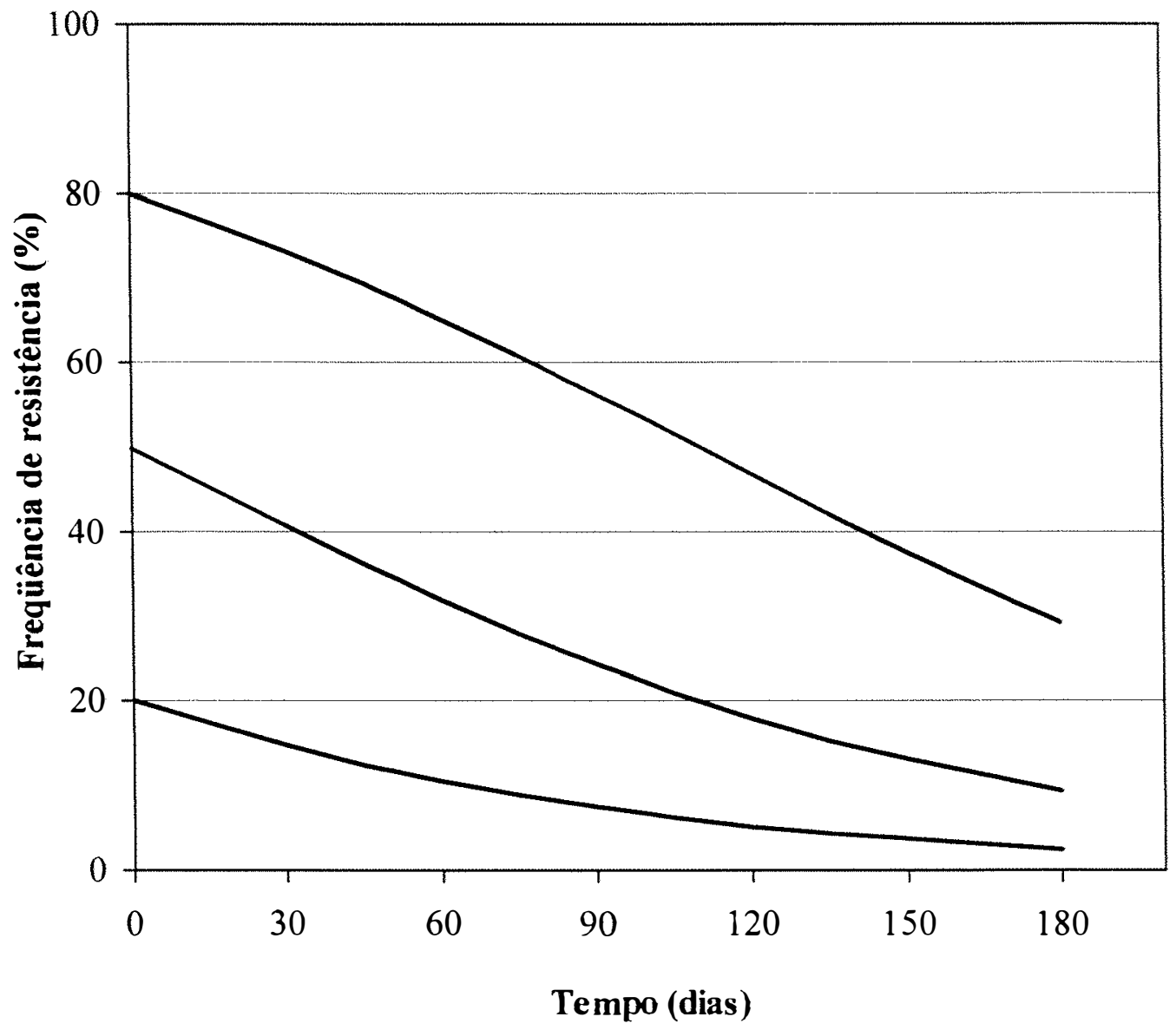

Figura 5. Mudanças nas frequiências esperadas de resistência obtidas através de simulação de aumento populacional das linhagens de Brevipalpus phoenicis susceptível e resistente ao dicofol com razões finitas de aumento $(\lambda)$ de 1,095 e 1,081 fềmeas/fềmea/dia. respectivamente. A simulação foi realizada em populações com freqüências iniciais de resistência de 20,50 e $80 \%$. 


\subsubsection{Implicações para o manejo da resistência de Brevipalpus phoenicis ao dicofol}

Este trabalho comprova que a resistência de $B$. phoenicis ao dicofol é instável na ausência de pressão de seleção com o acaricida. Nas condições em que os estudos foram realizados, observou-se que a instabilidade está ligada a diferenças no valor adaptativo da linhagem $\mathrm{R}$ em relação a linhagem $\mathrm{S}$. Em condições de campo a reversão da resistência também pode estar sendo auxiliada pela migração de ácaros susceptíveis de plantas hospedeiras e de outras áreas. Estes resultados sugerem que a resistência de B. phoenicis ao acaricida dicofol pode ser manejada em condições de campo.

Para o manejo da resistência é necessário estimar o intervalo mínimo para o restabelecimento da susceptibilidade (IMR) para o acaricida dicofol. Analisando a Figura 2 podemos ter uma indicação do IMR mínimo que seria necessário para a implantação de um programa de manejo da resistência deste ácaro para o dicofol. A curva para a população com a freqüência inicial de $80 \%$ de resistentes levou aproximadamente cinco meses para atingir a freqüência de resistência de $50 \%$. A curva para a população com a freqüência inicial de $50 \%$ de resistentes levou aproximadamente quatro meses para atingir a freqüência de $20 \%$. Assumindo que a freqüência crítica (freqüência de resistência a partir da qual a resistência passa a afetar o desempenho do produto) seja de $20 \%$, e partindo-se de uma população com $80 \%$ de ácaros resistentes, teoricamente será necessário um período igual ou superior a nove meses para que a freqüência de resistentes atinja valores inferiores ao da freqüência crítica. Os dados de decréscimo da freqüência de resistência encontrados em laboratório não podem ser extrapolados para as condições de campo. Sendo assim, para se encontrar um IMR ao acaricida dicofol, que possa ser utilizado num programa de manejo da resistência de $B$.

phoenicis ao dicofol nas condições dos pomares de citros do Brasil, é preciso avaliar a dinâmica da resistência em condições de campo. 


\subsection{CONCLUSÕES}

- A resistência de Brevipalpus phoenicis ao dicofol é instável na ausência de pressão seletiva com o dicofol.

- A linhagem resistente de B. phoenicis ao dicofol apresenta menor valor adaptativo em relação à linhagem susceptível de referência.

- O custo adaptativo da resistência de B. phoenicis ao dicofol está relacionado principalmente à menor fecundidade e longevidade da linhagem resistente em relação à linhagem susceptível de referência. 


\section{RESISTÊNCIA CRUZADA ENTRE O DICOFOL E OUTROS ACARICIDAS EM Brevipalpusphoenicis (ACARI: TENUIPALPIDAE)}

Autor: Everaldo Batista Alves

Orientador: Prof. Dr. Celso Omoto

\section{RESUMO}

Relações de resistência cruzada entre o dicofol e alguns acaricidas recomendados na cultura de citros foram avaliadas em Brevipalpus phoenicis (Geijskes) para identificar produtos alternativos a serem utilizados em um programa de manejo da resistência ao dicofol. Linhagens de $B$. phoenicis susceptível e resistente ao dicofol foram testadas com os acaricidas óxido de fenbutatina, propargite, fenpyroximate e bromopropilato. A linhagem de B. phoenicis resistente ao dicofol apresentou resistência cruzada positiva ao bromopropilato e resistência cruzada negativa ao fenpyroximate. Não foi detectada resistência cruzada entre o dicofol e os acaricidas óxido de fenbutatina

e propargite. Os resultados indicam que dentre os acaricidas testados, somente o bromopropilato deve ser evitado em programas de manejo da resistência de $B$. phoenicis ao dicofol. 


\title{
CROSS-RESISTANCE BETWEEN DICOFOL AND OTHER ACARICIDES IN Brevipalpus phoenicis (ACARI: TENUIPALPIDAE)
}

\author{
Author: Everaldo Batista Alves \\ Adviser: Prof. Dr. Celso Omoto
}

\section{SUMMARY}

Cross-resistance relationships between dicofol and other acaricides recommended in citrus were evaluated in Brevipalpus phoenicis (Geijskes) to find alternative products for managing dicofol-resistant mites. Susceptible and dicofolresistant B. phoenicis strains were tested against fenbutatin oxide, propargite, fenpyroximate and bromopropilate. Dicofol-resistant B. phoenicis showed positive cross-resistance to bromopropilate and negative cross-resistance to fenpyroximate. No cross-resistance was detected between dicofol and the acaricides fenbutatin oxide and propargite. Therefore, among the acaricides tested only bromopropilate should be avoided for managing dicofol resistance in B. phoenicis. 


\subsection{INTRODUÇÃO}

O conhecimento das relações de resistência cruzada entre os produtos recomendados para o controle do complexo de pragas em uma determinada cultura é uma das condições básicas para a implementação de qualquer estratégia de manejo da resistência envolvendo o uso de produtos químicos (Georghiou, 1983; Tabashnik, 1989; Denholm \& Rolland, 1992). Dentre as pragas que atacam a cultura de citros no Brasil, destacam-se o ácaro da leprose, Brevipalpus phoenicis (Geijskes), e o ácaro da falsa ferrugem, Phyllocoptruta oleivora (Ashmead). Estima-se que mais de 90 milhões de dólares são gastos anualmente com acaricidas na citricultura brasileira, o que representa aproximadamente 20\% do custo de produção (Negri, 1995; Salvo Filho, 1997). Devido à alta pressão de seleção com acaricidas, a evolução da resistência a acaricidas nestas duas espécies de ácaro tem sido um problema emergente (Gravena, 1994b; Omoto et al., 1994; Omoto, 1995). Sendo assim, a correta escolha do acaricida a ser utilizado em um determinado pomar tem sido fundamental para a obtenção de um controle satisfatório da praga, assim como para a preservação da vida útil dos acaricidas.

A resistência de $B$. phoenicis ao dicofol foi caracterizada no Capítulo 3. Estudos de dinâmica da resistência têm mostrado que a resistência de B. phoenicis ao dicofol é bastante instável; ou seja, a freqüência de resistência diminui significativamente na ausência da pressão seletiva (Capítulo 4). A instabilidade da resistência poderia ser explorada em um programa de manejo da resistência através da rotação com produtos que não apresentem resistência cruzada com o dicofol, até que se observe uma redução na freqüência de resistência a um nível abaixo da freqüência crítica (i.e., a frequiência de resistência a partir da qual a resistência se torna um problema econômico) (Dennehy, 1987).

Estudos de resistência cruzada com o dicofol têm sido realizados em outras espécies de ácaros, principalmente da família Tetranychidae. Mansour \& Plaut (1979) constataram resistência cruzada positiva entre o acaricida dicofol e o bromopropilato em uma população de Tetranychus cinnabarinus (Boisd.) resistente a dicofol. FergussonKolmes et al. (1991) também comprovaram a presença de resistência cruzada positiva 
entre o dicofol e os acaricidas bromopropilato, clorobenzilato e amitraz em uma linhagem isogênica de Tetranychus urticae (Koch) resistente ao dicofol. A ocorrência de resistência cruzada depende do mecanismo de resistência, e portanto não pode ser extrapolada interespecificamente, ou mesmo intraespecificamente. O objetivo do presente trabalho foi o de determinar as relações de resistência cruzada em $B$. phoenicis entre o dicofol e outros acaricidas recomendados na cultura de citros no Brasil, como o óxido de fenbutatina, propargite, fenpyroximate e bromopropilato.

\subsection{MATERIAL E MÉTODOS}

Duas linhagens de Brevipalpus phoenicis, uma susceptível e outra resistente ao acaricida dicofol, foram utilizadas no presente estudo. Uma população de $B$. phoenicis que vinha sendo criada em laboratório na ausência de pressão seletiva com acaricidas a mais de 5 anos foi tomada como a linhagem susceptível de referência (S). A linhagem de $B$. phoenicis resistente ao dicofol (R) foi obtida através da seleção com dicofol em condições laboratoriais, a partir de uma população de B. phoenicis coletada em um pomar comercial de citros da região de Itápolis, SP em 1997, onde a freqüência de uso deste acaricida era bastante alta. A caracterização da resistência de $B$. phoenicis ao dicofol foi estudada no Capítulo 2. As $\mathrm{CL}_{50} \mathrm{~S}$ estimadas para as linhagens $\mathrm{S}$ e $\mathrm{R}$ foram de 7,44 $\mu \mathrm{g}$ de dicofol / $\mathrm{mL}$ de água destilada [ppm (I.A.)] e 422,45 ppm (I.A.), respectivamente. A razão de resistência derivada da $\mathrm{CL}_{50}$ das duas linhagens foi de aproximadamente 57 vezes.

As linhagens $\mathrm{S}$ e $\mathrm{R}$ foram testadas com os acaricidas óxido de fenbutatina (Torque ${ }^{\circledR} 500 \mathrm{SC}$, suspensão concentrada. $500 \mathrm{~g}$ de óxido de fenbutatina/L, Cyanamid Química do Brasil Ltda.), propargite (Omite ${ }^{\circledR} 720$ CE BR, concentrado emulsionável, 720 g propargite/L, Uniroyal Química S.A.), fenpyroximate (Kendô ${ }^{\circledR} 50$ SC, suspensão concentrada, $50 \mathrm{~g}$ de fenpyroximate/L, Hoechst Schering AgrEvo do Brasil Ltda.) e bromopropilato (Neoron ${ }^{\circledR} 500 \mathrm{CE}$, concentrado emulsionável, $500 \mathrm{~g}$ bromopropilato/L, Novartis Biociências S.A.). O método de bioensaio adotado foi o de contato residual para todos os acaricidas. Cinco a seis concentrações de cada produto. que 
proporcionassem mortalidade entre 5 a $99 \%$ foram testadas em ambas as linhagens. As diferentes concentrações dos produtos escolhidas para os bioensaios foram preparadas através da diluição dos produtos comerciais em água destilada. Os bioensaios foram realizados em arenas de $2,6 \mathrm{~cm}$ de diâmetro confeccionadas com folhas de laranjeira da variedade Pera Rio coletadas em um. pomar sem aplicação de acaricidas. As arenas de folha foram mantidas sobre algodão embebido em água até a pulverização do produto. A aplicação foi feita sobre a superfície adaxial dos discos de folha através do uso da torre de pulverização de Potter (Burkard Manufacturing, Rickmansworth, Herts, Reino Unido) calibrada a uma pressão de 10 psi $(68,95 \mathrm{kPa})$. Foi utilizado um volume de $2 \mathrm{~mL}$ de solução em cada pulverização, obtendo-se uma deposição média de resíduo úmido de $1,56 \mathrm{mg} / \mathrm{cm}^{2}$ sobre as arenas. Após a aplicação, as arenas foram retornadas sobre o algodão umedecido até a secagem do produto. Em seguida, as arenas foram acondicionadas individualmente em placas acrílicas de $3,5 \mathrm{~cm}$ de diâmetro (Falcon 1008, Becton Dickinson Labware, Lincoln Park, NJ, Estados Unidos) contendo $2 \mathrm{~mL}$ de uma mistura ainda não geleificada de ágar-água na concentração de 2,3\%. Após a geleificação do substrato no fundo da placa, uma barreira para evitar a fuga dos ácaros foi construída ao redor dos discos de folha com a mesma mistura de ágar-água (adaptado de Vestergaard et al., 1995).

Foram transferidos 10 ácaros adultos por arena. Cada concentração foi repetida 5 a 6 vezes ao longo do tempo e cada repetição foi constituída por aproximadamente 40 ácaros. Após a infestação dos ácaros nas arenas, as placas foram tampadas e mantidas em câmara climática regulada à temperatura de $25 \pm 1^{\circ} \mathrm{C}$, umidade relativa de $70 \pm 10 \%$ e fotofase de 14 horas. A mortalidade foi avaliada 24 horas após a infestação com o auxílio de um pincel com um único pêlo e microscópio estereoscópico. Os ácaros foram virados de costas e aqueles que retornaram à posição normal e andaram foram considerados vivos. As repetições que apresentaram uma mortalidade superior a $15 \%$ na testemunha foram descartadas, assim como aquelas cuja perda de ácaros no ágar ultrapassou $15 \%$.

Os dados de mortalidade de cada produto para as duas linhagens foram submetidos à análise de próbite através do programa POLO-PC (LeOra Software, 1987). 
Um teste de paralelismo das linhas de concentração-resposta de cada produto para as linhagens $\mathrm{S}$ e $\mathrm{R}$ foi conduzido. As relações de resistência cruzada entre os produtos estudados e o dicofol foram obtidas através da análise de sobreposição ou não dos intervalos de confiança das $\mathrm{CL}_{50}$ s estimadas de cada produto para as linhagens $\mathrm{S}$ e $\mathrm{R}$. O nível de significância adotado para os testes foi de 0,05 .

\subsection{RESULTADOS E DISCUSSÃO}

As respostas de concentração-mortalidade das linhagens de Brevipalpus phoenicis susceptível $(\mathrm{S})$ e resistente $(\mathrm{R})$ ao dicofol quando testadas com óxido de fenbutatina, propargite, fenpyroximate e bromopropilato encontram-se na Tabela 5 e Figuras 6 a 9 .

Os acaricidas óxido de fenbutatina, propargite e fenpyroximate mostraram-se como opções viáveis dentro de um programa de manejo da resistência de B. phoenicis ao dicofol. Não foi detectada presença de resistência cruzada entre o dicofol e os acaricidas óxido de fenbutatina e propargite. Pelo teste de paralelismo das linhas de regressão estimada através da análise de próbite, verificou-se que as respostas das duas linhagens foram semelhantes para o óxido de fenbutatina $\left(\chi^{2}=0,285 ;\right.$ g.l. $\left.=1 ; P>0,05\right)$ (Figura 6) e propargite $\left(\chi^{2}=0,027\right.$; g.l. $\left.=1 ; P>0,05\right)$ (Figura 7$)$. Foi verificada uma sobreposição dos intervalos de confiança das $\mathrm{CL}_{50} \mathrm{~S}$ do óxido de fenbutatina e propargite estimados para as duas linhagens (Tabela 5).

Trabalhos realizados em outras espécies de ácaros também tem mostrado a inexistência de resistência cruzada entre o dicofol e acaricidas organoestânicos, como por exemplo em Panonychus ulmi (Koch) (Pree \& Wagner, 1987), Tetranychus cinnabarinus (Mansour \& Plaut, 1979) e Tetranychus urticae (Fergusson-Kolmes et al., 1991). Com relação ao propargite, Fergusson-Kolmes et al. (1991) não detectaram presença de resistência cruzada entre o dicofol e propargite em $T$. urticae. Por outro lado, Mansour \& Plaut (1979) reportaram presença de uma moderada resistência cruzada

entre o dicofol e propargite em $T$. cinnabarinus. Pelo fato dos autores não terem 
utilizado uma linhagem isogênica, há a possibilidade da ocorrência de resistência múltipla na linhagem de $T$. cinnabarinus testada.

Resistência cruzada negativa foi verificada entre o dicofol e fenpyroximate em B. phoenicis, ou seja, uma maior susceptibilidade ao fenpyroximate foi verificada para a linhagem $\mathrm{R}$ em relação à linhagem $\mathrm{S}$ (Tabela 5 e Figura 8). Não foram verificadas diferenças estatísticas no coeficiente angular estimado pela análise de próbite para as linhagens S e R $\left(\chi^{2}=0,003\right.$; g.l. $\left.=1 ; P>0,05\right)$ (Figura 8), indicando que as duas linhagens respondem de maneira semelhante ao fenpyroximate. No entanto, $\mathrm{CL}_{50}$ estimada para a linhagem $\mathrm{R}$ foi estatisticamente inferior ao da linhagem $\mathrm{S}$ (Tabela 5). Esta situação seria a ideal para um programa de manejo da resistência. Estudos mais detalhados com relação à vantagem de fenpyroximate no manejo da resistência de B. phoenicis ao dicofol são discutidos no Capítulo 6.

Os estudos realizados na presente pesquisa não permitem explicar as causas da resistência cruzada negativa entre os dois acaricidas; pois haveria a necessidade da elucidação dos mecanismos de resistência de B. phoenicis ao dicofol. FergussonKolmes et al. (1991) detectaram resistência cruzada negativa entre o dicofol e clorpirifós etil em T. urticae. Uma maior ativação de clorpirififós para clorpirifós-oxon através das enzimas oxidativas mediadas pelo citocromo P-450 na linhagem de $T$. urticae resistente ao dicofol foi apontada por Hatano et al. (1992).

Resistência cruzada positiva foi verificada entre o dicofol e bromopropilato em B. phoenicis, ou seja, a linhagem de B. phoenicis resistente ao dicofol também se mostrou resistente ao bromopropilato (Tabela 5; Figura 9). A estimativa da $\mathrm{CL}_{50}$ do bromopropilato para a linhagem $\mathrm{R}$ não foi possível de ser realizada devido à repelência ocasionada pelo produto em concentrações superiores a $320 \mathrm{ppm}$ (I.A.) (Tabela 6). Sendo assim, a maioria dos ácaros testados foram perdidos na solução ágar-água; diminuindo assim a precisão na estimativa da mortalidade nas concentrações testadas para a linhagem R. Ácaros sobreviventes da linhagem $\mathrm{R}$ foram observados mesmo a uma alta concentração de bromopropilato de 3.200 ppm (I.A.). No entanto, a linhagem $\mathrm{S}$ se mostrou altamente susceptível a este acaricida. As $\mathrm{CL}_{50}$ e $\mathrm{CL}_{99}$ estimadas para a linhagem $\mathrm{S}$ através da análise de próbite foram de 5,81 (IC 95\% 4,64-7,29) e 21,91 (IC 
95\% 13,12-37,16) ppm de bromopropilato, respectivamente. Pela impossibilidade de obtenção de uma linhagem isogênica $d e$ B. phoenicis resistente ao dicofol devido ao seu modo de reprodução predominantemente por telitoquia, os resultados obtidos poderiam ser interpretados como sendo uma resistência múltipla. Porém, de acordo com os resultados obtidos com outras espécies de ácaro como T. cinnabarinus (Mansour \& Plaut, 1979) e T. urticae (Fergusson-Kolmes et al., 1991), há grandes indícios de resistência cruzada entre o dicofol e bromopropilato.

A partir dos dados obtidos no presente trabalho, fica evidente que em um programa de manejo da resistência de $B$. phoenicis ao dicofol, o acaricida bromopropilato deve ser evitado dentro de um esquema de rotação de acaricidas. A vantagem da resistência cruzada negativa entre o dicofol e fenpyroximate no manejo da resistência de $B$. phoenicis ao dicofol deve ser melhor explorada. Além dos acaricidas testados no presente trabalho, há a necessidade de estudos de caracterização da resistência de $B$. phoenicis a outros acaricidas recomendados em citros no Brasil, assim como as suas relações de resistência cruzada. Devido ao reduzido número de cromossomos em B. phoenicis ( $n=2)$, há um problema potencial de seleção de linhagens do ácaro resistente a mais de um produto através da resistência múltipla (Omoto, 1995). Sendo assim, o uso racional de acaricidas em citros deve ser observado com grande atenção para a maximização do controle de $B$. phoenicis a um menor custo possível. 
Tabela 5. Respostas de concentração-mortalidade das linhagens de Brevipalpus phoenicis susceptível (S) e resistente $(\mathrm{R})$ ao dicofol quando testadas com óxido de fenbutatina, propargite, fenpyroximate e bromopropilato.

\begin{tabular}{|c|c|c|c|c|c|}
\hline Produto & Linhagem & $n$ & $\begin{array}{c}\mathrm{CL}_{50} \\
(95 \% \text { IC) } \\
\mu \mathrm{g} \mathrm{IA} / \mathrm{mL} \mathrm{H}_{2} \mathrm{O}\end{array}$ & $\begin{array}{c}\text { Coeficiente } \\
\text { angular } \\
\pm \text { desvio padrão }\end{array}$ & $\begin{array}{c}\text { Interpretação } \\
\text { da resistência } \\
\text { cruzada }\end{array}$ \\
\hline \multirow[t]{2}{*}{$\begin{array}{l}\text { Óxido de } \\
\text { Fenbutatina }\end{array}$} & S & 1.090 & $\begin{array}{c}67,21 \\
(57,22-79,55)\end{array}$ & $3,12 \pm 0.17$ & $-\cdots$ \\
\hline & $\mathrm{R}$ & 849 & $\begin{array}{c}61,60 \\
(57,30-66,21)\end{array}$ & $3,26 \pm 0,19$ & ausente \\
\hline \multirow[t]{2}{*}{ Propargite } & $\mathrm{S}$ & 956 & $\begin{array}{c}298,23 \\
(260,74-334,54)\end{array}$ & $4,45 \pm 0,26$ & $\cdots$ \\
\hline & $\mathrm{R}$ & 857 & $\begin{array}{c}346,55 \\
(327,58-366,05)\end{array}$ & $4,50 \pm 0,25$ & ausente \\
\hline \multirow[t]{2}{*}{ Fenpyroximate } & $\mathrm{S}$ & 1.306 & $\begin{array}{c}25,26 \\
(21,09-30,16)\end{array}$ & $2,63 \pm 0,13$ & --- \\
\hline & $\mathrm{R}$ & 1.072 & $\begin{array}{c}14,50 \\
(13,34-15,69)\end{array}$ & $2,62 \pm 0,15$ & negativa \\
\hline \multirow[t]{2}{*}{ Bromopropilato } & $S$ & 958 & $\begin{array}{c}5,81 \\
(4,64-7,29)\end{array}$ & $4,03 \pm 0,21$ & $-\cdots$ \\
\hline & $\mathrm{R}$ & $\cdots$ & $>320.00 *$ & $\cdots$ & positiva \\
\hline
\end{tabular}

$n=$ número de ácaros testados

* não foi possível estimar a $\mathrm{CL}_{50}$ devido ao efeito de repelência 
Tabela 6. Percentagem de ácaros da linhagem de Brevipalpus phoenicis resistente ao dicofol, vivos, mortos e presos na solução ágar-água, 24 horas após a exposição em resíduos de diferentes concentrações do acaricida bromopropilato.

\begin{tabular}{ccccc}
\hline $\begin{array}{l}\text { Concentração de } \\
\text { bromopropilato } \\
\left(\mu \text { I.A./mL } \mathbf{H}_{2} \mathbf{O}\right)\end{array}$ & $\boldsymbol{n}$ & vivos & mortos na arena & $\begin{array}{c}\text { presos na solução } \\
\text { de ágar-água }\end{array}$ \\
\cline { 3 - 5 } & & 96,25 & 3,75 & 0,00 \\
320 & 240 & 78,75 & 12,92 & 8,33 \\
560 & 320 & 39,38 & 25,31 & 35,31 \\
1.000 & 320 & 27,19 & 37,81 & 35,00 \\
1.800 & 280 & 30,00 & 22,50 & 47,50 \\
3.200 & 190 & 48,42 & 11,58 & 40,00 \\
\hline
\end{tabular}

n=número de ácaros testados 


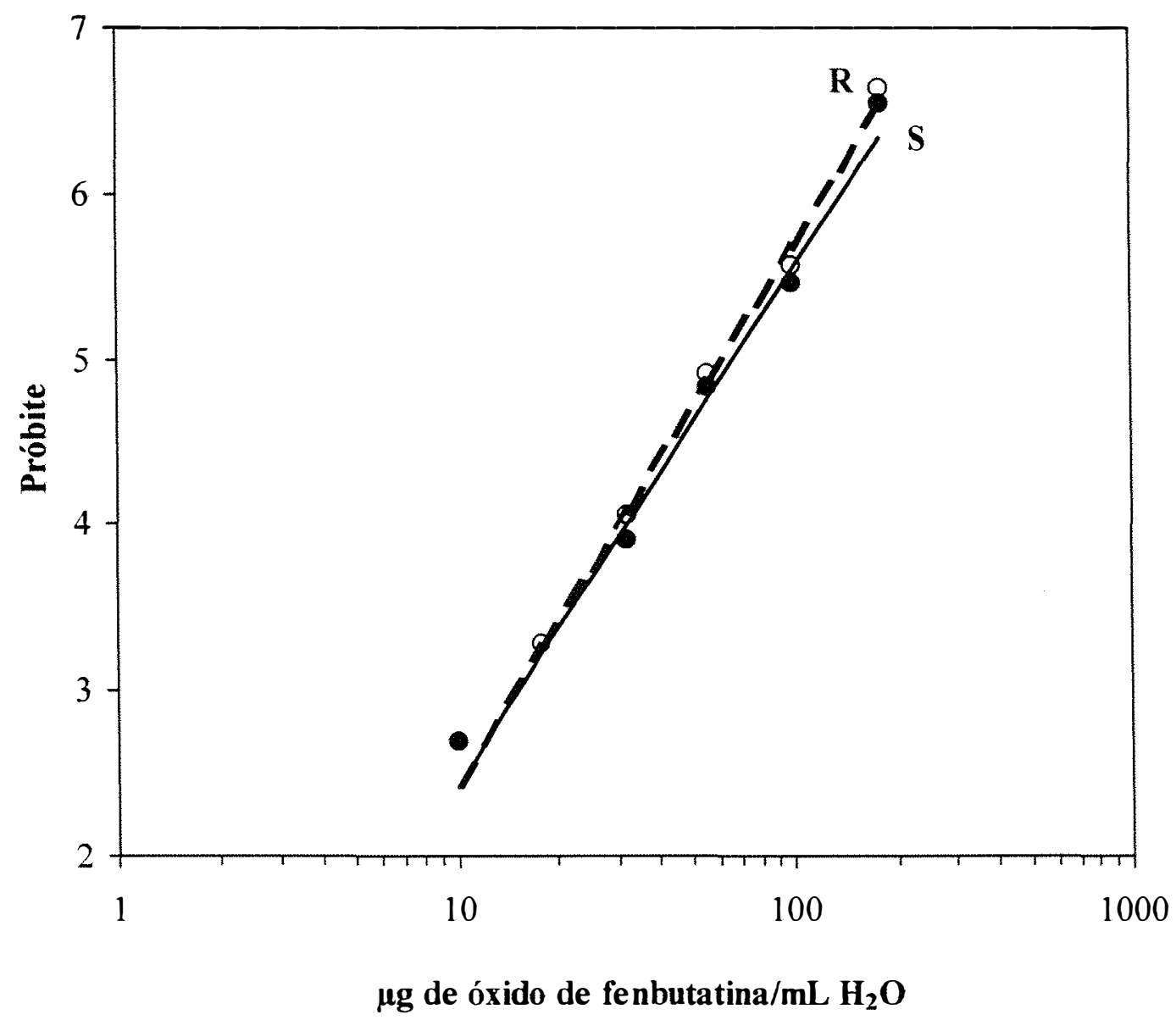

Figura 6. Respostas de concentração-mortalidade das linhagens de Brevipalpus phoenicis susceptível (S) e resistente (R) ao dicofol testadas com óxido de fenbutatina. 


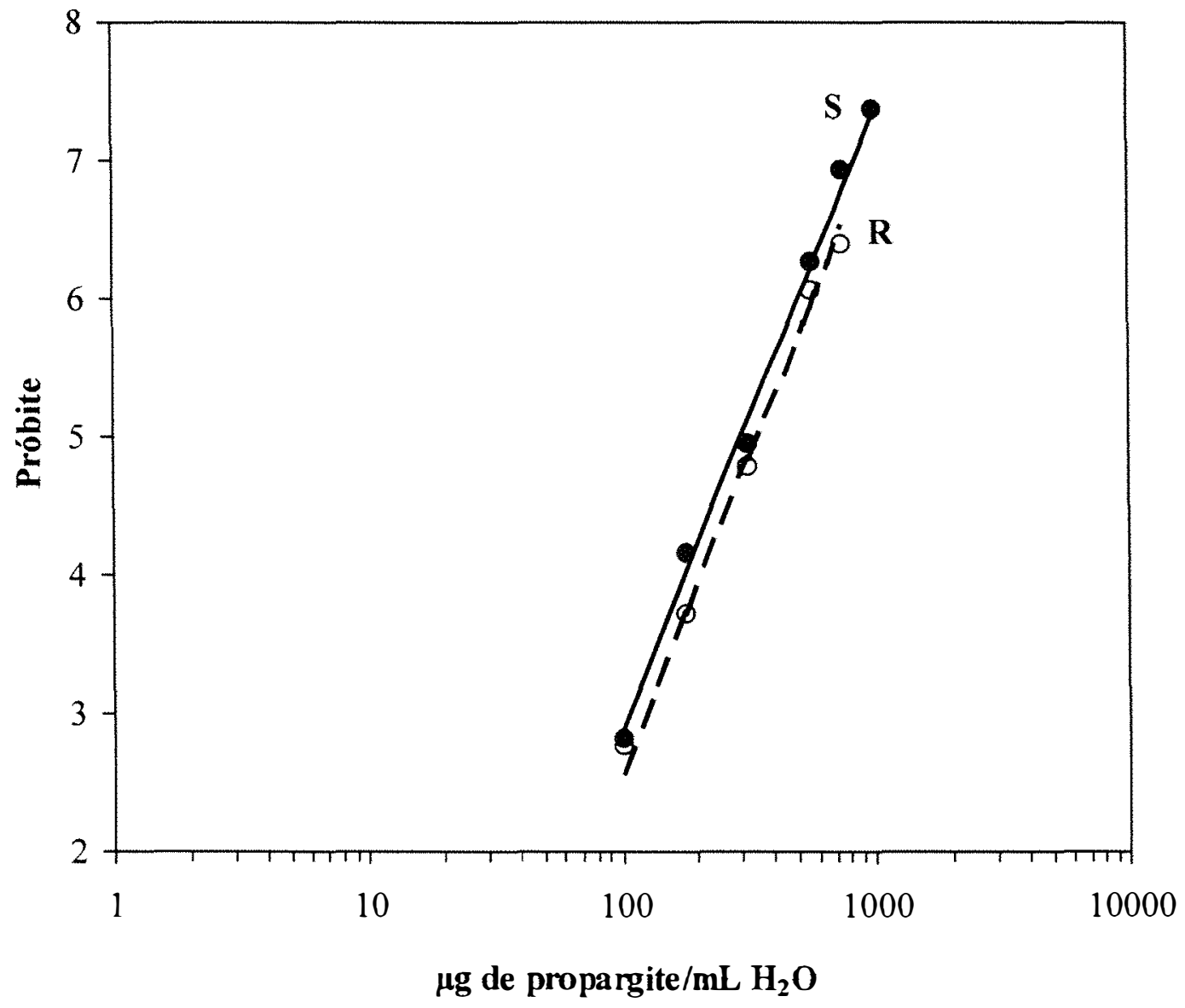

Figura 7. Respostas de concentração-mortalidade das linhagens de Brevipalpus phoenicis susceptível (S) e resistente (R) ao dicofol testadas com propargite. 


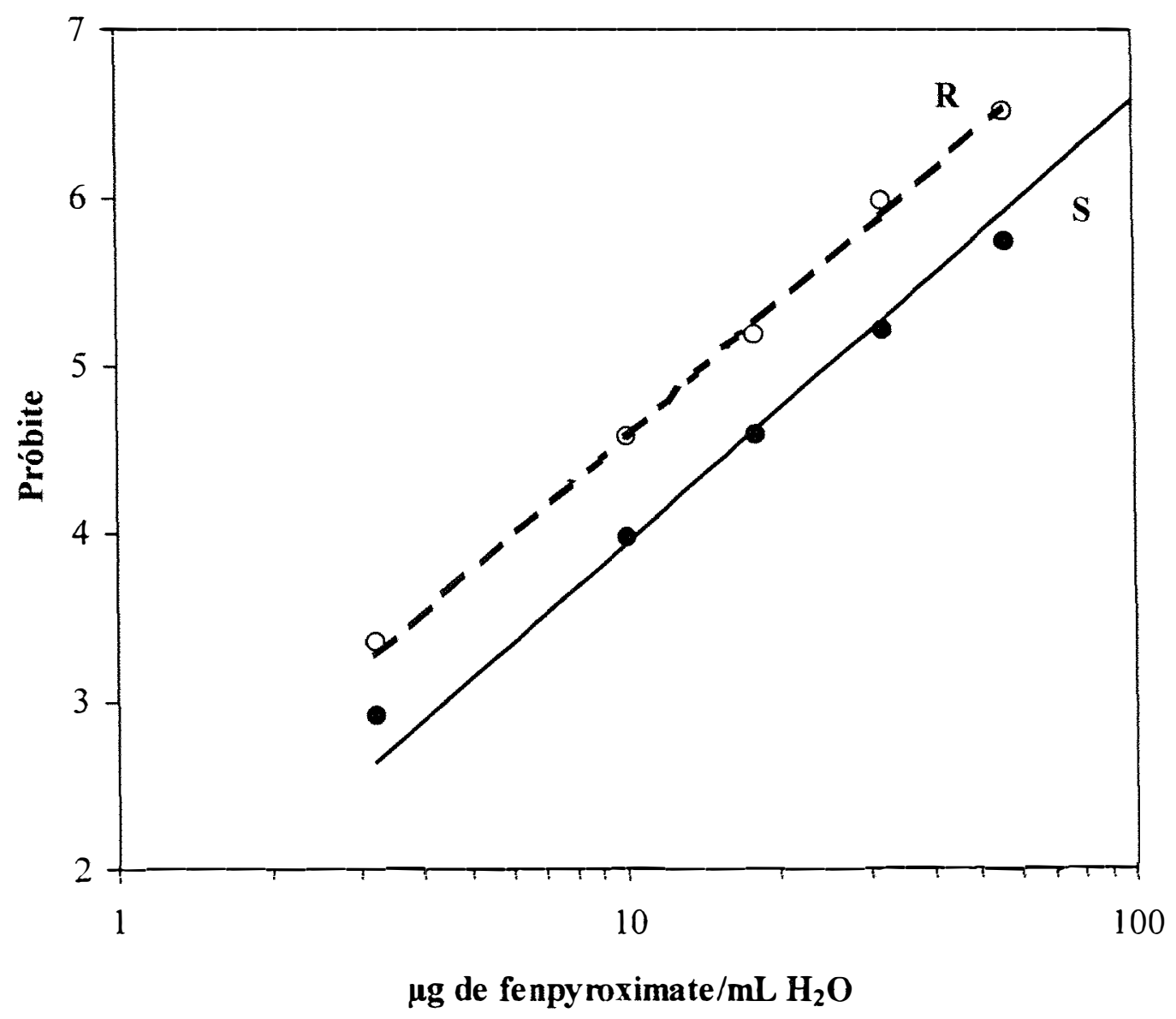

Figura 8. Respostas de concentração-mortalidade das linhagens de Brevipalpus phoenicis susceptível (S) e resistente (R) ao dicofol testadas com fenpyroximate. 


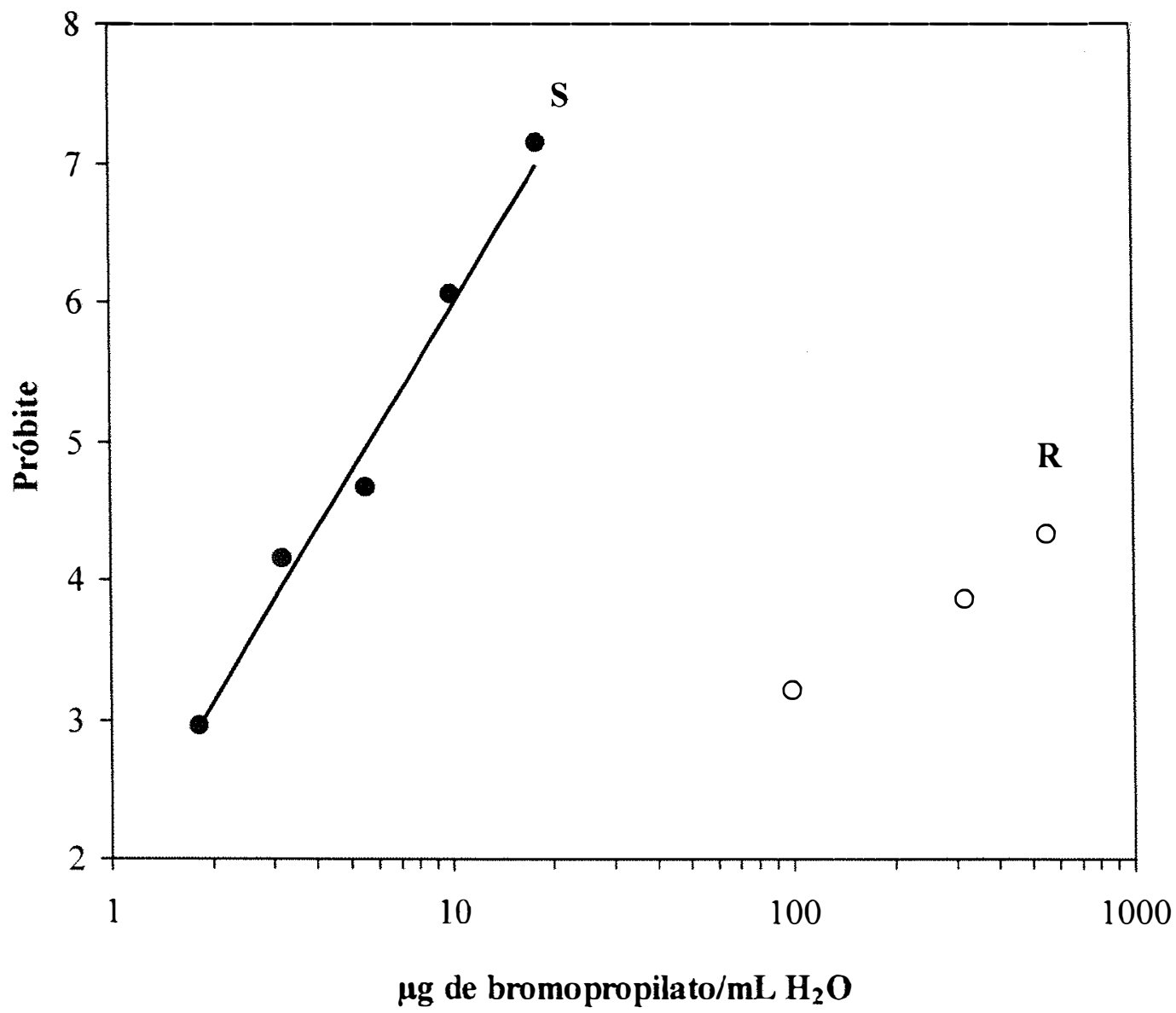

Figura 9. Respostas de concentração-mortalidade das linhagens de Brevipalpus phoenicis susceptível (S) e resistente (R) ao dicofol testadas com bromopropilato. 


\subsection{CONCLUSÕES}

- Não há resistência cruzada entre dicofol e os acaricidas óxido de fenbutatina e propargite em Brevipalpus phoenicis.

- Há resistência cruzada negativa entre dicofol e fenpyroximate em $B$. phoenicis.

- Há resistênica cruzada positiva entre dicofol e bromopropilato em B. phoenicis. 


\title{
6 MISTURA DE DICOFOL COM FENPYROXIMATE NO MANEJO DA RESISTÊNCIA DE Brevipalpus phoenicis (ACARI: TENUIPALPIDAE) AO DICOFOL
}

\author{
Autor: Everaldo Batista Alves \\ Orientador: Prof. Dr. Celso Omoto
}

\section{RESUMO}

A mistura dos acaricidas dicofol e fenpyroximate para o manejo da resistência de Brevipalpus phoenicis (Geijskes) ao dicofol foi avaliada no presente estudo. Inicialmente, a interação de dicofol e fenpyroximate foi testada a partir das $\mathrm{CL}_{25} \mathrm{~S}$ de cada produto para as linhagens de B. phoenicis susceptível (S) e resistente (R) ao dicofol. Foi observada uma interação sinérgica da mistura para as duas linhagens. Posteriormente, a persistência dos resíduos de dicofol (na dosagem comercial de $360 \mathrm{~g}$ de ingrediente ativo [I.A.] / $1.000 \mathrm{~L}$ de água), fenpyroximate (50 g de I.A. / $1.000 \mathrm{~L}$ de água) e mistura de dicofol e fenpyroximate (240 e $25 \mathrm{~g}$ de I.A. / $1.000 \mathrm{~L}$ de água, respectivamente) foi avaliada em um pomar comercial de citros. Após a aplicação dos produtos, frutos foram coletados periodicamente e infestados com as linhagens $\mathrm{S}$ e R no laboratório. Resíduos de dicofol e da mistura discriminaram as linhagens, ou seja, uma maior mortalidade da linhagem $\mathrm{S}$ em relação à $\mathrm{R}$ foi observada em todas as avaliações. Resíduos de fenpyroximate não discriminaram as linhagens, porém a dosagem aplicada do produto não proporcionou controle eficiente de B. phoenicis. O sinergismo entre o dicofol e fenpyroximate não foi eficiente no manejo da resistência de $B$. phoenicis ao dicofol. 


\title{
MIXTURE OF DICOFOL AND FENPYROXIMATE FOR MANAGING RESISTANCE OF Brevipalpus phoenicis (ACARI: TENUIPALPIDAE) TO DICOFOL
}

\author{
Author: Everaldo Batista Alves \\ Adviser: Prof. Dr. Celso Omoto
}

\section{SUMMARY}

The mixture of the acaricides dicofol and fenpyroximate for managing resistance of Brevipalpus phoenicis (Geijskes) to dicofol was evaluated in this study. Initially, we analyzed the interaction of dicofol and fenpyroximate by testing the $\mathrm{LC}_{25} \mathrm{~S}$ of each product for both susceptible (S) and dicofol-resistant $(\mathrm{R})$ strains of $B$. phoenicis. Synergistic interaction was detected with the mixture for both strains. Then, the persistence of the residues of dico fol (at recommended rate of $360 \mathrm{~g}$ of active ingredient [A.I.] / 1,000 L of water), fenpyroximate (at $50 \mathrm{~g}$ of A.I. / 1,000 L of water) and the mixture of dicofol and fenpyroximate (at 240 and $25 \mathrm{~g}$ of A.I. / 1,000 L of water, respectively) was evaluated in a commercial citrus grove. After application of the products, fruits were collected periodically and infested with mites of S and R strains in the laboratory. Residues of the dicofol and the mixture discriminated the strains; that is, higher mortality of $\mathrm{S}$ strain in relation to $\mathrm{R}$ strain was observed throughout the experiment. Residues of fenpyroximate did not discriminate the strains, however, fenpyroximate by itself did not give an acceptable control of $B$. phoenicis. The sinergism between dicofol and fenpyroximate was not effective for managing resistance of $B$. phoenicis to dicofol. 


\subsection{INTRODUÇÃO}

A mistura de produtos tem sido uma das estratégias bastante discutida em programas de manejo da resistência de pragas a pesticidas (Georghiou, 1983; Roush, 1989; Tabashnik, 1989). O princípio da mistura é que os indivíduos resistentes a um determinado produto $\mathrm{A}$ serão controlados pelo produto $\mathrm{B}$ e vice-versa; e que a resistência a cada composto é independente e inicialmente rara, e portanto, a ocorrência de indivíduos resistentes aos dois produtos será extremamente rara (Curtis, 1985; Mani, 1985).

A mistura de produtos para o manejo da resistência foi estudada em diferentes situações através de simulações e modelos matemáticos. Com base nestes modelos a mistura foi preferível para o manejo da resistência comparado à aplicação seqüencial de produtos (Mani, 1985; Roush, 1989; Tabashnik, 1989). Além disso, a mistura pode levar à redução das concentrações requeridas dos compostos para obter uma dada mortalidade se os modos de ação dos produtos forem independentes e apresentarem um

efeito sinérgico (Sun \& Johnson, 1960; Bynum Jr. et al., 1990, 1997). Apesar dos avanços teóricos com relação à mistura de produtos, poucos são os trabalhos práticos existentes para a avaliação desta estratégia.

A mistura de acaricidas tem sido adotada na citricultura brasileira para o controle de Brevipalpus phoenicis (Geijskes). Entre as misturas registradas está o dicofol com fenpyroximate que foi objeto de estudo neste trabalho devido a sua importância e crescente uso pelos citricultores. Sendo assim, procurou-se obter alguns subsídios para o manejo da resistência de $B$. phoenicis ao acaricida dicofol utilizando a mistura de dicofol e fenpyroximate. Foram realizados trabalhos preliminares de laboratório para conhecer o tipo de interação destes acaricidas em mistura e também estudos de campo para avaliar a persistência de resíduos de dicofol, fenpyroximate e da mistura de dicofol e fenpyroximate sobre as linhagens de $B$. phoenicis susceptível e resistente ao dicofol. 


\subsection{MATERIAL E MÉTODOS}

Duas linhagens de Brevipalpus phoenicis, uma susceptível e outra resistente ao acaricida dicofol, foram utilizadas neste trabalho. Uma população de B. phoenicis que vinha sendo criada em laboratório na ausência de pressão seletiva com acaricidas, por um período superior a 5 anos, foi tomada como a linhagem susceptível de referência (S). A linhagem de B. phoenicis resistente ao dicofol (R) foi obtida através da seleção com dicofol em condições laboratoriais, a partir de uma população de B. phoenicis coletada em um pomar comercial de citros da região de Itápolis, SP em 1997, onde a freqüência de uso deste acaricida era bastante alta.

\subsubsection{Interação de dicofol e fenpyroximate}

O tipo de interação existente para os acaricidas dicofol e fenpyroximate em mistura e a influência desta interação no controle das linhagens $\mathrm{S}$ e $\mathrm{R}$ de $B$. phoenicis foram realizadas a partir da avaliação da mortalidade ocasionada pelas $\mathrm{CL}_{25} \mathrm{~S}$ estimadas para cada produto nas duas linhagens.

Linhas de concentração-resposta dos acaricidas dicofol (Kelthane ${ }^{\circledR} 480 \mathrm{CE}$, concentrado emulsionável, $480 \mathrm{~g}$ de dicofol/L, Rohm and Haas Química Ltda.) e fenpyroximate (Kêndo ${ }^{\circledR} 50 \mathrm{SC}$ suspensão concentrada, $50 \mathrm{~g}$ de fenpyroximate/L, Hoechst Schering AgrEvo do Brasil Ltda.) foram estimadas para as linhagens S e R (Capítulos 3 e 4). As $\mathrm{CL}_{25}$ S do dicofol e fenpyroximate estimadas para a linhagem $\mathrm{S}$ foram de $5 \mu \mathrm{g}$ I.A. / $\mathrm{mL}$ de água destilada [ppm (I.A.)] e $24 \mathrm{ppm}$ (I.A.), respectivamente. Para a linhagem $\mathrm{R}$ as $\mathrm{CL}_{25} \mathrm{~S}$ do dicofol e fenpyroximate estimadas foram de $260 \mathrm{ppm}$ (I.A.) e 8 ppm (I.A.), respectivamente.

O método de bioensaio utilizado foi o de contato residual. Arenas de $2,6 \mathrm{~cm}$ de diâmetro confeccionadas com folhas de laranjeira da variedade Pera Rio foram pulverizadas com as $\mathrm{CL}_{25}$ S de dicofol e fenpyroximate em mistura e isoladamente. As arenas de folha foram mantidas sobre algodão embebido em água até a pulverização do produto. A aplicação foi feita sobre a superfície adaxial dos discos de folha através do 
uso da torre de pulverização de Potter (Burkard Manufacturing, Rickmansworth, Herts, Reino Unido) calibrada a 10 psi $(68,95 \mathrm{kPa})$. Foi utilizado um volume de $2 \mathrm{~mL}$ de solução em cada pulverização, obtendo-se uma deposição média de resíduo úmido de $1,56 \mathrm{mg} / \mathrm{cm}^{2}$. Após a aplicação, as arenas foram retornadas sobre o algodão umedecido até a secagem do produto. Em seguida, as arenas foram acondicionadas individualmente em placas acrílicas de 3,5 cm de diâmetro (Falcon 1008, Becton Dickinson Labware, Lincoln Park, NJ, Estados Unidos) contendo $2 \mathrm{~mL}$ de uma solução ainda não geleificada de ágar-água na concentração de 2,3\%. Após a geleificação do substrato no fundo da placa, uma barreira para evitar a fuga dos ácaros foi construída ao redor dos discos de folha com a mesma mistura de ágar-água (adaptado de Vestergaard et al., 1995).

Foram transferidos 10 ácaros adultos por arena. Cada tratamento foi repetido 6 vezes ao longo do tempo. Em cada repetição foram testados aproximadamente 40 ácaros por tratamento. Após a infestação dos ácaros nas arenas, as placas foram tampadas e mantidas em câmara climatizada regulada à temperatura de $25 \pm 1^{\circ} \mathrm{C}$, umidade relativa de $70 \pm 10 \%$ e fotofase de 14 horas. A mortalidade foi avaliada 24 horas após a infestação com o auxílio de pincel com um único pêlo e microscópio estereoscópico. Os ácaros foram virados de costas e aqueles que retomaram à posição normal e andaram foram considerados vivos. As repetições que apresentaram mortalidade superior a $15 \%$ na testemunha foram descartadas, assim como as repetições cuja perda de ácaros na solução ágar-água ultrapassou 15\%.

I Para a avaliação da interação dos produtos em mistura e sua influência no controle das linhagens $\mathrm{S}$ e $\mathrm{R}$ foi utilizado o teste de $\chi^{2}$ onde a mortalidade observada na mistura foi comparada com a mortalidade esperada obtida através da soma da mortalidade observada com a $\mathrm{CL}_{25}$ de dicofol mais a mortalidade observada com a $\mathrm{CL}_{25}$ de fenpyroximate para cada linhagem. Se assumíssemos que os produtos agem de forma independente e apresentam interação aditiva, a mortalidade da mistura deveria ser próxima à mortalidade esperada. Se ocorresse interação sinérgica entre os produtos, a mistura deveria proporcionar mortalidade superior à mortalidade esperada. E se ocorresse efeito antagônico entre os produtos, a mortalidade observada na mistura 
deveria ser menor que a mortalidade esperada. O nível de significância dos testes foi de $\alpha=0,05$.

\subsubsection{Persistência de resíduos da mistura de dicofol e fenpyroximate e dos produtos isolados}

O experimento foi conduzido em um pomar de laranja da variedade Natal localizado no município de Iracemápolis-SP. As plantas do pomar apresentavam aproximadamente 3,5 metros de altura com idade de 25 anos e os frutos se encontravam maduros e na fase final de desenvolvimento. O espaçamento entre linhas era de 6 metros. Os acaricidas dicofol, fenpyroximate e a mistura de dicofol e fenpyroximate foram utilizados de acordo com as recomendações comerciais. O dicofol foi utilizado na dosagem de $360 \mathrm{~g}$ de I.A. / $1.000 \mathrm{~L}$ de água, o fenpyroximate na dosagem de $50 \mathrm{~g}$ de I.A. / $1.000 \mathrm{~L}$ de água e a mistura de dicofol e fenpyroximate na dosagem de $240 \mathrm{~g}$ e 25 g de I.A. /1.000 L de água, respectivamente. Para a aplicação dos produtos foi utilizado um pulverizador atomizador de $2.000 \mathrm{~L}$, com capacidade para pulverizar 115 plantas a uma pressão de 170 psi $(1172,11 \mathrm{kPa})$. Três blocos contendo quatro linhas de plantas cada um foram delimitados para a aplicação dos produtos. Cada bloco foi pulverizado com um acaricida e entre os blocos foi mantida uma linha como bordadura sem a aplicação de produto. A aplicação foi realizada em 26 de agosto de 1998. Chuvas foram registradas a partir do $8^{\mathrm{o}}$ dia após a aplicação.

Após a aplicação, os frutos foram coletados periodicamente para a avaliação da atividade biológica dos resíduos sobre as linhagens $\mathrm{S}$ e $\mathrm{R}$ de $B$. phoenicis. Coletas de frutos foram feitas antes da aplicação (testemunha), uma hora após a aplicação e no $1^{\circ}$, $3^{\circ}, 5^{\circ}, 7^{\circ}$ e $14^{\circ}$ dia após a aplicação. Em cada coleta foram retirados oito frutos de cada tratamento. Frutos foram coletados ao longo das linhas centrais de cada bloco e levados ao laboratório. Foram escolhidos frutos da periferia da planta e posicionados aproximadamente a $1.7 \mathrm{~m}$ de altura. No laboratório, em cada fruto foram construídas duas arenas de aproximadamente $1,5 \mathrm{~cm}$ de diâmetro cada uma com algodão umedecido, na superfície do fruto que recebeu a maior deposição de produto. Sobre a camada de 
algodão umedecido que circundava as arenas foi depositado uma camada de ágar-água a 2,3\% ainda não geleificada para evitar perdas de ácaros. Cada arena de um fruto foi infestada com uma das linhagens de B. phoenicis. Aproximadamente 10 ácaros adultos foram transferidos em cada arena. Os frutos foram mantidos em sala climatizada à temperatura de $25 \pm 2{ }^{\circ} \mathrm{C}$, umidade relativa ao redor de $70 \%$ e fotofase de 14 horas. A avaliação da mortalidade foi realizada 48 horas após a infestação.

Os dados proporcionais de mortalidade $(P)$ foram transformados para arc sen $(\operatorname{RAIZ}(P / 100))$ e submetidos à análise de variância. Foram avaliados o comportamento das linhagens diante de diferentes idades de resíduos dos acaricidas e a atividade biológica destes para cada linhagem testada. Ao se rejeitar a hipótese da nulidade a partir do teste $F$, as médias dos tratamentos foram comparadas pelo teste de Tukey a 5\% de probabilidade.

\subsection{RESULTADOS E DISCUSSÃO}

\subsubsection{Interação de dicofol e fenpyroximate}

A mistura de dicofol com fenpyroximate apresentou um efeito sinérgico tanto para a linhagem $\mathrm{S}\left(\chi^{2}=58,2\right.$; g.l. $\left.=5 ; P<0,05\right)$ como para a linhagem $\mathrm{R}\left(\chi^{2}=70,5\right.$; g.l. $=5 ; P<0,05)$ de Brevipalpus phoenicis (Figuras 10 e 11). A mortalidade obtida através da mistura foi significativamente superior à soma das mortalidades dos produtos utilizados isoladamente para as duas linhagens. Uma possível explicação para os resultados se deve à resistência cruzada negativa, ou seja, foi observado que o fenpyroximate proporcionou uma maior mortalidade da linhagem $\mathrm{R}$ em relação a $\mathrm{S}$ na mesma concentração (Capítulo 5).

Geralmente, as dosagens dos produtos utilizados isoladamente são utilizadas também em mistura. Segundo Sun \& Johnson (1960) o efeito sinérgico dos produtos em mistura poderia levar a uma redução nas dosagens destes produtos. Deste modo, estudos mais detalhados devem ser conduzidos com a mistura de dicofol e fenpyroximate para encontrar uma proporção ideal destes acaricidas para o controle de B. phoenicis. 


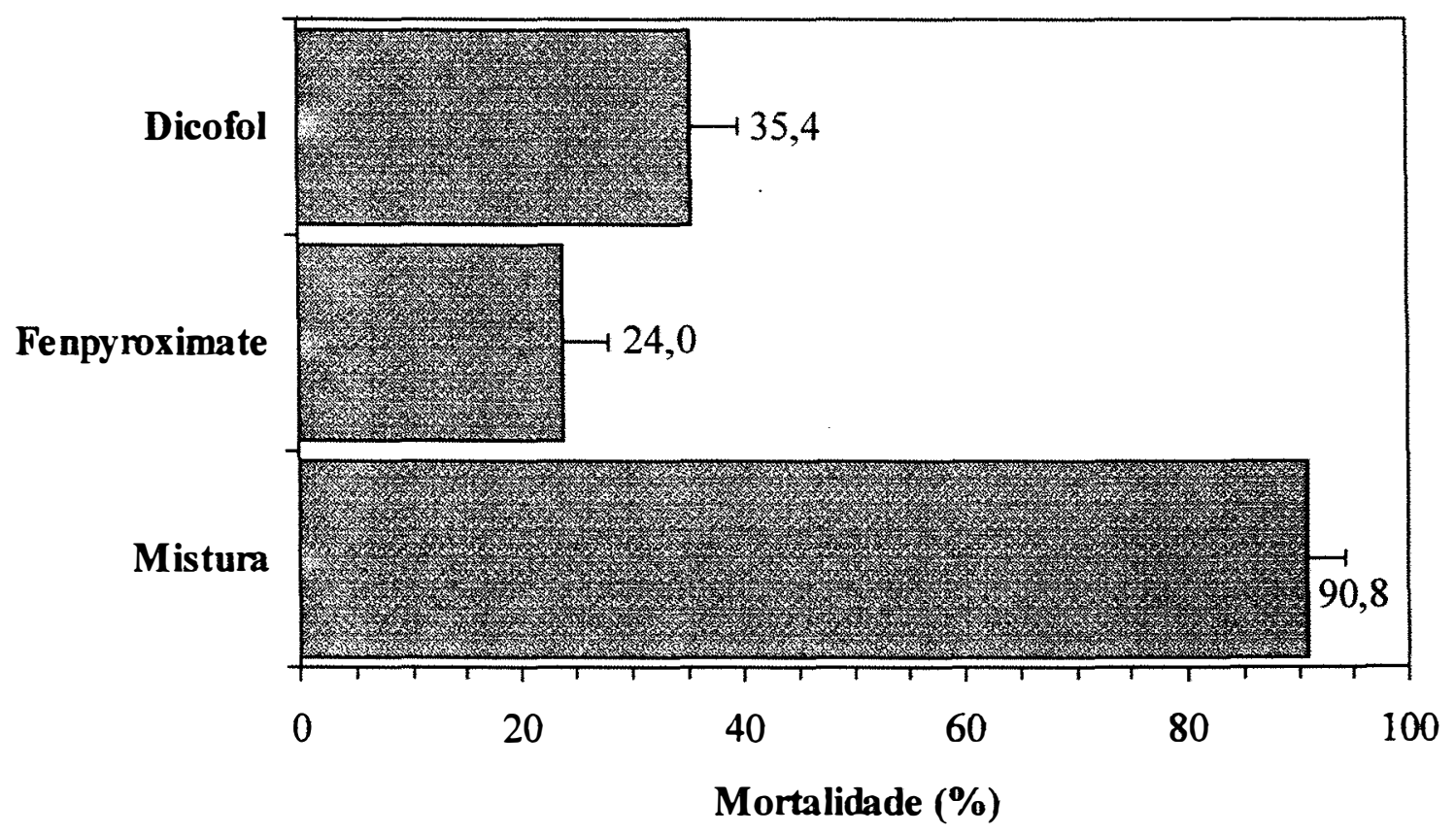

Figura 10. Mortalidade ( \pm erro padrão da média) de ácaros da linhagem de Brevipalpus phoenicis susceptível ao dicofol ocasionada pelas concentrações de $5 \mu \mathrm{g}$ de dicofol / $\mathrm{mL}$ de água destilada [ppm (I.A.)] e 24 ppm de fenpyroximate aplicadas isoladamente e em mistura. 


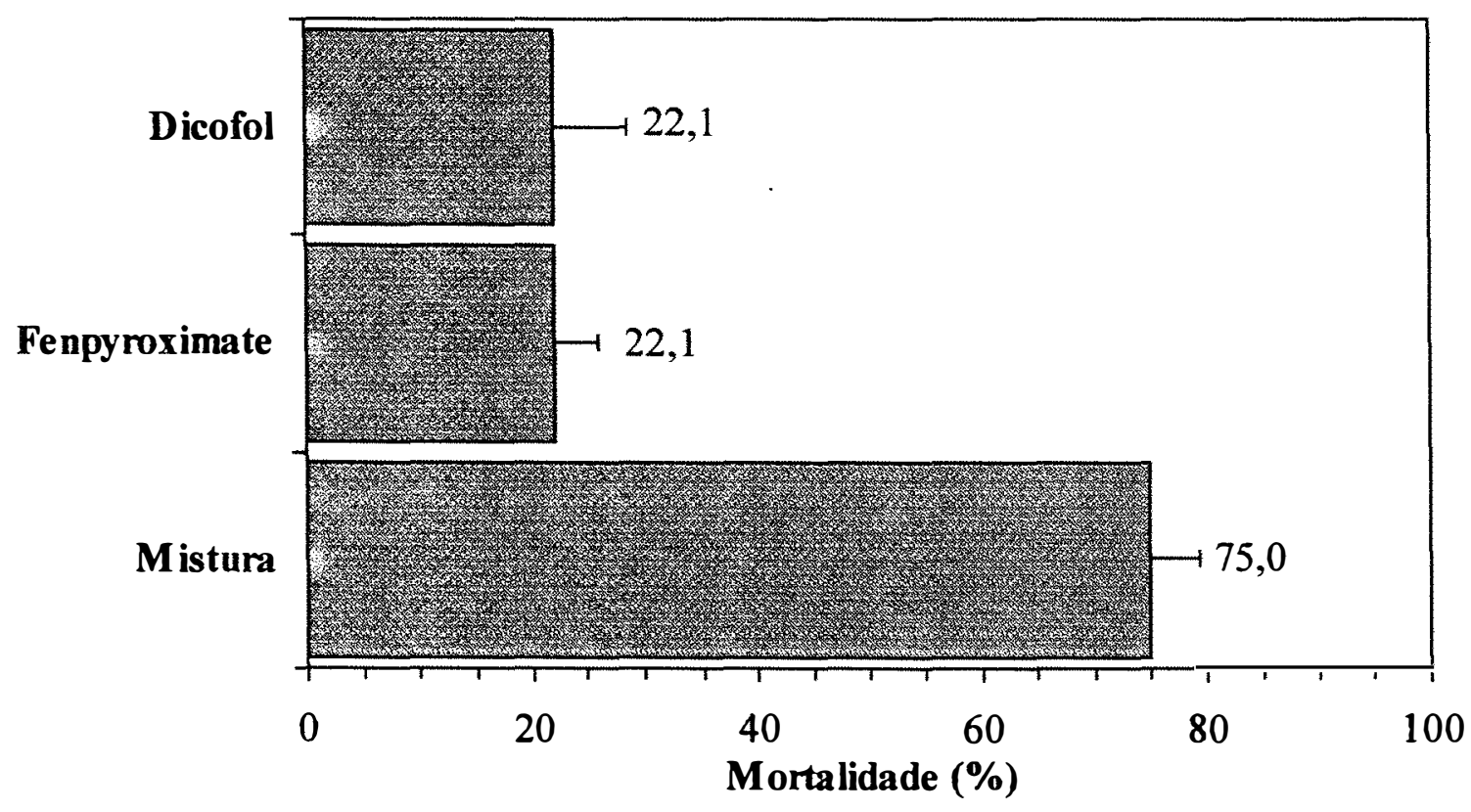

Figura 11. Mortalidade ( \pm erro padrão da média) de ácaros da linhagem de Brevipalpus phoenicis resistente ao dicofol ocasionada pelas concentrações de $260 \mu \mathrm{g}$ de dicofol / $\mathrm{mL}$ de água destilada [ppm (I.A.)] e 8 ppm de fenpyroximate aplicadas isoladamente e em mistura. 


\subsubsection{Persistência de resíduos da mistu ra de dicofol e fenpyroximate e dos produtos isolados}

O efeito de linhagem foi altamente significativo para o acaricida dicofol $(F=$ 1994,76; g.l. $=1$, 36; $P<0,05)$. Mesmo utilizando resíduos com menos de 4 horas de idade provindos de frutos com aplicação de dicofol a $360 \mathrm{ppm}$ (I.A.) até o ponto de escorrimento, não foi possível saturar o mecanismo que confere resistência de $B$. phoenicis ao dicofol (Figura 12). A mortalidade da linhagem $\mathrm{R}$ foi inferior a 10\% para as diferentes idades de resíduos do dicofol. Foi verificado uma mortalidade de $100 \%$ da linhagem $\mathrm{S}$ até o $7^{\mathrm{o}}$ dia e no $14^{\circ}$ dia após a aplicação do dicofol observou-se uma mortalidade de aproximadamente $72 \%$ da linhagem S, em avaliações realizadas 24 horas após a infestação dos ácaros. Porém, quando os ácaros susceptíveis foram expostos por 48 horas, a mortalidade foi superior a $95 \%$. A interação entre as linhagens de $B$. phoenicis com os resíduos de diferentes idades do dico fol não foi significativa $(F=0,56$; g.l. $=5,36 ; P>0,05)$, indicando que as linhagens $\mathrm{S}$ e $\mathrm{R}$ respondem de forma semelhante às diferentes idades de resíduo do dicofol.

Para o acaricida fenpyroximate o efeito da linhagem não foi significativo $(F=$ $3,02 ;$ g.l. $=1,36 ; P>0,05)$. As linhagens $\mathrm{S}$ e $\mathrm{R}$ de $B$. phoenicis não foram discriminadas pelo fenpyroximate em nenhuma das idades de resíduos testadas. No entanto, os resíduos do fenpyroximate não proporcionaram um controle eficiente de ambas as linhagens (Figura 13). Até o $5^{\circ}$ dia a mortalidade das linhagens $\mathrm{S}$ e $\mathrm{R}$ variaram entre 30 a $50 \%$. Após este período, a mortalidade das linhagens $\mathrm{S}$ e $\mathrm{R}$ reduziram para aproximadamente $20 \%$ e $10 \%$, respectivamente. A interação das linhagens de $B$. phoenicis com os resíduos de diferentes idades do fenpyroximate não foi significativa ( $F$ $=0,92 ;$ g.l. $=5,36 ; P>0,05)$. A degradação do produto no decorrer do tempo foi significativa $(F=10,52 ; g . l .=5,36 ; P<0,05)$.

Os dados obtidos para o fenpyroximate explicam algumas reclamações feitas por técnicos e citricultores, com relação ao desempenho do acaricida fenpyroximate no controle de B. phoenicis. Segundo trabalhos apresentados no Capítulo 5, observou-se que a concentração de 56 ppm de fenpyroximate (próxima à concentração recomendada 
de $50 \mathrm{ppm}$ no campo) proporcionou um controle de apenas $80 \%$ da linhagem $\mathrm{S}$ e $95 \%$ da linhagem R. Geralmente os bioensaios conduzidos em laboratório superestimam o efeito do produto, sendo necessário uma menor concentração do produto comparado àquela exigida em campo para obter mortalidades de $100 \%$.

Os produtos utilizados em mistura devem apresentar a mesma persistência e proporcionar uma alta mortalidade da praga para que a mistura seja eficiente no manejo da resistência (Georghiou, 1983; Roush, 1989; Tabashnik, 1989). Fatos que não foram observados no presente estudo. O fenpyroximate não apresentou controle satisfatório de B. phoenicis e este acaricida apresentou uma persistência menor que o dicofol. Uma razão para isso seria devido à concentração do dicofol aplicada ser muito mais elevada do que a exigida para causar $100 \%$ de mortalidade dos ácaros susceptíveis, ao contrário do fenpyroximate cuja concentração aplicada não propocionou mortalidade adequada.

Para a mistura de dicofol e fenpyroximate o efeito da linhagem foi altamente significativo $(F=354,50 ;$ g.l. $=1,36 ; P<0,05)$. A mistura foi bastante eficiente no controle da linhagem $\mathrm{S}$. Porém, a mortalidade da linhagem $\mathrm{R}$ foi baixa com a mistura. Desta forma, os resíduos de diferentes idades da mistura de dicofol e fenpyroximate não foram capazes de evitar a discriminação entre as linhagens (Figura 14). A interação das linhagens de $B$. phoenicis com os resíduos de diferentes idades da mistura não foi significativa $(F=1,53 ;$ g.l. $=5,36 ; P>0,05)$, indicando que as linhagens $\mathrm{S}$ e $\mathrm{R}$ respondem de forma semelhante às diferentes idades de resíduo. Porém a degradação do produto no decorrer do tempo foi significativa $(F=7,53 ;$ g.l. $=5,36 ; P<0,05)$. O efeito de redução da atividade biológica da mistura foi mais evidente para a linhagem R.

O sinergismo do dicofol e fenpyroximate em mistura também foi observado no campo. O uso de aproximadamente metade da dosagem do dicofol e fenpyroximate em mistura proporcionaram mortalidade aproximadamente igual para a linhagem S e superior para a linhagem $\mathrm{R}$, comparado àquela observada para o dicofol utilizado em sua dosagem comercial recomendada para o controle de B. phoenicis (Figuras 12 e 14). Ao comparar o uso de mistura com o de fenpyroximate em sua dosagem comercial, também foi verificado um efeito benéfico da mistura para o controle das linhagens $S$ e $R$. A mistura proporcionou uma mortalidade da linhagem $\mathrm{S}$ superior àquela proporcionada 
pelo uso de apenas fenpyroximate. Para a linhagem $\mathrm{R}$, a mistura proporcionou mortalidade aproximadamente igual àquela proporcionada com o uso de apenas fenpyroximate (Figuras 13 e 14).

Pelos resultados obtidos acredita-se que a discriminação entre as linhagens S e $\mathrm{R}$ de $B$. phoenicis exercida pela mistura seja inicialmente ocasionada devido o fenpyroximate não estar oferecendo um controle adequado de $B$. phoenicis e posteriormente pelo fato do fenpyroximate apresentar uma degradação mais rápida que o dicofol.

\subsubsection{Implicações para o manejo da resistência de Brevipalpus phoenicis ao dicofol}

Devido ao efeito sinérgico observado entre os acaricidas dicofol e fenpyroximate, a mistura destes acaricidas se mostrou bastante promissora no manejo da resistência de $B$. phoenicis ao dicofol. Porém, uma melhor definição das dosagens dos produtos em mistura deve ser estabelecida para aumentar a sua eficácia no controle de $B$. phoenicis. Sem dúvida, esta mistura deve ser recomendada somente em pomares de citros onde a freqüência de resistência de $B$. phoenicis ao dicofol ainda seja baixa.

$\mathrm{O}$ conhecimento da interface entre o produto e a praga tem sido de fundamental importância para a implementação de estratégias de manejo da resistência, uma vez que o modo de exposição e a persistência do produto no ambiente constituem-se como fatores determinantes na evolução da resistência (Georghiou \& Taylor, 1977b; Taylor et al. 1983; Omoto et al., 1995a). No presente trabalho foi avaliado apenas o contato residual da mistura sobre $B$. phoenicis. Talvez, o benefício do sinergismo entre dicofol e fenpyroximate seja mais evidente em condições de campo através de um contato direto da mistura sobre os ácaros no momento da pulverização. Sendo assim, um melhor entendimento da interface entre a mistura de dicofol com fenpyroximate e o ácaro $B$. phoenicis devem ser considerados para a definição das dosagens de cada produto na mistura. 


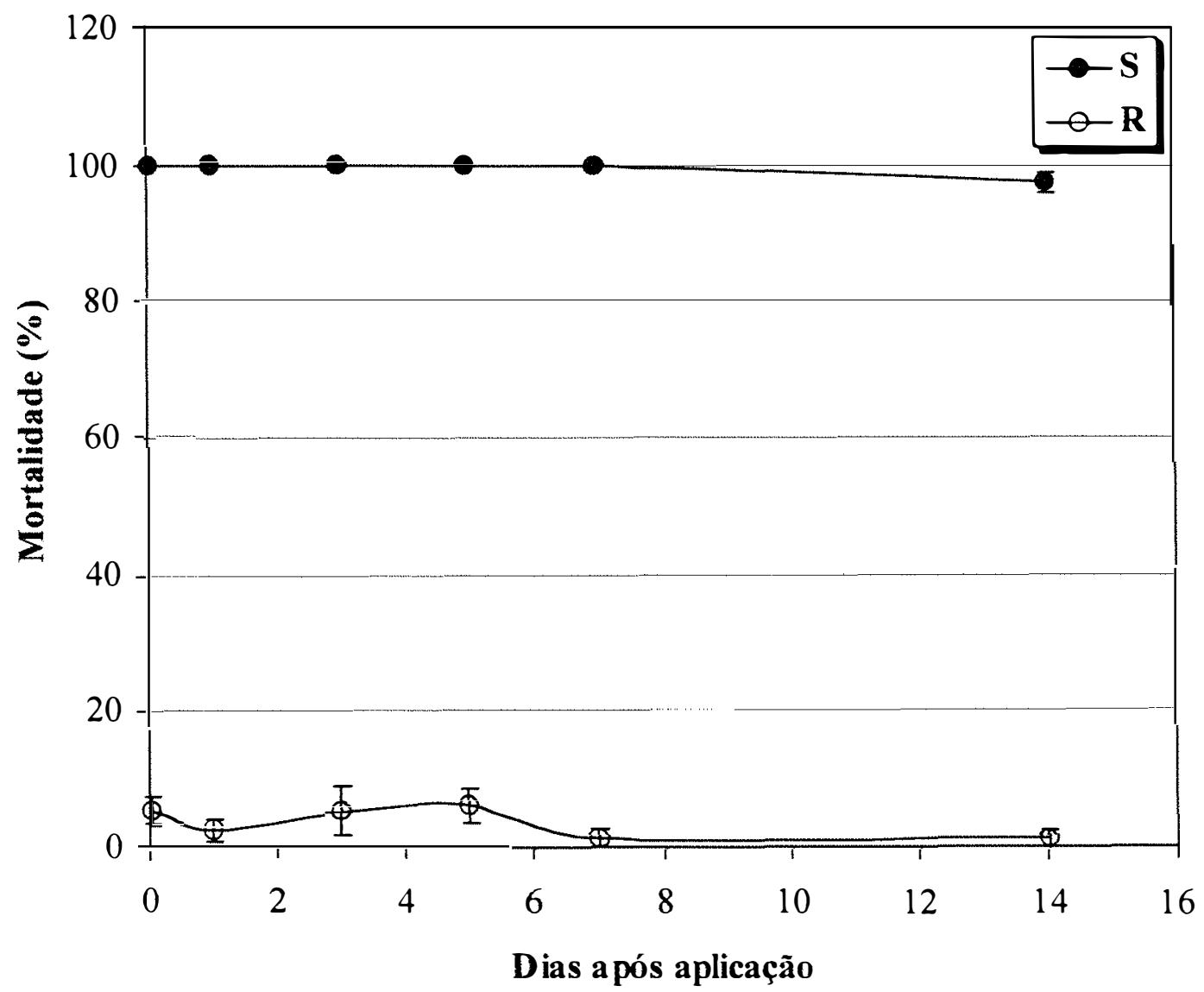

Figura 12 - Avaliação em laboratório das respostas (porcentagem de mortalidade \pm erro padrão da média) das linhagens de Brevipalpus phoenicis susceptível (S) e resistente $(\mathrm{R})$ ao dicofol, expostas a diferentes idades de resíduos de dicofol durante 48 horas. 


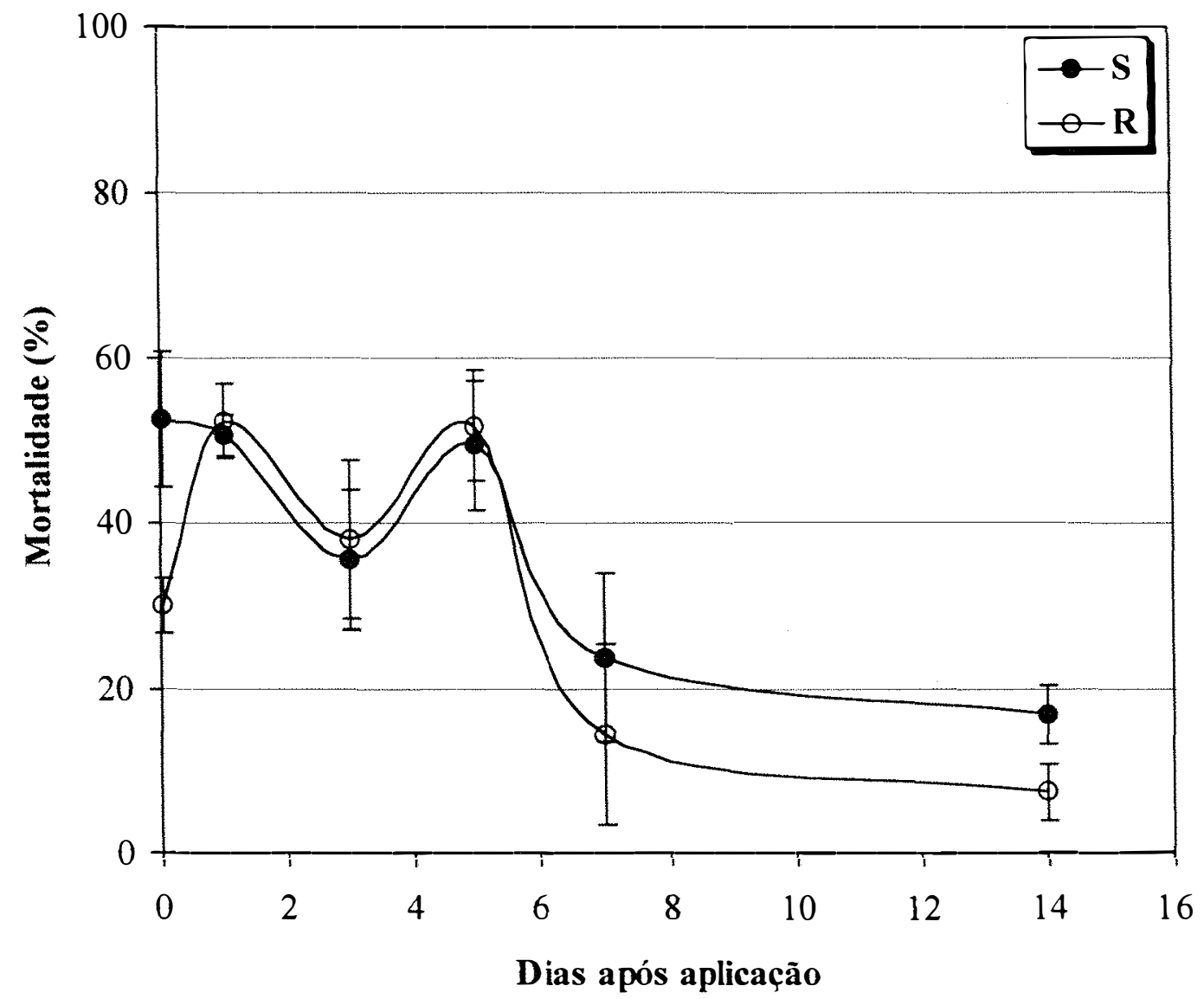

Figura 13 - Avaliação em laboratório das respostas (porcentagem de mortalidade \pm erro padrão da média) das linhagens de Brevipalpus phoenicis susceptível (S) e resistente ( $R$ ) ao dicofol, expostas a diferentes idades de resíduos de fenpyroximate durante 48 horas. 


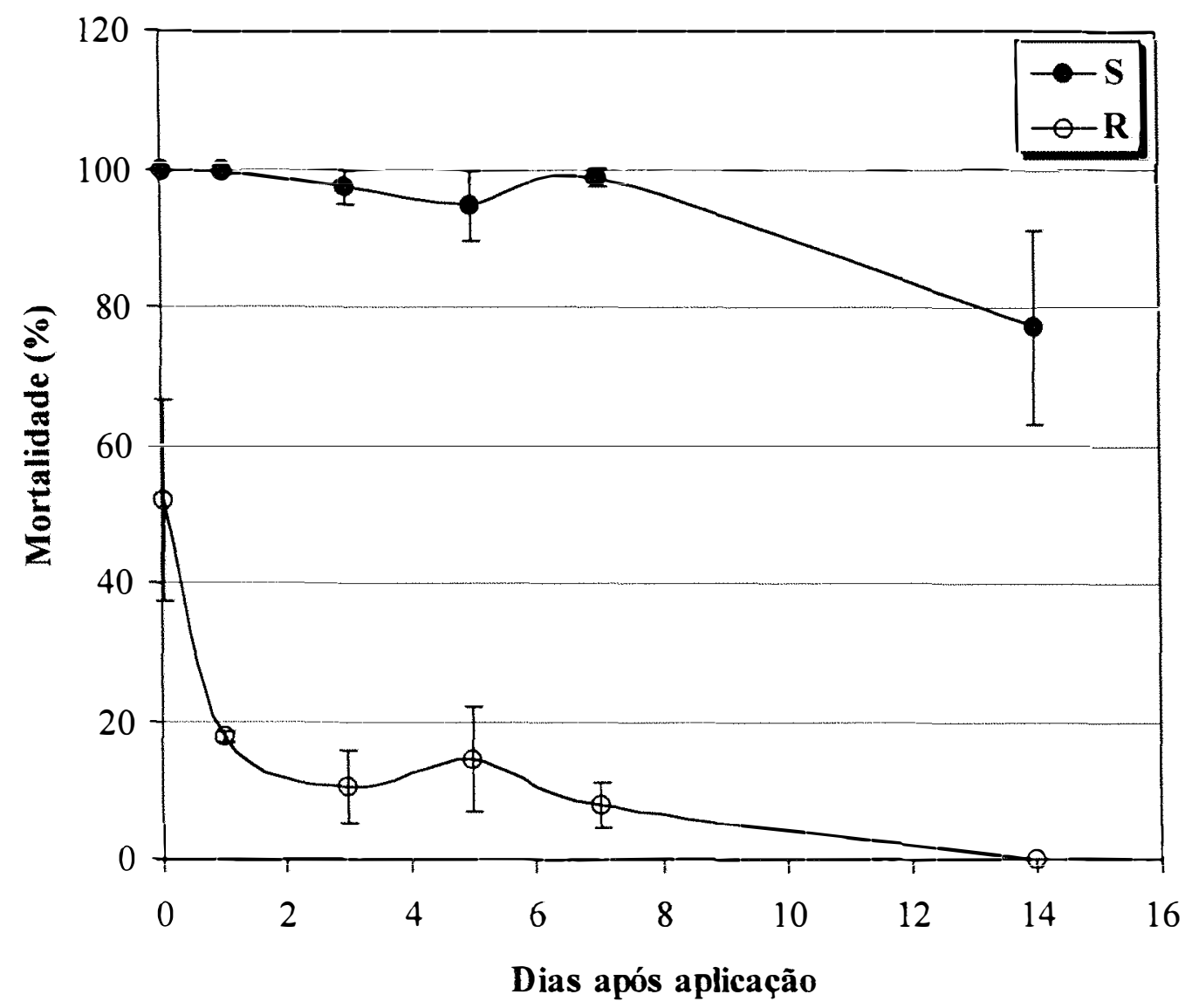

Figura 14 - Avaliação em laboratório das respostas (porcentagem de mortalidade \pm erro padrão da média) das linhagens de Brevipalpus phoenicis susceptível (S) e resistente (R) ao dicofol, expostas a diferentes idades de resíduos da mistura de dicofol e fenpyroximate durante 48 horas. 


\subsection{CONCLUSÕES}

- Os produtos dicofol e fenpyroximate quando utilizados em mistura apresentaram um efeito sinérgico sobre as linhagens de Brevipalpus phoenicis susceptível e resistente ao dicofol.

- A mistura de dicofol com fenpyroximate na dosagem recomendada não foi efetiva para o manejo da resistência de B. phoenicis ao dicofol. 


\section{CONCLUSÕES GERAIS}

- A intensidade da resistência de Brevipalpus phoenicis ao dicofol é de 56,82 (IC 95\% $53,54-60,29)$.

- Concentrações discriminatórias entre 32 e 100 ppm de dicofol podem ser utilizadas para um programa de monitoramento da resistência de B. phoenicis ao dicofol.

- A resistência de B. phoenicis ao dicofol é instável na ausência de pressão seletiva com o dicofol.

- A linhagem resistente de B. phoenicis ao dicofol apresenta menor valor adaptativo em relação à linhagem susceptível de referência.

- O custo adaptativo da resistência de B. phoenicis ao dicofol está relacionado principalmente à menor fecundidade e longevidade da linhagem resistente em relação à linhagem susceptível de referência.

- Não há resistência cruzada entre dicofol e os acaricidas óxido de fenbutatina e propargite em $B$. phoenicis.

- Há resistência cruzada negativa entre dicofol e fenpyroximate em B. phoenicis.

- Há resistênica cruzada positiva entre dicofol e bromopropilato em B. phoenicis.

- Os produtos dicofol e fenpyroximate quando utilizados em mistura apresentaram um efeito sinérgico sobre as linhagens de B. phoenicis susceptível e resistente ao dicofol.

- A mistura de dicofol com fenpyroximate na dosagem recomendada não foi efetiva para o manejo da resistência de B. phoenicis ao dicofol. 


\section{REFERÊNCIAS BIBLIOGRÁFICAS}

ALVES, E. B.; RIBEIRO, P. C.; CAMPOS, F. J. et al. A resistência do ácaro da leprose (Brevipalpus phoenicis) ao dicofol pode ser manejada? In: CONGRESSO BRASILEIRO DE ENTOMOLOGIA, 17., Rio de Janeiro, 1998. Resumos. Rio de Janeiro: SEB, 1998. v.2, p.1048.

BARTLETT, A. C. Genetic changes during insect domestication. In: KING, E. G.; LEPPLA, N. C. (Ed.) Advances and challenges in insect rearing. Washington: USDA, ARS, 1984. p.2-8.

BYNUM Jr., E. D.; ARCHER, T. L.; PLAPP Jr., F. W. Action of insecticides to spider mites (Acari: Tetranychidae) on corn in the Texas high plains: toxicity, resistance, and synergistic combinations. Journal of Economic Entomology, v.83, n.4, p.1236-1242, Aug. 1990.

BYNUM Jr., E. D.; ARCHER, T. L.; PLAPP Jr., F. W. Comparison of banks grass mite and twospotted spider mite (Acari: Tetranychidae): responses to insecticides alone and in synergistic combinations. Journal of Economic Entomology, v.90, n.5, p.1125-1130, Oct. 1997.

CHAGAS, C. M.; ROSSETTI, V. Transmissão experimental de leprose dos citros por meio de implantação de tecido foliar no caule. Fitopatologia Brasileira, v.5, n.2, p.211-214, jul. 1980. 
CHIAVEGATO, L. G. Bioecologia do ácaro da leprose Brevipalpus phoenicis (Geijskes, 1939) (Acari: Tenuipalpidae) em citros. In: CONGRESSO BRASILEIRO DE ENTOMOLOGIA, 10., Rio de Janeiro, 1986. Resumos. Rio de Janeiro: SEB, 1986a. p.35.

CHIAVEgATO, L. G. Biologia do ácaro Brevipalpus phoenicis em citros. Pesquisa Agropecuária Brasileira, v.21, n.8, p. 813-816, ago. 1986b.

CHIAVEgATO, L. G. A leprose dos citros no Estado de São Paulo. Laranja, v. 8, n.1, p.7-18, dez. 1987.

CHIAVEgato, L. G.; MISCHAN, M. M. Comportamento do ácaro Brevipalpus phoenicis (Geijskes, 1939) (Acari: Tenuipalpidae) em frutos de diferentes variedades cítricas. Científica, v.15, n.1/2, p.17-22, 1987.

CHIAVEGATO, L. G.; SALIBE, A. A. Prejuizos provocados pelo ácaro Brevipalpus phoenicis (Geijskes, 1939) em algumas variedades cítricas. In: CONGRESSO BRASILEIRO DE FRUTICULTURA 6., Recife, 1981. Anais. Recife: Sociedade Brasileira de Fruticultura, 1981. v.2, p.709-718.

CRANHAM, J. E.; HELLE, W. Pesticide resistance in Tetranychidae. In: HELLE, W; SABELIS, M. W. (Ed.) Spider mites: their biology, natural enemies and control. New York: Elsevier, 1985. cap.3.4, p.405-421. (World Crop Pests, 1B).

CROFT, B. A.; VAN DE BAAN, H. E. Ecological and genetic factors influencing evolution of pesticide resistance in tetranychid and phytoseiid mites. Experimental \& Applied Acarology, v.4, p.277-300, 1988. 
CURTIS, C. F. Theoretical models of the use of insecticide mixtures for the management of resistance. Bulletin of the Entomological Research, v.75, p.259$265,1985$.

DENHOLM. I.; ROWLAND, M. W. Tactics for managing pesticide resistance in arthropods: theory and practice. Annual Review of Entomology, v.37, p.91-112, 1992.

DENNEHY, T. J. Decision-making for managing pest resistance to pesticides. In: FORD, M. G.; HOLLOMAN, D. W.; KHAMBAY, B. P. S.; SAWICKI, R. M. (Ed.) Combating resistance to xenobiotics: biological and chemical approaches. Chichester: Ellis Horwood, 1987. p.118-126.

DENNEHY, T. J.; GRANETT, J. Monitoring dicofol-resistant spider mites (Acari: Tetranychidae) in California Cotton. Journal of Economic Entomology, v.77, n.6, p.1386-1392, Dec. 1984a.

DENNEHY, T. J.; GRANETT, J. Spider mite resistance to dicofol in San Joaquin Valley Cotton: inter- and intraspecific variability in susceptibility of three species of Tetranychus (Acari: Tetranychidae). Journal of Economic Entomology, v.77, n.6, p.1381-1385. Dec. 1984b.

DENNEHY, T. J.; NYROP, J. P.; MARTINSON, T. E. Caracterization and exploitation of instability of spider mite resistance to acaricides. In: GREEN, M. B.; LeBARON, H. M.; MOBERG, W. K. (Ed.) Managing resistance to agrochemicals: from fundamental research to practical strategies. Washington: American Chemical Society, 1990. cap.5, p. 77-91. 
DENNEHY, T. J.; NYROP, J. P.; REISSIG, W. H. et al. Characterization of resistance to dicofol in spider mites (Acari: Tetranychidae) from New York apple orchards. Journal of Economic Entomology, v.81, n.6, p.1551-1561, Dec. 1988.

FERGUSSON-KOLMES, L. A.; SCOTT, J. G.; DENNEHY, T. J. Dicofol resistance in Tetranychus urticae (Acari: Tetranychidae): cross-resistance and pharmacokinetics. Journal of Economic Entomology, v.84, n.1, p.41-48, Feb. 1991.

FFRENCH-CONSTANT, R. H.; ROUSH, R. T. Resistance detection and documentation: the relative roles of pesticidal and biochemical assays. In: ROUSH, R. T.; TABASHNIK, B. E. (Ed.) Pesticide resistance in arthropods. New York: Chapman and Hall, 1990. cap.2, p.4-38.

FLEXNER, J. L.; THEILING, K. M.; CROFT, B. A. et al. Fitness and immigration: factor affecting reversion of organotin resistance in the twospotted spider mite (Acari: Tetranychidae). Journal of Economic Entomology, v.82, n.4, p.996-1002, Aug. 1989.

FNP CONSULTORIA \& COMÉRCIO. AGRIANUAL 99: anuário estatístico da agricultura brasileira. São Paulo, 1999. p.250-277: Citros.

GEORGHIOU, G. P. The evolution of resistance to pesticides. Annual Review of Ecology and Systematics, v.3, p.133-168, 1972.

GEORGHIOU, G. P. Management of resistance in arthropods. In: GEORGHIOU, G. P.; SAITO, T. (Ed.) Pest resistance to pesticides. New York: Plenum, 1983. p.769-792. 
GEORGHIOU, G. P. The magnitude of the resistance problem. In: NATIONAL RESEARCH COUNCIL. Pesticide resistance: strategies and tactics for management. Washington: National Academy Press, 1986. p. 14-43.

GEORGHIOU, G. P.; TAYLOR, C.E. Genetic and biological influences in the evolution of isecticide resistance. Journal of Economic Entomology, v.70, n.3, p.319-323, June 1977a.

GEORGHIOU, G. P.; TAYLOR, C.E. Operational influences in the evolution of insecticide resistance. Journal of Economic Entomology, v.70, n.5, p. 653-658, Oct. 1977b.

GEORGHIOU, G. P.; TEJADA, A. L. The ocurrence of resistance to pesticides in arthropods. Rome: FAO, 1991.318 p.

GONZÁLEZ, R. H. Revision of the Brevipalpus phoenicis "complex" with descriptions of new species from Chile and Thailand (Acarina, Tenuiplapidae). Acarologia, v.17, n.1. p.81-91, 1975.

GRAVENA, S. Manejo integrado de pragas em citros no Brasil: uma visão atual. In: SEMINÁRIO INTERNACIONAL DE CITROS-MIP, 3., Bebedouro, 1994. Manejo integrado de pragas dos citros: anais. Campinas: Fundação Cargill, 1994a. p.41-56.

GRAVENA, S. Rotação de acaricidas no MIP-Citros: menos desequilíbrio e resistência. Laranja, v.15, n.2, p.375-395, 1994b. 
GRAVENA, S.; FERNANDES, O A.; PAZINI, W. C. Amostragem seqüencial para os ácaros da falsa ferrugem Phyllocoptruta oleivora (Ashm.) e da leprose Brevipalpus phoenicis (Geijskes) no manejo integrado de pragas dos citros. Laranja, v.9, p.147-160, nov. 1988.

GRAVENA, S.; BENETOLI, I.; MOREIRA, P. H. R et al. Euseius citrifolius Denmark \& Muma predation on citrus leprosis mite Brevipalpus phoenicis (Geijskes) (Acari: Phytoseiidae: Tenuipalpidae). Anais da Sociedade Entomologica do Brasil, v.23, n.2, p.209-218, 1994.

GUIRADO, N.; SILVERIO, J. L. Leprose e declínio: Problemas sérios da citricultura paulista. Laranja, v.13, n.2, p.541-552, 1992.

HATANO, R.; SCOTT, J. G.; DENNEHY, T. J. Enhanced activation is the mechanism of negative cross-resistance to chlorpyrifos in the dicofol-IR strain of Tetranychus urticae (Acari: Tetranychidae). Journal of Economic Entomology, v.85, n.4, p.1088-1091, Aug. 1992.

HELLE, W.; PIJNACKER, L. P. Parthenogenesis, chromosomes and sex. In: HELLE. W.; SABELIS, M. W. (Ed.) Spider mites: their biology, natural enemies and control. New York: Elsevier, 1985. p.129-140. (World Crop Pests, 1A).

HELLE, W.; BOLLAND, H. R.; HEITMANS, W. R. B. Chromosomes and types of parthenogenesis in the fase spider mites (Acari: Tenuipalpidae). Genetica, v.54, p.45-50, 1980.

HERNE, D. C.; CHIBA. M. Mortality of the european red mite (Acarina: Tetranychidae) relative to distribution and degradation of dicofol deposits on peach leaves. Canadian Entomologist, v.107, p.801-806, Aug. 1975. 
HOSKINS, W. M.; GORDON, H. T. Arthropod resistance to chemicals. Annual Review of Entomology, v.1, p.89-122, 1956.

HOYT, S. C.; HARRIES, F. H. Laboratory and field studies on orchard-mite resistance to Kelthane. Journal of Economic Entomology, v.54, n.1, p.12-16, Feb. 1961.

INOUE, K. Relationship between dicofol resistance and fitness in the citrus red mite, Panonychus citri (McG.). Journal of Pesticide Science, v.5, p.165-175, 1980.

KITAJMA, E. W.; LOVISOLO, O.; COLARICCIO, A. et al. Vírus causador da leprose dos citros. In: OLIVEIRA, C. A. L. de; DONADIO, L. C. (Ed.) Leprose dos citros. Jaboticabal: FUNEP, 1995. p.19-24.

KITAJIMA, E. W.; MÜlleR, G. W.; COSTA, A. S. et al. Short, rod-like particles associated with citrus leprosis. Virology, v.50, n.1, p.254-258, Oct. 1972.

KNORR, L. C.; DENMARK, H. A. Injury to citrus by the mite Brevipalpus phoenicis. Journal of Economic Entomology, v.63, n.6, p.1996-1998, Dec. 1970.

KOMATSU, S. S.; NAKANO, O. Estudos visando o manejo do ácaro da leprose em citros através do ácaro predador Euseius concordis (Acari: Phytoseiidae). Laranja, v.9, p.125-146, nov. 1988.

LAL, L. Biology of Brevipalpus phoenicis (Geijskes) (Tenuipapidae: Acarina). Acarologia, v.20, n.1, p.97-101, 1978.

LEORA SOFTWARE. POLO-PC: a user's guide to Probit Or LOgit analysis. Berkeley, 1987. 20p. 
MABLE, B. K.; PREE, D. J. Stability of dicofol resistance in populations of european red mite (Acari: Tetranychidae) on apples in Southern Ontario. Journal of Economic Entomology, v.85, n.3, p.642-650, June 1992.

MACDONALD, R. S.; SURGEONER, G. A.; SOLOMON, K. R. et al. Effect of four spray regimes on the development of permethrin and dichlorvos resistance, in the laboratory, by the house fly (Diptera: Muscidae). Journal of Economic Entomology, v.76, n.3, p.417-422, 1983.

MANI, G. S. Evolution of resistance in the presence of two insecticides. Genetics, v.109, p.761-783, Apr. 1985.

MANSOUR, F. A.; PLAUT, H. N. The effectiveness of various acaricides against resistant and susceptible carmine spider mites. Phytoparasitica, v.7, n.3, p.185193, 1979.

MEYER, M. K. P. S. Mite pests of crops in southern Africa. Pretoria: Department of Agriculture and Fisheries, 1981. 92p. (Science Bulletin, 397).

MORAES, G.J.; SÁ, L. A. N. de. Perspectivas do controle biológico do ácaro da leprose em citros. In: OLIVEIRA, C. A. L. de; DONADIO, L. C. (Ed.) Leprose dos citros. Jaboticabal: FUNEP, 1995. p. 117-128.

MYAZAKI, I; SUPLICY FILHO, N.; SAMPAIO, A. S. Comportamento do "ácaro da leprose" dos citros, Brevipalpus phoenicis (Geijskes, 1939), sob ação de acaricidas O Biológico, v.48, n.1, p.21-24, jan. 1982.

NAKANO, O. Rotatividade de ingredientes ativos em citros. In: OLIVEIRA, C. A. L. de; DONADIO, L. C. (Ed.) Leprose dos citros. Jaboticabal: FUNEP. 1995. p. 189-194. 
NAKANO, O. ; SANCHES, G. A.; ISHIDA, A. K. Redução da infestação do ácaro da leprose Brevipalpus phoenicis (Geijskes, 1939) em citros através do controle da verrugose. Laranja, v.8, n.1, p.19-33, dec. 1987.

NEGRI, J. D. de. A extensão rural no MIP-Citros. In: SEMINÁRIO INTERNACIONAL DE CITROS-MIP, 3., Bebedouro, 1994. Manejo integrado de pragas dos citros: anais. Campinas: Fundação Cargill, 1994. p. 269-275.

NEGRI, J. D. de. Citrus IPM in the State of São Paulo, Brazil: a view of the extension service. In: INTERNATIONAL PLANT PROTECTION CONGRESS, 13., The Hague, 1995. Abstracts. European Journal of Plant Pathology, suppl. 1995. Abst. 239.

OLIVEIRA, C. A. L. de. Flutuação populacional e medidas de controle do ácaro da leprose Brevipalpus phoenicis (Geijskes, 1939) em citros. Laranja, v.7, n.1, p.131, nov. 1986.

OLIVEIRA, C. A. L. de. Ácaros dos citros. São Bernardo do Campo: Basf Brasileira, Departamento de Agroquímicos, 1994. 18 p.

OMOTO, C. Resistência de Brevipalpus phoenicis (Acari: Tenuipalpidae) aos produtos químicos na citricultura. In: OLIVEIRA, C. A. L. de; DONADIO, L. C. (Ed.) Leprose dos citros. Jaboticabal: FUNEP, 1995. p.179-188.

OMOTO, C. Acaricide resistance management of leprosis mite (Brevipalpus phoenicis) in brazilian citrus. Pesticide Science, v.52, p.189-198, 1998. 
OMOTO, C.; DENNEHY, T. J.; McCOY, C. W. et al. Detection and characterization of the interpopulation variation of citrus rust mite (Acari: Eriophyidae) resistance to dicofol in Florida citrus. Journal of Economic Entomology, v.87, n.3, p.566-572, June 1994.

OMOTO, C.; DENNEHY, T. J.; McCOY, C. W. et al. Interface between citrus rust mite (Acari: Eriophyidae) and dicofol: implications for resistance management. Journal of Economic Entomology, v.88, n.5, p.1129-1137. Oct. 1995a.

OMOTO, C.; DENNEHY, T. J.; McCOY, C. W. et al. Management of citrus rust mite (Acari: Eriophyidae) resistance to dicofol in Florida citrus. Journal of Economic Entomology, v.88, n.5, p.1120-1128. Oct. 1995 b.

OOMEN, P. A. Studies on population dynamics of the scarlet mite, Brevipapus phoenicis, a pest of tea in Indonesia. Wageningen: Veenman \& Zonen, 1982. 88p.

OVERMEER, W. P. J.; VAN ZON, A. Q.; HELLE, W. The stability of acaricide resistance in spider mite (Tetranychus urticae) populations from rose houses. In: Entomologia Experimentalis \& Applicata, v.18, p.68-74, 1975.

PREE, D. J. Inheritance and management of cyhexatin and dicofol resistance in the european red mite (Acari: Tetranychidae). Journal of Economic Entomology, v.80, n.6, p.1106-1112, Dec. 1987.

PREE, D. J.; WAGNER, H. W. Occurrence of cyhexatin and dicofol resistance in the european red mite, Panonychus ulmi (Koch) (Acari: Tetranychidae), in Southern Ontario. Canadian Entomologist, v.119, p.287-290, Mar. 1987. 
REIS, P. R. Aspectos bioecológicos e seletividade de agroquímicos a Iphiseiodes zuluagai Denmark \& Muma, 1972 (Acari; Phytoseiidae). Piracicaba, 1996. 154 p. Tese (Doutorado) - Escola Superior de Agricultura "Luiz de Queiroz", Universidade de São Paulo.

ROBERTSON, J. L.; PREISLER, H. K. Pesticide bioassays with arthropods. Boca Raton: CRC Press, 1992.127p.

RODRIGUES, J. C. V. Leprose dos citros: cito-histopatologia, transmissibilidade e relação com o vetor Brevipalpus phoenicis Geijskes (Acari: Tenuipalpidae). Piracicaba, 1995. 79 p. Dissertação (Mestrado) - Centro de Energia Nuclear na Agricultura, Universidade de São Paulo.

ROUSH, R. T. Designing resistance management programs: How can you choose? Pesticide Science, v.26. p.423-441, 1989.

ROUSH, R. T.; DALY, J. C. The role of population genetics in resistance research and management. In: ROUSH, R. T.; TABASHNIK, B. E. (Ed) Pesticide resistance in arthropods. New York: Chapman and Hall, 1990. cap. 5, p.97-152.

ROUSH, R. T.; McKENZIE, J. A. Ecological genetics of insecticide and acaricide resistance. Annual Review of Entomology, v.32; p.361-380, 1987.

ROUSH, R. T.; MILLER, G. L. Considerations for design of insecticide resistance monitoring programs. Journal of Economic Entomology, v.79, n.2, p.293-298, Apr. 1986.

SALVA, R. A. Prática do monitoramento de MIP-Citros no Brasil. In: SEMINÁRIO INTERNACIONAL DE CITROS-MIP, 3., Bebedouro, 1994. Manejo integrado de pragas dos citros: anais. Campinas: Fundação Cargill, 1994. p. 255-267. 
SALVA, R. A.; MASSARI, C. A. Situação do ácaro da leprose no Estado de São Paulo (Levantamento-Fundecitrus Agosto 1995). In: OLIVEIRA, C. A. L. de; DONADIO, L. C. (Ed.) Leprose dos citros. Jaboticabal: FUNEP, 1995. p.13-18.

SALVO FILHO, A. de. Notas sobre o tratamento fitossanitário em citros. Laranja, v.18, n.1, p.155-163, 1997.

SILVEIRA NETO, S.; NAKANO, O.; BARBIN, D. et al. Manual de ecologia dos insetos. São Paulo: Ceres, 1976.419p.

SUN, Y. P.; JOHNSON, E. R. Analysis of joint action of insecticides against house flies. Journal of Economic Entomology, v.53, n.5, p.887-892, Oct. 1960.

SUPLICY FILHO, N.; CINTRA, A. F.; MYAZAKI, I. et al. Comportamento do "ácaro da leprose" Brevipalpus phoenicis (Geijskes, 1939) em relação a alguns acaricidas na zona de Limeira. O Biológico, v.48, p.21-24, 1977.

TABASHNIK, B. E. Managing resistance with multiple pesticide tactics: theory, evidence, and recommendations. Journal of Economic Entomology, v.82, n.5, p.1263-1269, Oct. 1989.

TAYLOR, C. E.; QUAGLIA, F.; GEORGHIOU, G. P. Evolution of resistance to insecticides: a cage study on the influence of migration and insecticide decay rates. Journal of Economic Entomology, v.76, n.4, p.704-707, Aug. 1983.

TRINDADE, M. L. B.; CHIAVEGATO, L. G. Caracterização biológica dos ácaros Brevipalpus obovatus D., B. californicus B. e B. phoenicis G. (ACARI: TENUIPALPIDAE). Anais da Sociedade Entomológica do Brasil, v.23, n.2, p.189-195. 1994. 
VESTERGAARD, S.; GILlESPIE, A. T.; BUTT, T. M. et al. Pathogenicity of the hyphomycete fungi Verticillium lecanii and Metarhizium anisopliae to the western flower thrips, Frankliniella occidentalis. Biocontrol Science and Technology, v. 5 p.185-192, 1995.

YAMAMOTO, P. T.; SENE PINTO, A. de; PAIVA, P. E. B. et al. Seletividade de agrotóxicos aos inimigos naturais de pragas dos citros. Laranja, v.13, n.2, p.709$755,1992$. 
APÊNDICE 1 Tabela de vida e fertilidade da linhagem de Brevipalpus phoenicis susceptível de referência (S) ao acaricida dicofol.

\begin{tabular}{|c|c|c|c|c|c|}
\hline Fase & $x^{1}$ & $\mathrm{mx}^{2}$ & $1 \mathbf{x}^{3}$ & $\mathbf{m x} . \mathbf{I x}$ & mx.Ix.x \\
\hline Ovo & - & - & 0,97 & - & - \\
\hline Larva & - & - & 0,92 & - & - \\
\hline Protocrisálida & - & - & 0,92 & - & - \\
\hline Protoninfa & - & - & 0,91 & - & - \\
\hline Deutocrisálida & - & - & 0,87 & - & - \\
\hline Deutoninfa & - & - & 0,87 & - & - \\
\hline Teliocrisálida & $\overline{-}$ & $\overline{-}$ & 0,87 & - & $\overline{-}$ \\
\hline \multirow[t]{23}{*}{ Adulta } & 21,5 & 0,000 & 0,87 & 0,000 & 0,000 \\
\hline & 22,5 & 0,000 & 0,84 & 0,000 & 0,000 \\
\hline & 23,5 & 0,655 & 0,84 & 0,554 & 13,010 \\
\hline & 24,5 & 1,034 & 0,84 & 0,874 & 21,415 \\
\hline & 25,5 & 1,241 & 0,84 & 1,049 & 26,747 \\
\hline & 26,5 & 1,310 & 0,84 & 1,107 & 29,341 \\
\hline & 27,5 & 1,207 & 0,84 & 1,020 & 28,044 \\
\hline & 28,5 & 1,448 & 0,84 & 1,224 & 34,877 \\
\hline & 29,5 & 1,621 & 0,84 & 1,369 & 40,398 \\
\hline & 30,5 & 1,379 & 0,84 & 1,165 & 35,547 \\
\hline & 31,5 & 1,759 & 0,84 & 1,486 & 46,808 \\
\hline & 32,5 & 1,621 & 0,84 & 1,369 & 44,506 \\
\hline & 33,5 & 1,448 & 0,84 & 1,224 & 40,995 \\
\hline & 34,5 & 1,552 & 0,84 & 1,311 & 45,235 \\
\hline & 35,5 & 1,448 & 0,84 & 1,224 & 43,443 \\
\hline & 36,5 & 1,103 & 0,84 & 0,932 & 34,032 \\
\hline & 37,5 & 1,345 & 0,84 & 1,136 & 42,612 \\
\hline & 38,5 & 1,207 & 0,84 & 1,020 & 39,262 \\
\hline & 39,5 & 1,069 & 0,84 & 0,903 & 35,678 \\
\hline & 40,5 & 1,000 & 0,84 & 0,845 & 34,221 \\
\hline & 41.5 & 1,138 & 0,84 & 0,962 & 39,903 \\
\hline & 42,5 & 0,759 & 0,84 & 0,641 & 27,243 \\
\hline & 43.5 & 0,667 & 0,79 & 0,524 & 22,814 \\
\hline
\end{tabular}


APÊNDICE 1 Tabela de vida e fertilidade da linhagem de Brevipalpus phoenicis susceptível de referência (S) ao acaricida dicofol

\begin{tabular}{|c|c|c|c|c|c|}
\hline Fase & $x^{1}$ & $m x^{2}$ & $1 x^{3}$ & mx.lx & mx.lx.x \\
\hline \multirow[t]{29}{*}{ Adulta } & 44,5 & 0,840 & 0,73 & 0,612 & 27,228 \\
\hline & 45,5 & 0,560 & 0,73 & 0,408 & 18,560 \\
\hline & 46,5 & 0,810 & 0,61 & 0,495 & 23,033 \\
\hline & 47,5 & 0,952 & 0,61 & 0,583 & 27,680 \\
\hline & 48,5 & 0,500 & 0,58 & 0,291 & 14,131 \\
\hline & 49,5 & 0,600 & 0,58 & 0,350 & 17,307 \\
\hline & 50,5 & 0,444 & 0,52 & 0,233 & 11,771 \\
\hline & 51,5 & 0,588 & 0,50 & 0,291 & 15,005 \\
\hline & 52,5 & 0,357 & 0,41 & 0,146 & 7,648 \\
\hline & 53,5 & 0,583 & 0,35 & 0,204 & 10,912 \\
\hline & 54,5 & 0,182 & 0,32 & 0,058 & 3,176 \\
\hline & 55,5 & 0,556 & 0,26 & 0,146 & 8,085 \\
\hline & 56,5 & 1,444 & 0,26 & 0,379 & 21,401 \\
\hline & 57,5 & 0,444 & 0,26 & 0,117 & 6,701 \\
\hline & 58,5 & 0,375 & 0,23 & 0,087 & 5,113 \\
\hline & 59,5 & 0,429 & 0,20 & 0,087 & 5,201 \\
\hline & 60,5 & 0,571 & 0,20 & 0,117 & 7,051 \\
\hline & 61,5 & 0,000 & 0,15 & 0,000 & 0,000 \\
\hline & 62,5 & 0,400 & 0,15 & 0,058 & 3,642 \\
\hline & 63,5 & 0,200 & 0,15 & 0,029 & 1,850 \\
\hline & 64,5 & 0,200 & 0,15 & 0,029 & 1,879 \\
\hline & 65,5 & 1,000 & 0,12 & 0,117 & 7,634 \\
\hline & 66,5 & 0,000 & 0,12 & 0,000 & 0,000 \\
\hline & 67,5 & 1,000 & 0,06 & 0,058 & 3,933 \\
\hline & 68,5 & 0,000 & 0,03 & 0,000 & 0,000 \\
\hline & & & & $\Sigma=26,835=R o$ & 875,07312 \\
\hline & & & & $T=36,3360$ & \\
\hline & & & & $r m=0,090535$ & \\
\hline & & & & $\lambda=1,0947604$ & \\
\hline
\end{tabular}


APÊNDICE 2 Tabela de vida e fertilidade da linhagem de Brevipalpus phoenicis resistente (R) ao acaricida dicofol.

\begin{tabular}{|c|c|c|c|c|c|}
\hline Fase & $x^{1}$ & $\mathrm{mx}^{2}$ & $\mathbf{l x}^{3}$ & $\mathbf{m x} . \mathbf{I x}$ & mx.lx.x \\
\hline Ovo & - & - & 0,98 & - & - \\
\hline Larva & - & - & 0,83 & - & - \\
\hline Protocrisálida & - & $\overline{-}$ & 0,81 & $\overline{-}$ & - \\
\hline Protoninfa & - & - & 0,81 & 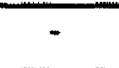 & - \\
\hline Deutocrisálida & - & - & 0,81 & - & - \\
\hline Deutoninfa & - & - & 0,81 & - & - \\
\hline Teliocrisálida & - & - & 0,81 & - & - \\
\hline \multirow[t]{23}{*}{ Adulta } & 21.5 & 0,000 & 0,81 & 0,000 & 0,000 \\
\hline & 22,5 & 0,129 & 0,81 & 0,105 & 2,352 \\
\hline & 23,5 & 0,806 & 0,81 & 0,653 & 15,353 \\
\hline & 24,5 & 1,000 & 0,81 & 0,810 & 19,847 \\
\hline & 25,5 & 0,903 & 0,81 & 0,732 & 18,658 \\
\hline & 26,5 & 0,967 & 0,78 & 0,758 & 20,083 \\
\hline & 27,5 & 1,069 & 0,76 & 0,810 & 22,278 \\
\hline & 28,5 & 1,214 & 0,73 & 0,888 & 25,322 \\
\hline & 29,5 & 1,179 & 0,73 & 0,862 & 25,440 \\
\hline & 30,5 & 0,786 & 0,73 & 0,575 & 17,535 \\
\hline & 31,5 & 1,143 & 0,73 & 0,836 & 26,341 \\
\hline & 32,5 & 1,107 & 0,73 & 0,810 & 26,328 \\
\hline & 33,5 & 0,889 & 0,71 & 0,627 & 21,010 \\
\hline & 34,5 & 0,889 & 0,71 & 0,627 & 21,638 \\
\hline & 35,5 & 0,731 & 0,68 & 0,497 & 17,626 \\
\hline & 36,5 & 0,600 & 0,65 & 0,392 & 14,307 \\
\hline & 37,5 & 0,600 & 0,65 & 0,392 & 14,699 \\
\hline & 38,5 & 0,364 & 0,57 & 0,209 & 8,049 \\
\hline & 39,5 & 0,300 & 0,52 & 0,157 & 6,193 \\
\hline & 40,5 & 0,765 & 0,44 & 0,340 & 13,759 \\
\hline & 41,5 & 0,375 & 0,42 & 0,157 & 6,507 \\
\hline & 42,5 & 0,462 & 0,34 & 0,157 & 6,664 \\
\hline & 43,5 & 0,727 & 0,29 & 0,209 & 9,094 \\
\hline
\end{tabular}


APÊNDICE 2 Tabela de vida e fertilidade da linhagem de Brevipalpus phoenicis resistente (R) ao acaricida dicofol.

\begin{tabular}{|c|c|c|c|c|c|}
\hline Fase & $x^{1}$ & $m x^{2}$ & $\mathbf{l x}^{3}$ & $\mathbf{m x} . \mathbf{l x}$ & $\mathbf{m x} . \mathbf{I x} . \mathbf{x}$ \\
\hline \multirow[t]{21}{*}{ Adulta } & 44,5 & 0,300 & 0,26 & 0,078 & 3,489 \\
\hline & 45,5 & 0,500 & 0,26 & 0,131 & 5,945 \\
\hline & 46,5 & 0,875 & 0,21 & 0,183 & 8,506 \\
\hline & 47,5 & 0,750 & 0,21 & 0,157 & 7,448 \\
\hline & 48,5 & 0,125 & 0,21 & 0,026 & 1,267 \\
\hline & 49,5 & 0,125 & 0,21 & 0,026 & 1,294 \\
\hline & 50,5 & 0,286 & 0,18 & 0,052 & 2,639 \\
\hline & 51,5 & 1,000 & 0,18 & 0,183 & 9,421 \\
\hline & 52,5 & 1,000 & 0,18 & 0,183 & 9,604 \\
\hline & 53,5 & 0,500 & 0,10 & 0,052 & 2,796 \\
\hline & 54,5 & 0,333 & 0,08 & 0,026 & 1,424 \\
\hline & 55,5 & 0,500 & 0,05 & 0,026 & 1,450 \\
\hline & 56,5 & 0,000 & 0,05 & 0,000 & 0,000 \\
\hline & 57,5 & 0,500 & 0,05 & 0,026 & 1,503 \\
\hline & 58,5 & 0,500 & 0,05 & 0,026 & 1,529 \\
\hline & 59,5 & 0,000 & 0,05 & 0,000 & 0,000 \\
\hline & 60,5 & 0,500 & 0,05 & 0,026 & 1,581 \\
\hline & 61,5 & 0,000 & 0,05 & 0,000 & 0,000 \\
\hline & 62,5 & 0,000 & 0,03 & 0,000 & 0,000 \\
\hline & 63,5 & 0,000 & 0,03 & 0,000 & 0,000 \\
\hline & 64,5 & 0,000 & 0,03 & 0,000 & 0,000 \\
\hline & & & & $\Sigma=12,805=R o$ & 418,978 \\
\hline & & & & $T=32,7204$ & \\
\hline & & & & $r m=0,077928$ & \\
\hline & & & & $\lambda=1,0810448$ & \\
\hline
\end{tabular}

